\title{
norden
}

\section{Psychosocial working environment}

Workplace Inspection of the psychosocial working environment in the Nordic countries 

2 norden 



\section{Psychosocial working environment}

Workplace Inspection of the psychosocial working environment in the Nordic countries

Tom Hansen, Lars Christian Lidsmoes, Peter Laursen, Leo Mathiassen, Anne-Marie Jensen, Christina Suhr Raby, Louise Sørensen, Hannele Jurvelius, Jenny Rintala, Steinar Harðarson, Pórunn Sveinsdóttir, Stian Rosenberg Søvik, Bård Hjorth, Pia Schyberg and Marianne Tiborn

TemaNord 2015:508 
Psychosocial working environment

Workplace Inspection of the psychosocial working environment in the Nordic countries

Tom Hansen, Lars Christian Lidsmoes, Peter Laursen, Leo Mathiassen, Anne-Marie Jensen, Christina Suhr Raby, Louise Sørensen, Hannele Jurvelius, Jenny Rintala, Steinar Harðarson, Pórunn Sveinsdóttir, Stian Rosenberg Søvik, Bård Hjorth, Pia Schyberg and Marianne Tiborn

ISBN 978-92-893-3944-5 (PRINT)

ISBN 978-92-893-3946-9 (PDF)

ISBN 978-92-893-3945-2 (EPUB)

http://dx.doi.org/10.6027/TN2015-508

TemaNord 2015:508

ISSN 0908-6692

(C) Nordic Council of Ministers 2015

Layout: Hanne Lebech

Cover photo: Signelements

Print: Rosendahls-Schultz Grafisk

Copies: 100

Printed in Denmark

This publication has been published with financial support by the Nordic Council of Ministers. However, the contents of this publication do not necessarily reflect the views, policies or recommendations of the Nordic Council of Ministers.

\section{www.norden.org/en/publications}

\section{Nordic co-operation}

Nordic co-operation is one of the world's most extensive forms of regional collaboration, involving Denmark, Finland, Iceland, Norway, Sweden, and the Faroe Islands, Greenland, and Åland.

Nordic co-operation has firm traditions in politics, the economy, and culture. It plays an important role in European and international collaboration, and aims at creating a strong Nordic community in a strong Europe.

Nordic co-operation seeks to safeguard Nordic and regional interests and principles in the global community. Common Nordic values help the region solidify its position as one of the world's most innovative and competitive.

\section{Nordic Council of Ministers}

Ved Stranden 18

DK-1061 Copenhagen $\mathrm{K}$

Phone (+45) 33960200

www.norden.org 


\section{Contents}

Preface

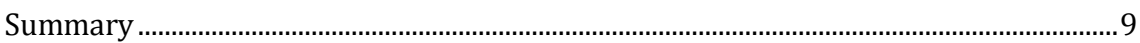

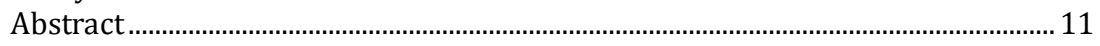

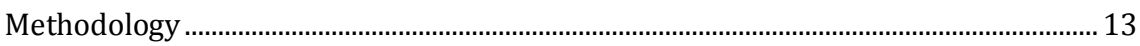

1. Clarification of the concept of PWE, theoretical background and

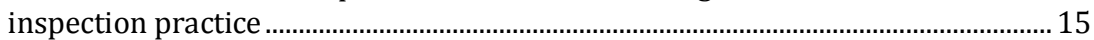

1.1 Theoretical background for PWE inspection................................................ 17

1.2 PWE inspections in practice .......................................................................... 19

2. Comparison of PWE regulations in the Nordic countries....................................... 29

2.1 Areas for inspection by the working environment authority........................ 31

2.2 Obligations and rights of the employer - general regulations for the physical and the psychosocial working environment.....................................33

2.3 Separate regulations for the psychosocial working environment................ 37

2.4 Collaboration on the working environment at the enterprise ...................... 39

2.5 Duties and rights of employees ......................................................................... 39

2.6 How the authorities deal with anonymity and confidentiality ...................... 41

$2.7 \quad$ Authorities' sanction options ........................................................................... 42

2.8 The legal basis for the psychosocial working environment.......................... 49

3. The Nordic strategies for PWE inspection............................................................... 51

3.1 National working environment strategies .................................................... 52

3.2 Policy and strategies for PWE inspection by authorities ................................ 55

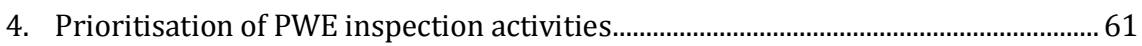

4.1 Inspection authorities' prioritisation of PWE inspections ........................... 61

4.2 Training inspectors to conduct PWE inspection................................................. 67

4.3 Time spent on PWE inspections......................................................................... 70

4.4 Number of PWE-related improvement notices .............................................. 72

5. Methods to carry out PWE inspections in the Nordic countries............................... 75

5.1 Inspection methods in the Nordic countries - summary ............................... 75

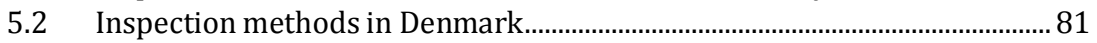

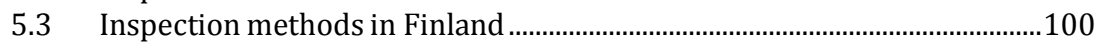

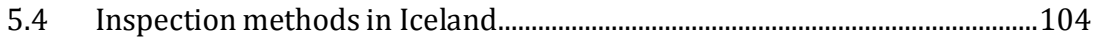

5.5 Inspection methods in Norway …………........................................................106

5.6 Inspection methods in Sweden.......................................................................115

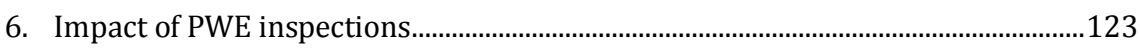

6.1 How to measure the impact of PWE inspections .........................................124

6.2 Primary trends ........................................................................................... 125

6.3 Description of initiatives by the Nordic countries to measure

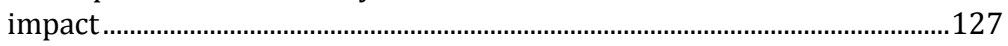

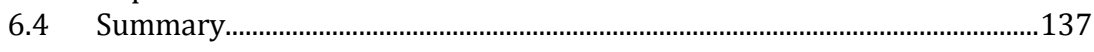

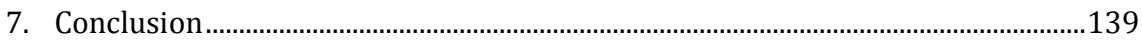


References...

. .145

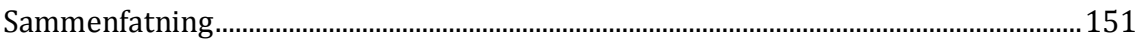

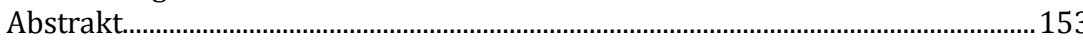

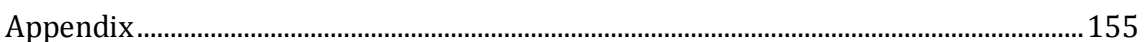




\section{Preface}

In June 2010, the Danish Working Environment Authority hosted a conference in Copenhagen attended by working environment authorities from the Nordic countries. The psychosocial working environment (PWE) was among the subjects dealt with at this conference and the various presentations by the Nordic working environment authorities stimulated curiosity and gave birth to the idea of a common Nordic analysis of PWE inspection.

With Denmark as the driver behind this initiative, a project was launched at the beginning of 2012 with support from the Nordic Council of Ministers. The project was temporarily halted in June 2012 to be launched again at the beginning of 2013.

The project application to the Nordic Council of Ministers set three goals for the analysis:

- "Methods for mapping the psychosocial working environment and how these relate to working environment legislation.

- Reaction options (improvement notices, guidelines, etc.) provided for by working environment legislation in the individual Nordic countries.

- As far as possible, how these reaction options (improvement notices, guidelines, etc.) have a positive effect on the psychosocial working environment at affected enterprises."

At their first meeting, the project working group developed these goals into a plan with related questions. PWE inspection is subject to legislation and to political prioritisation of the inspection work carried out by the Nordic working environment authorities.

This analysis therefore focuses on the following topics:

- Definition and clarification the concept of PWE.

- National legislative frameworks and the working environment authorities' reaction options regarding PWE.

- Political strategy - a description of how PWE inspection is being prioritised. 
- Inspection activities - a description of when the national working environment authorities carry out PWE inspection.

- Inspection methods - a description of how the national working environment authorities carry out PWE inspection in practice.

- Impact - a description of completed impact studies on PWE inspection. 


\section{Summary}

This analysis report includes a descriptive account of the topics mentioned above. It accounts for how these topics are being dealt with in the five countries, and for differences and similarities between them. Each chapter includes a description of the national conditions in each of the five countries in alphabetical order.

- Chapter 1:

Clarification of the concept of PWE, theoretical background and inspection practice is introduced with a definition and delimitation of the concept of psychosocial working environment (PWE). There is no official, common Nordic definition of the concept of psychosocial working environment. The following interpretation of the concept is therefore how the working group for this project has chosen to understand the concept in order to ensure a common basis. The chapter accounts for the various theoretical backgrounds underlying PWE inspection in the different Nordic countries; that is the theoretical framework forming the basis for PWE inspection in each country. Finally, the chapter describes the psychosocial and organisational risk factors targeted by each of the five countries in their inspection work.

- Chapter 2:

Comparison of PWE regulations in the Nordic countries is a comparison of the current regulations forming the basis for PWE inspection in each of the Nordic countries. This chapter begins with a brief historical outline of when PWE regulations were adopted in the working environment legislation of the respective countries.

- Chapter 3:

Nordic working environment authorities' strategies for inspection includes a description of the targets and strategies for national working environment action, focusing on efforts aimed at the psychosocial working environment. This chapter begins with a comparison of the overall working environment strategies of the Nordic countries. The chapter then outlines the different national strategies in more detail. Finally, there is a more detailed account of 
the strategies, targets and areas of initiative of the Nordic working environment authorities.

- Chapter 4:

PWE inspection activities begin with a brief summary of how the Nordic countries prioritise their respective psychosocial and organisational working environment inspection in their overall working environment inspection activities. The chapter then describes how the national working environment authorities select the enterprises, sectors and types of job to target for inspection. This chapter also explains how inspectors are trained to carry out PWE inspection in the five Nordic countries. Finally, the chapter describes the time spent by the individual countries on PWE inspection, as well as the resulting number of improvement notices, etc. concerning the psychosocial and organisational working environment.

- Chapter 5:

Methods for inspection of the psychosocial working environment deals with the national working environment authorities' respective approaches to inspection. First the chapter provides a summary of how the Nordic countries carry out inspection of key psychosocial risk factors and organisational working conditions in practice. The chapter also describes the extent to which the authorities inspect the individual enterprise's psychosocial working environment and overall, systematic working environment efforts. Subsequently, the chapter outlines how the five countries structure their inspections, before, during and after the individual inspection visit, and which standardised tools are used to identify psychosocial working environment issues. Finally, there is a description of the individual working environment authorities' preferred methods for inspection in this area. Because this is the most extensive and detailed chapter, the introductory summary is followed by a detailed account of the inspection practice in each country.

- Chapter 6:

Impact of PWE inspections deals with the impact of PWE inspections by the national working environment authorities and how this impact is measured. There are no simple and unequivocal answers in this chapter. Rather, the chapter presents thoughts and trends that show the direction and approach taken by the different countries. Finally, the chapter outlines the Nordic countries' initiatives to ensure and measure impacts and it describes relevant perspectives. 
It is important to note that the report is a summary of the national accounts prepared by the members of the working group and other employees in the respective Nordic working environment authorities. The working group plans to publish these national accounts as separate reports, including also quality assurance procedures for inspection, examples of improvement notices following inspection visits, etc.

\begin{abstract}
This report outlines how the authorities in Denmark, Finland, Iceland, Norway and Sweden carry out inspections of the psychosocial working environment at the enterprises. The report offers a comparison of the Nordic working environment strategies as well as a detailed presentation of the different initiatives. It also presents how different methods are used in the selection of enterprises for inspection and how the inspectors are trained to carry out the inspections. The report rounds off with a description of the different national inspection methods and how to measure their effects.
\end{abstract}





\section{Methodology}

This analysis of inspection by the Nordic working environment authorities of the psychosocial working environment was carried out exclusively as a descriptive analysis. The purpose of the analysis is to provide as detailed an overview as possible of how inspection of the psychosocial working environment is being carried out in the five Nordic countries; Denmark, Finland, Iceland, Norway and Sweden. This overview can serve as inspiration for the working environment authorities in the Nordic countries, with a view to developing individual country's PWE inspection further.

Each of the report's six chapters has been prepared on the basis of the following principles:

- Representatives from each country analysed PWE inspection in their respective country.

- Analyses of individual sub areas were performed on the basis of responses to a number of common guiding questions; these questions were adjusted during the course of the project, however, overall, each country answered the same line of questions.

- Each country completed the analysis in its official language, except for Iceland which completed the analysis in Swedish. Acting as project manager, Denmark subsequently collated and summarised the analyses by the different countries in a report in Danish.

- This collective analysis (i.e. this report) does not include all of the details in each country's separate analysis. However, it does include a fairly detailed account of the most important points from the analysis of each country.

- This analysis is limited in scope in that it is based on the PWE inspection practice of the individual country at the time of the analysis. This means that certain inspection methods and activities may subsequently have been replaced by newer ones that are not described in this report. 



\section{Clarification of the concept of PWE, theoretical background and inspection practice}

Psychological working environment is a term for that part of the working environment which has to do with the nature and content of the work, the organisation of the work, and the social relations and conditions under which the work is performed. In Norway, a distinction is made between "organisational working environment" and "psychosocial working environment". Organisational working environment is about how the individual enterprise formally manages its working environment and what its working environment is like in practice, while the concept of psychosocial working environment is about human-to-human relationships and interactions in the work situation. The Norwegian working environment legislation only uses the concept of psychosocial working environment in the context of requirements concerning humanto-human relationships in the work situation.

Since "psychosocial working environment" and "psychosocial risk factors" are widely used in international literature, these two concepts will be used in the following.

All types of enterprise, regardless of whether they produce physical products or provide services, have a psychosocial working environment. The psychosocial working environment is the result of the interaction of factors pertaining to work and the people carrying out the work. This is a complex interaction, which is influenced by many factors. Thus, the psychosocial working environment is determined by the type of work being carried out; how this work is organised and planned; the qualifications required of the employees to perform the work; how they experience their work situation; and how they react in relation to this. Finally, the psychosocial working environment is embedded in a cultural and societal context.

The psychosocial working environment can be stimulating or it can stressful. Either way, it influences the health of the individual employee. It is this potentially stressful impact of the working environment that is of interest to the working environment authorities, because it is their job to assist enterprises in preventing illness and injuries arising from con- 
ditions in the working environment. The national working environment authorities therefore spotlight conditions in the working environment (risk factors) which national and international research indicates may pose a health or safety risk to employees.

The Nordic countries differ in respect of the risk factors they target in their PWE inspection, and the taxonomy for the individual risk factors also varies. However, from an overall perspective, these psychosocial risk factors can be divided into factors concerning the organisation of work; relational factors; factors concerning working hours etc.; as well as a group of "other factors".

Table 1: Risk factors in the psychosocial (and organisational) working environment

\begin{tabular}{|c|c|c|c|}
\hline Organisation of the work & Relational factors & Working hours etc. & Other factors \\
\hline Work load & Bullying & Working hours & Risk of traumatic incidents \\
\hline Time pressure & $\begin{array}{l}\text { Violence and threate- } \\
\text { ning behaviour }\end{array}$ & $\begin{array}{l}\text { Staggered working } \\
\text { hours }\end{array}$ & $\begin{array}{l}\text { Lack of permanent work- } \\
\text { place }\end{array}$ \\
\hline $\begin{array}{l}\text { Lack of influence on own } \\
\text { work }\end{array}$ & Harassing behaviour & Shift work & $\begin{array}{l}\text { Frequent work-related } \\
\text { travel outside normal } \\
\text { working hours }\end{array}$ \\
\hline $\begin{array}{l}\text { Conflicting or unclear } \\
\text { demands }\end{array}$ & Sexual harassment & Night work & Pay scheme \\
\hline $\begin{array}{l}\text { High attentional de- } \\
\text { mands }\end{array}$ & Teasing & Lack of resting periods & Inadequate management \\
\hline High emotional demands & Integrity and dignity & Excessive overtime & $\begin{array}{l}\text { Lack of personal develop- } \\
\text { ment for employees }\end{array}$ \\
\hline Many interruptions & Discrimination & $\begin{array}{l}\text { Lack of overtime } \\
\text { compensation }\end{array}$ & $\begin{array}{l}\text { Lack of work contracts and } \\
\text { employment contracts }\end{array}$ \\
\hline $\begin{array}{l}\text { Highly controlled or fixed } \\
\text { work }\end{array}$ & Solitary work & & Control measures \\
\hline Large responsibility & Lack of social support & & Unclear job description \\
\hline Large information load & Poor collaboration & & \\
\hline $\begin{array}{l}\text { Lack of information } \\
\text { channels in the organisa- } \\
\text { tion }\end{array}$ & Crisis support & & \\
\hline Organisational change & $\begin{array}{l}\text { Lack of employee } \\
\text { rehabilitation }\end{array}$ & & \\
\hline \multicolumn{4}{|l|}{ Lack of breaks } \\
\hline \multicolumn{4}{|l|}{$\begin{array}{l}\text { Lack of instruction and } \\
\text { training }\end{array}$} \\
\hline \multicolumn{4}{|l|}{$\begin{array}{l}\text { Technology (tools and } \\
\text { equipment) }\end{array}$} \\
\hline Unclear division of labour & & & \\
\hline
\end{tabular}


Factors in the psychosocial/organisational working environment will be considered risk factors because each factor, alone or in combination with other factors, poses a safety and/or health risk to employees. Some factors pose a risk to employees in and of themselves (e.g. the risk of exposure to violence), while others are included as individual elements in a more or less complex issue. Some factors are not risk factors as such, e.g. "instruction and training". However, they are factors which may be crucial for whether the psychosocial working environment poses a safety or health risk to employees. In order to fairly represent the analysis and practice of each country, this report describes all of the risk factors that were known in at least one of the Nordic countries at the time of the analyses.

\subsection{Theoretical background for PWE inspection}

Different models exist for the relationship between the psychosocial working environment and the individual. Karasek's Demand-Control Model has become a widespread model for understanding, on the one hand, job demands (such as demands on employees to be able to cope with large amounts of information, large responsibility, or large emotional demands), and on the other hand, the control/resources available to the individual in the work situation (influence, possibility to actively adapt terms and conditions of the work). For example, if there is an imbalance between job demands and the individual's possibilities for meeting these demands, then this lack of alignment between demands and ability can pose a risk to the mental and physical health of the individual. Similarly, social relations in the workplace can be such that they pose a risk to the individual employee. This will be the case for bullying, violence and threatening behaviour, when individual employees are unable to effectively defend themselves against the offensive behaviour targeted at them.

When the Danish Working Environment Authority (Arbejdstilsynet) carries out inspection of the psychosocial working environment in Denmark, its task is to identify whether the psychosocial effects or demands involved in the work, and to which the employees are exposed, have been adequately prevented, so that they do not pose a safety or health risk. The central theory of work and occupational psychology on which Arbejdstilsynet bases its inspection is the Demand-Control Model developed by Robert Karasek and Töres Theorell. This model illustrates the correlation between demands and control in different types of job. The 
central notion of the model is that the impact of psychological demands is determined by how much control/influence the individual has on his or her own work situation. During PWE inspection, Arbejdstilsynet supplements Karaksek's concepts of control and influence with other resources and preventive measures. Furthermore, Arbejdstilsynet has been inspired by Johannes Siegrist's Effort-Reward Model, which is based on employee's own experience of the efforts they make and the rewards they achieve. According to this model an imbalance between effort and reward can lead to stress.

The Finnish working environment authority (Työsuojeluhallinto) has developed a reference frame for PWE inspection. This reference frame describes the harmful effects of the psychosocial risk factors as well as factors which can increase or prevent the risk these entail and which can influence the amount of strain to which the employee is exposed. The reference frame also includes the employer's measures to reduce workrelated nuisance and risks. Just as in Denmark, the background for the Finnish reference frame is the classical work-psychology theories, i.e. Robert Karasek's Demand-Control Model and Johannes Siegrist's EffortReward Model. Finland also bases its work on the more recent Job Demands-Resources (JD-R) Model described by Arnold Bakker and Eva Demeroutis. Furthermore, Finland's reference frame also considers the fact that the personal capacities of the individual are an important factor in determining job strain.

The Icelandic working environment authority (Vinnueftirlitid) bases PWE inspection on the workplace rather than on the individual. Inspections are targeted at factors such as the organisation of work, management, roles, support options at work, information channels, communication as well as prevention and management of bullying.

In Norway, PWE inspection is not carried out according to a specific theoretical model but according to the understanding that imbalances between individuals and their working conditions must generally be avoided. Norway has been a first-mover with regard to implementing a requirement in its working environment legislation that work must be organised such that it provides employees opportunity for professional and personal development (section 12 of the 1977 Working Environment Act, and Part 4 of the 2005 Working Environment Act). This requirement is based e.g. on national research (Einar Thorsrud and Fred Emery) that has demonstrated the importance of task variation, a need to learn, a need for autonomy, for contact with others and to see one's job as meaningful in relation to society. 
Like in Denmark and Finland, in Sweden Karasek's and Tehorell's Demand-Control Model has had the greatest influence on the risk factors targeted in inspection work. Johan Cullberg's crisis and development theory is also used as a theoretical basis for inspection work. For example this theory has influenced the design of regulations on psychological first aid and crisis support.

\subsection{PWE inspections in practice}

Below are descriptions of the risk factors which are included in the inspection practice of all of the countries. These descriptions are followed by descriptions of practice with regard to the other risk factors, and these have been grouped thematically. The practice of each country with regard to each of the risk factors is described within the following themes:

- Organisation of work.

- Relational factors.

- Working hours etc.

- Other factors.

There is a "practice" when a country targets inspections at a risk factor. In this context, it is of no importance whether risk factors are targeted every time, just as long as they are targeted. With regard to the gross list of factors/risk factors, each country has described the practice it had at the time (i.e. at the beginning of 2014) with regard to each of the risk factors. The countries have used the following categorisation in their description of their practice:

A. There is a practice for targeting this risk factor in inspections.

B. This risk factor is only targeted in inspections in exceptional circumstances.

C. The risk factor is included in the assessment of other specific psychosocial and organisational risk factors, or it is included in an overall assessment of the psychosocial working environment.

D. These risk factors are only targeted if an enterprise itself brings them up during the inspection, or if the national working environment authority has received a complaint about this matter.

- These risk factors are not targeted in inspections. 


\subsubsection{Risk factors that are part of the inspection practice of all Nordic countries}

All five Nordic countries have practices (Category A) that involve targeting the following three risk factors:

- Violence and threatening behaviour.

- Bullying, including sexual harassment. Norway uses the concept of "trakassering eller annen utilbørlig opptreden" (harassment or other inappropriate behaviour). Sexual harassment is included in this concept and, therefore, does not appear separately on Norwegian checklists in connection with inspections. Sweden uses the concept of "kränkande särbehandling" (harassing behaviour) which covers bullying. Risk factors related to bullying are also described in this context. These include teasing, discrimination as well as integrity and dignity.

- Lack of instruction and training.

In Denmark, the risk factors teasing and discrimination are typically considered bullying behaviour and are therefore included in the assessment of this risk factor, while integrity and dignity are not covered by PWE inspection. Discrimination is also regulated in separate antidiscrimination legislation.

Lack of instruction and training is typically included in the inspection of other risk factors or in an overall assessment of the psychosocial working environment. Lack of instruction and training may also be targeted separately (i.e. as a non-PWE risk factor).

In Finland, the risk factors teasing and harassing behaviour are typically included in inspection of the risk factor bullying, while integrity and dignity are not covered by PWE inspection. As a general rule, discrimination is not covered by PWE inspection, as the Finnish working environment legislation includes separate regulations on discrimination.

In Iceland, the risk factor harassing behaviour is only targeted in inspections on the basis of complaints, or if someone brings attention to this risk factor in connection with a specific inspection visit. The risk factor discrimination is included in the inspection of other risk factors (bullying) or in an overall assessment of the psychosocial working environment. Integrity and dignity are not targeted by inspection in Iceland.

In Norway, the risk factors violence/threatening behaviour, bullying and harassing behaviour are targeted at some inspections, while other inspection activities only inspect these risk factors if there have been complaints from employees or if the topic is brought up in connection 
with the inspection. The risk factors sexual harassment and integrity and dignity are only inspected on the basis of complaints from employees, or if the topic is brought up during the inspection visit.

The Swedish working environment authority, Arbetsmiljöverket, does not target discrimination in its inspection, as this risk factor is regulated in Sweden's anti-discrimination law, which belongs under a different authority.

Table 2: Risk factors for which every Nordic country has an inspection practice

\begin{tabular}{llllll}
\hline & DK & FI & IS & NO & SE \\
\hline Violence and threatening behaviour & A & A & A & A/D & A \\
Bullying & A & A & A & A/D & A \\
Sexual harassment & A & A & A & D & A \\
Harassing behaviour & A & A & D & A/D & A \\
Lack of instruction and training. & A/C & A & A & & A \\
Teasing & A & A & A & A/D & A \\
Integrity and dignity & - & - & - & D & A \\
Discrimination & C & C & C & - & -
\end{tabular}

A: There is a practice for targeting this risk factor in inspections.

C: These risk factors are included in the assessment of other specific psychosocial and organisational risk factors, or they are included in an overall assessment of the psychosocial working environment. $D$ : These risk factors are only targeted if an enterprise itself brings them up during the inspection, or if the national working environment authority has received a complaint about this matter.

-: These risk factors are not targeted in inspections.

\subsubsection{Risk factors related to the organisation of work}

The organisation of work involves the following risk factors:

- Work load.

- Time pressure.

- Lack of influence on own work.

- Unclear or conflicting demands.

- High attentional demands.

- High emotional demands.

- Many interruptions.

- Highly controlled or fixed work, monotony, lack of variety.

- Large responsibility (for people or assets).

- Large information load.

- Lack of information channels in the organisation.

- Organisational change.

- Lack of breaks.

- Technology and unclear division of labour. 


\section{National practices for inspecting risk factors related to the organisation of work}

Denmark, Iceland, Norway and Sweden have the same practice with regard to the risk factors large responsibility, large information load and unclear division of labour. These risk factors are included in the inspection of other risk factors or in an overall assessment of the psychosocial working environment.

Denmark has a practice of targeting the risk factors work load and time pressure under one. However, inspection may focus exclusively on time pressure. Furthermore, there is a practice of targeting the risk factor high emotional demands in working with people. All other risk factors relating to the organisation of work are typically included as a part of the inspection of other risk factors or in an overall assessment of the psychosocial working environment. Furthermore, the risk factor unclear or conflicting demands is also targeted separately, albeit only rarely.

Finland has the same practice for all of the risk factors relating to the organisation of work, except for the risk factors organisational change and lack of breaks. According to the Finnish practice, the risk factors related to the organisation of work are included in an overall assessment of the psychosocial working envirenment. There is no practice in Finland for inspecting the risk factor organisational change. Lack of breaks is not considered a part of PWE inspection, however inspection of this risk factor is being carried out according to separate regulations.

Iceland has a practice of inspecting the risk factor technology, while the risk factors highly controlled or fixed work, monotony, lack of variety are only targeted in exceptional circumstances. The risk factors work load, time pressure, large responsibility, large information load, lack of information channels in the organisation, lack of breaks and unclear division of labour are included as a part of the inspection of other risk factors or in an overall assessment of the psychosocial working environment. The risk factors unclear or conflicting demands, high attentional demands, many interruptions and organisational change are inspected in the event of complaints or if these risk factors are brought up in connection with an inspection visit. Lack of influence on own work as well as high emotional demands are not targeted in inspections.

Norway has a practice of inspecting the risk factors organisational change and lack of breaks. In Norway, highly controlled or fixed work is included under the ergonomic working environment area, based on the understanding that highly controlled or fixed work leads to physical strain. All risk factors may be included as a part of the inspection of other risk factors or in an overall assessment of the psychosocial working 
environment. Furthermore, the risk factors work load, time pressure, lack of influence on own work, unclear or conflicting demands, high attentional demands, high emotional demands, many interruptions, as well as large information load and lack of information channels in the organisation may be included in inspection visits in connection with complaints or if these risk factors are brought up in connection with an inspection visit.

In Sweden, there is a practice to carry out inspection of the risk factors work load, time pressure, lack of influence on own work, unclear or conflicting demands, high attentional demands and high emotional demands. The risk factor lack of breaks may be targeted, but this only happens in exceptional circumstances. The risk factors time pressure, highly controlled or fixed work, large responsibility, large information load, organisational change and unclear division of labour may be included as a part of the inspection of other risk factors or in an overall assessment of the psychosocial working environment. Lack of information channels in the organisation and technology may be included in inspection visits in connection with complaints or if these risk factors are brought up during an inspection visit. The risk factor many interruptions is not targeted in inspections.

Table 3: Risk factors related to the organisation of work

\begin{tabular}{llllll} 
& DK & FI & IS & NO & SE \\
\hline Work load & A & C & C & C/D & A \\
Time pressure & A & C & C & C/D & A/C \\
Lack of influence on own work & C & C & - & C/D & A \\
Conflicting or unclear demands & A/C & C & D & C/D & A \\
High attentional demands & (B)/C & C & D & C/D & A \\
High emotional demands & $\mathrm{A}$ & $\mathrm{C}$ & - & C/D & A \\
Many interruptions & $\mathrm{C}$ & $\mathrm{C}$ & $\mathrm{D}$ & $\mathrm{C} / \mathrm{D}$ & - \\
Highly controlled work, monotony & $\mathrm{B}$ & $\mathrm{C}$ & $\mathrm{B}$ & $\mathrm{A} / \mathrm{C}$ & $\mathrm{C}$ \\
Large responsibility & $\mathrm{C}$ & $\mathrm{C}$ & $\mathrm{C}$ & $\mathrm{C}$ & $\mathrm{C}$ \\
Large information load & $\mathrm{C}$ & $\mathrm{C}$ & $\mathrm{C}$ & $\mathrm{C} / \mathrm{D}$ & $\mathrm{C}$ \\
Lack of information & $\mathrm{C}$ & $\mathrm{C}$ & $\mathrm{C}$ & $\mathrm{C} / \mathrm{D}$ & $\mathrm{D}$ \\
Organisational change & $\mathrm{C}$ & - & $\mathrm{D}$ & $\mathrm{A} / \mathrm{C}$ & $\mathrm{C}$ \\
Lack of breaks & $\mathrm{C}$ & $\mathrm{C}$ & $\mathrm{C}$ & $\mathrm{A} / \mathrm{C}$ & $\mathrm{B}$ \\
Technology & $\mathrm{C}$ & $\mathrm{C}$ & $\mathrm{A}$ & $\mathrm{C}$ & $\mathrm{D}$ \\
Unclear division of labour & $\mathrm{C}$ & $\mathrm{C}$ & $\mathrm{C}$ & $\mathrm{C}$ & $\mathrm{C}$ \\
\hline
\end{tabular}

A: There is a practice for targeting this risk factor in inspections.

$B$ : This risk factor is only targeted in inspections in exceptional circumstances.

C: These risk factors are included in the assessment of other specific psychosocial and organisational risk factors, or they are included in an overall assessment of the psychosocial working environment. $D$ : These risk factors are only targeted if an enterprise itself brings them up during the inspection, or if the national working environment authority has received a complaint about this matter.

-: These risk factors are not targeted in inspections. 


\subsubsection{Risk factors concerning relational matters}

Relational risk factors include solitary work, lack of social support, first aid, crisis support, poor collaboration and lack of employee rehabilitation.

\section{National practices for inspecting relational risk factors}

In Denmark, there is a practice to carry out inspection of the risk factor first aid (i.e. psychological first aid). Solitary work and lack of social support are inspected as separate risk factors in exceptional circumstances, however, typically, these risk factors are included in the inspection of other risk factors or as a part of an overall assessment of the psychosocial working environment. The risk factors crisis support, poor collaboration and lack of employee rehabilitation are not targeted in inspections.

In Finland lack of social support and poor collaboration are included in the overall assessment of the psychosocial working environment. Crisis support is dealt with at inspections that focus on violence and traumatic events. Solitary work and first aid are not considered a part of PWE inspection, however inspection of these risk factors is being carried out according to separate regulations. As a general rule, the risk factor lack of employee rehabilitation is not targeted in inspections.

In Iceland, there is a practice of carrying out inspection of the risk factor first aid, while the risk factors solitary work and lack of social support are included in inspection of other risk factors or as a part of an overall assessment of the psychosocial working environment. The risk factors crisis support, poor collaboration and lack of employee rehabilitation are not targeted in inspections.

Norway has a practice of inspecting the risk factors solitary work and lack of employee rehabilitation. Solitary work, lack of social support and poor collaboration are included in inspection of other risk factors or as a part of an overall assessment of the psychosocial working environment. In some cases, the risk factor lack of social support is targeted in inspections on the basis of complaints, or if someone brings attention to this risk factor during a specific inspection visit. The risk factors first aid and crisis support are not targeted in inspections.

In Sweden, the risk factors solitary work, lack of social support, first aid and crisis support are included in inspection of other risk factors or as a part of an overall assessment of the psychosocial working environment. Poor collaboration and lack of employee rehabilitation are inspected in the event of complaints or if these risk factors are brought up during an inspection visit. 
Table 4: Risk factors concerning relational matters in the working environment

\begin{tabular}{llllll}
\hline & DK & FI & IS & NO & SE \\
\hline Solitary work & B/C & C & C & A/C & C \\
Lack of social support & B/C & C & C & C/D & C \\
First aid & A & C/ & A & - & C \\
Crisis support & - & C & - & - & C \\
Poor collaboration & - & C & - & C & D \\
Lack of employee rehabilitation & - & - & - & A & D \\
\hline
\end{tabular}

A: There is a practice for targeting this risk factor in inspections.

B: This risk factor is only targeted in inspections in exceptional circumstances.

C: These risk factors are included in the assessment of other specific psychosocial and organisational risk factors, or they are included in an overall assessment of the psychosocial working environment. D: These risk factors are only targeted if an enterprise itself brings them up during the inspection, or if the national working environment authority has received a complaint about this matter.

-: These risk factors are not targeted in inspections.

\subsubsection{Working hours etc.}

The risk factors pertaining to working hours etc. include working hours (length of the work day), staggered working hours, shift work, night work, lack of resting periods, excessive overtime and lack of overtime compensation.

National practices for inspecting factors relating to working hours etc. In Denmark, there is a practice of carrying out inspection of nightshift planning, while excessive overtime is included in inspection of other risk factors or as a part of an overall assessment of the psychosocial working environment. The other factors under working hours etc. are not targeted in inspections. Lack of resting periods is targeted, however not as a part of PWE inspection.

As a general rule, Finland does not include factors relating to working hours etc. in their PWE inspection, however the Finnish working environment authorities do carry out inspection of whether employers have included working hours in the enterprise's risk assessment. There are separate regulations concerning working hours etc. Lack of overtime compensation is not targeted in inspections.

In Iceland, the risk factors working hours, staggered working hours, shift work, night work and lack of resting periods are targeted in inspections on the basis of complaints, or if someone brings attention to problems with this risk factor during a specific inspection visit. Lack of overtime compensation is not targeted in inspections.

Norway has a practice of carrying out inspection of the risk factors working hours, night work, lack of resting periods, excessive overtime and lack of overtime compensation. Inspection of the risk factors work- 
ing hours, night work and excessive overtime depends on the inspection activity, in that, in some cases, these risk factors are targeted separately, while in other cases they are included in the inspection of other risk factors or as a part of an overall assessment of the psychosocial working environment. The risk factor staggered working hours is inspected in the event of complaints or if this risk factor is brought up in connection with an inspection visit. Lack of overtime compensation is included as a permanent element in a number of inspection activities. The Norwegian national working environment authority, Arbeidstilsynet, inspects work contracts for an item defining overtime compensation and, in many cases, Arbeidstilsynet also checks whether employees are actually paid overtime compensation.

Sweden carries out inspection of the risk factors working hours, night work and lack of resting periods if the workplace is not covered by a collective agreement on working hours, and primarily on the basis of complaints or if someone brings attention to these risk factors during an inspection visit. The other risk factors related to working hours etc. are not targeted for inspection.

Table 5: Risk factors related to working hours etc.

\begin{tabular}{llllll}
\hline & DK & FI & IS & NO & SE \\
\hline Working hours & - & C & D & A/C & D \\
Staggered working hours & - & C & D & D & - \\
Shift work & - & C & D & C & - \\
Night work & A & C & D & A/C & B \\
Lack of resting periods & - & C & D & A & B \\
Excessive overtime & C & C & D & A/C & - \\
Lack of overtime compensation & - & - & - & A/D & - \\
\hline
\end{tabular}

A: There is a practice for targeting this risk factor in inspections.

$B$ : This risk factor is only targeted in inspections in exceptional circumstances.

C: These risk factors are included in the assessment of other specific psychosocial and organisational risk factors, or they are included in an overall assessment of the psychosocial working environment. D: These risk factors are only targeted if an enterprise itself brings them up during the inspection, or if the national working environment authority has received a complaint about this matter.

-: These risk factors are not targeted in inspections.

\subsubsection{Other psychosocial risk factors}

Other psychosocial risk factors include lack of permanent worksite, frequent work-related travel outside normal working hours, pay scheme, inadequate management, lack of personal development for employees, lack of work contracts and employment contracts, control measures and unclear job descriptions. 


\section{National practices for inspecting other psychosocial risk factors}

Denmark does not target these risk factors in inspections.

In Finland the factors lack of permanent worksite, frequent work-related travel outside normal working hours and unclear job descriptions are included in an overall assessment of the psychosocial working environment. The other risk factors in this section are not targeted for inspection.

The Icelandic practice is to include unclear job descriptions in the inspection of other risk factors or to include it as a part of an overall assessment of the psychosocial working environment. The other risk factors in this section are not targeted for inspection.

Norway has a practice of carrying out inspection of the risk factors lack of work contracts and employment contracts and control measures. Sometimes pay scheme is targeted as a separate risk factor, and sometimes this factor is included in an overall assessment of the psychosocial working environment. The risk factor inadequate management is inspected in the event of complaints or if this risk factor is brought up in connection with the inspection visit. Inadequate management is also included as a part of an overall assessment of the psychosocial working environment. The practice with regard to the factors lack of personal development for employees and unclear job descriptions is to include these in the inspection of other risk factors or to include them as a part of an overall assessment of the psychosocial working environment. The factors lack of permanent worksite and frequent work-related travel outside normal working hours are not targeted in inspections.

The Swedish practice with regard to inadequate management is to only carry out inspection of this factor in exceptional circumstances. The unclear job descriptions risk factor is included in the inspection of other risk factors or as a part of an overall assessment of the psychosocial working environment. The other risk factors in this section are not targeted for inspection. 
Table 6: Other psychosocial risk factors than those mentioned above

\begin{tabular}{llllll}
\hline & DK & FI & IS & NO & SE \\
\hline Lack of permanent workplace & - & C & - & - & - \\
Frequent work-related travel outside normal working & - & C & - & - & - \\
hours & & & & & \\
Pay scheme & - & - & - & B/C & - \\
Inadequate management & - & - & - & C/D & B \\
Lack of personal development for employees & - & - & - & $\mathrm{C}$ & - \\
Lack of work contracts and employment contracts & - & - & - & A & - \\
Control measures & - & - & - & A & - \\
Unclear job description & - & C & C & C & C \\
\hline
\end{tabular}

A: There is a practice for targeting this risk factor in inspections.

B: This risk factor is only targeted in inspections in exceptional circumstances.

C: These risk factors are included in the assessment of other specific psychosocial and organisational risk factors, or they are included in an overall assessment of the psychosocial working environment. D: These risk factors are only targeted if an enterprise itself brings them up during the inspection, or if the national working environment authority has received a complaint about this matter

-: These risk factors are not targeted in inspections. 


\section{Comparison of PWE regulations in the Nordic countries}

This chapter compares existing legislation on the psychosocial working environment in the five Nordic countries. This is a general description which highlights regulatory differences and similarities, including:

- How PWE is represented and provided statutory basis in working environment legislation and how PWE is applied in the legislation.

- General and separate regulations that apply to PWE, including statutory exemptions.

- The duties and rights of employers and employees.

- The duty of confidentiality of the respective working environment authorities and their sanction options.

In this chapter, "general regulations" mean regulations that apply to both the psychological and the physical working environment such as requirements for planning and organisation of work.

For a description of the distinction in Norway between organisational and psychosocial working environment, see chapter 1 on clarification of the concept of PWE.

\section{Historical background for PWE legislation in the Nordic countries}

In Denmark, a new Working Environment Act was prepared in 1975 and entered into force on 1st January 1977. This was the first time that the psychosocial working environment had been covered by working environment legislation. The new Act was based on a broader understanding of health, and the objective of the Act was to ensure a safe and healthy working environment for employees. In 2013, the Act specified that it is to cover both the physical and the psychological working environment.

In Finland, separate provisions on the psychosocial working environment were included in the Occupational Safety and Health Act in 2003. This act replaced the previous Occupational Safety and Health Act of 1958, as the old act no longer reflected the requirements of 
modern working life. The aim of the new Occupational Safety and Health Act was to improve working conditions and to prevent that employees leave the labour market early due to poor health. For this reason, a number of requirements were introduced with the act relating to psychosocial strain; requirements relating to violence, solitary work, as well as bullying and other inappropriate behaviour. The emphasis of the act shifted from an emphasis exclusively on traditional working environment problems to an emphasis which also covers psychosocial working environment problems.

The current Working Environment Act in Iceland was adopted in 1980. The concept of the psychosocial working environment is not mentioned in this act but already in its first version, the act included sections that dealt with the obligations of the enterprise to enter into agreements on an occupational health service. The objective was to promote employees' physical and psychological health and ensure that work was adapted to the ability and skills of the individual employee. In 2003, provisions were stipulated in the act which required employers to carry out systematic, preventive working environment efforts. These requirements included a risk assessment of the psychosocial working environment. In 2004, bullying and other inappropriate behaviour were also included in the act.

Organisational working conditions have been a part of the working environment legislation in Norway since Arbeidervernlovgivningen (the Workers' Protection Act) in 1915. However, it was the Working Environment Act of 1977 that first reflected larger recognition of the significance of psychosocial conditions in the workplace. Section 12 of this act, which addresses organisation and planning of work, is afforded special significance. This section introduced regulations on the organisation of work as well as requirements for a satisfactory workplace based not only on physical parameters. In 1995, Section 12 was extended with provisions pertaining e.g. to bullying. These provisions have been continued in Norway's current Working Environment Act from 2005.

In Sweden, a new Working Environment Act was adopted in 1977 which included provisions on the psychosocial working environment. In 1982, the Swedish working environment authority, Arbetsmiljöverket, introduced the first instructions on how to apply these provisions in its guidelines on the psychological and social aspects of the working environment ("Psykiska och sociala aspekter på arbetsmiljön"). These guidelines stressed the importance of personal and professional development, the need for social contact, the organisation of work, the employees' awareness of their co-responsibility for safety and health at the work- 
place, physical and chemical factors, as well as the planning of working hours. The first binding Executive Order within this area was issued with an Executive Order on solitary work in 1982.

\section{PWE in working environment legislation}

In principle, general working environment regulation in the Nordic countries applies to psychosocial working environment problems. However, not all of the regulations are applied in practice in connection with improvement notices relating to the psychosocial working environment.

Within the regulations applied for the psychological working environment, the national working environment authorities assess whether there is a safety or health risk in the psychological working environment at the enterprise. This could be violence, threats of violence, and other traumatic events at the workplace, or high emotional demands when working with people. If one or several risk factors are present, this may justify a reaction, including an improvement notice, from the inspection authority. However, there are differences between countries in the risk factors targeted in PWE inspection, and in how inspection is to be carried out.

None of the Nordic countries have included a definition of "psychosocial working environment" in their legislation.

None of the countries have exemptions in their legislation concerning PWE. Therefore, all general working environment regulations in principle apply to both the physical and the psychosocial working environment. The area for inspection may however be limited in scope e.g. by agreements with and between the social partners (see section 2.1.)

\subsection{Areas for inspection by the working environment authority}

\subsubsection{Agreements between the social partners}

In Finland, Norway and Sweden, the national working environment authorities carry out inspection of working time regulations.

Sweden has an Act on Working Hours, under which the national working environment authority, Arbetsmiljöverket, carries out inspection. The social partners may however derogate from this act by entering into collective agreements on working hours. Arbetsmiljöverket generally does not inspect areas for which a collective agreement has been established. By far the majority of enterprises are covered by a collective agreement. 
Collective agreements on working hours can be established in Finland, Iceland and Norway, and the area is subject to inspection regardless of whether an agreement has been established.

In Denmark, agreements may be established for all areas pertaining to the psychosocial working environment, except for violence, risk of violence and solitary work which entails a risk of violence. Working hours, overtime and resting periods are not considered a part of the psychosocial working environment in Denmark. In practice, the collective agreements that have been established in Denmark concern either the entire psychosocial working environment area or just bullying. The collective agreements mean that, with regard to the enterprises and job groups covered by an agreement, the Danish working environment authority, Arbejdstilsynet, does not inspect the areas covered by the agreement. Only a few collective agreements have been established between the social partners about the psychological working environment in Denmark, and only a few enterprises in Denmark are covered by collective agreements about the psychological working environment.

It should be noted that enterprises with a working environment certificate are also exempt from ordinary inspection by Arbejdstilsynet. However, Arbejdstilsynet will always make inspection visits in the event of serious accidents, just as it will always assess whether inspection is required in the event of working environment complaints.

Denmark is unique in that Arbejdstilsynet follows recommendations from the so-called Methods Committee with regard to the aspects of the psychosocial working environment it addresses in improvement notices. These recommendations are not part of the legislation and therefore can be altered.

The report authored by the Methods Committee divided risk factors in the psychological working environment into two groups:

- Group 1 covers psychosocial working environment problems resulting from decisions by management which can be solved at the enterprise by management in collaboration with employees (e.g. lack of adequate compensation, lack of meaningful work and lack of job security). Arbejdstilsynet does not target these working environment problems in its inspection activities.

- Group 2 covers work-specific psychosocial working environment problems which Arbejdstilsynet targets in its inspection activities (e.g. high work load and time pressure, high emotional demands, violence, threatening behaviour and bullying). 


\subsubsection{Rest days, time off, working hours and night work}

Working hours, resting periods and time off are not considered part of the psychosocial working environment in Denmark. However, the Working Environment Act stipulates minimum requirements for resting periods and rest days. Arbejdstilsynet may also make inspection visits if requested by a complaint. There are no special regulations on night work in the Working Environment Act. However, the general regulations on planning and organisation of work apply to night work. For example, Arbejdstilsynet may impose an improvement notice if employees are working many consecutive night shifts while, at the same time, the work is characterised by stressful demands.

Finland carries out inspection of the risk factors working hours, resting periods, time off and night work. This is done primarily as a part of inspection of the enterprise's terms and conditions of employment; that is inspectors check whether the enterprise registers and carries an account of working hours. With regard to inspection of the psychosocial working environment, risks for employees' health associated with working hours are inspected.

In Iceland, regulations on working hours, resting periods, night work and time off are covered by inspection of the psychosocial working environment.

In Norway, regulations on working hours, resting periods, time off and night work are covered by the organisational working environment.

In Sweden, regulations on resting periods, time off, working hours and night work are covered by inspection of the psychosocial working environment, if the enterprise subject to inspection is not covered by a collective agreement.

\subsection{Obligations and rights of the employer - general regulations for the physical and the psychosocial working environment}

\subsubsection{Influence on own work}

Finland, Norway and Sweden have regulations pertaining to the influence of employees on their own work. In Sweden, for example, employees must have access to contribute to the design and development of their own work situation. In Norway and Sweden, planning of work must take account of the possibilities for autonomy, influence and professional responsibility. 
In Finland, employees have the right to propose working environment initiatives and to be informed of whether the employer will implement these proposals.

There are no corresponding regulations in Denmark and Iceland pertaining to the influence of employees on their own work.

\subsubsection{Personal and professional development}

Norway and Sweden have regulations stipulating that planning of work must ensure the employees opportunity for professional and personal development and variation in their work.

There are no corresponding regulations in Denmark, Finland and Iceland.

\subsubsection{Organisation and performance of work}

In all of the Nordic countries, the employer has a duty to plan and organise work so that it can be performed appropriately in terms of safety and health. This duty includes the physical as well as the psychosocial working environment. This type of general regulations on the planning, organisation and performance of work often forms the legal basis for PWE improvement notices (i.e. the regulations cited as the grounds for issuing an improvement notice) by the working environment authorities in the Nordic countries.

Sweden differs in this respect by having a number of separate Executive Orders on the psychological working environment which are used as the primary legal basis for improvement notices.

\subsubsection{Employer's duty to train, instruct and provide information to employees}

All of the five Nordic countries have regulations concerning the employer's duty to inform employees about specific work-related risks.

This duty to provide information etc. also applies to nuisance and problems associated with work.

Norway has regulation stipulating that employees are entitled to receive the required information and training, as well as to discuss and contribute to the design of their workplace. This regulation is worded as an employee right, while in the other Nordic countries it is worded as an employer obligation.

Furthermore, all five countries have regulations to the effect that employers have a duty to ensure that individual employees receive suffi- 
cient and appropriate training and instruction enabling them to carry out their work without risk of accidents or health impairment.

In Norway and Sweden, work instructions must be in writing if serious risks are involved.

\subsubsection{Adaption of work to the individual employee}

All five Nordic countries have regulations to the effect that work must be adapted to the physical and psychological qualifications of the individual employee.

In Norway, planning of work must also take account of the individual's life situation.

Sweden has a separate Executive Order on the Adaption of Work and Rehabilitation, which includes a requirement to find the necessary activities and routines for adapting work to the individual employee.

\subsubsection{Solitary work}

All of for the Nordic countries have regulations pertaining to solitary work in their working environment legislation. These regulations stipulate that if there is a special risk associated with solitary work, then the employer must prevent and reduce this risk.

In Denmark, employees are not allowed to work alone if working alone involves a special risk and if this risk cannot otherwise be prevented.

In Finland, the employer is obligated to ensure that employees working alone are able to have sufficient contact with other people in the enterprise. Furthermore, the employer has a duty to ensure that the employee has access to call for help.

In Iceland, the corresponding regulation is not worded as a regulation on solitary work but is instead included in the general duty of employers to assess whether there is a special risk in the work.

In Norway, there are two regulations for solitary work: one about the organisational working environment, and another about social contact. Thus, the employer must assess whether there is a special risk to the health and well-being of the employee, as well as whether the employee has sufficient opportunity for social contact.

Sweden has a separate Executive Order on Solitary Work. Here, solitary work is defined as work which is performed by an employee in physical or social isolation from other people. According to these regulations, the employer must take account of the employee's need for contact with other people, and the employer must pay particular attention 
to the physical and psychological qualifications of employees in relation to their work. Furthermore, the regulations also stipulate that work must not be carried out by one person alone if it entails a safety risk for the person in question.

\subsubsection{Supervision duty of the employer}

All of the countries have regulations to the effect that the employer has a duty to ensure effective supervision that work is performed appropriately in terms of safety and health.

\subsubsection{Workplace assessment and occupational health service}

For all of the countries, the employer is obligated to prepare a workplace assessment or similar which must include identification and risk assessment of working environment problems at the enterprise as well as an action plan for how to address these problems.

In all five countries except for Norway, the employer has a duty to obtain external assistance if the enterprise itself does not possess the required knowledge to perform a workplace assessment.

In Denmark, the employer is no longer obliged to provide employees access to an occupational health service. However, the Working Environment Act includes regulations stating that the employer must obtain external assistance to solve specific working environment problems for which the enterprise has received an improvement notice from the working environment authority (a so-called consultancy notice).

In Finland, the employer must ensure that employees have access to an occupational health service.

In Iceland, the employer must obtain assistance from an occupational health service for the preparation of a workplace assessment if the enterprise itself does not have the required knowledge to prepare such an assessment.

In Norway, employers are only obligated to ensure there is an occupational health service linked to the enterprise if risk conditions so dictate. A separate executive order states which sectors are covered by this obligation to link to an occupational health service. If the enterprise is covered by this obligation, employees must have access to using the occupational health service. The employer has a duty to obtain external assistance from the occupational health service if the enterprise itself does not possess the required knowledge to perform a workplace assessment. 
In Sweden, the employer must obtain assistance from an occupational health service, or similar external professional assistance, if the enterprise itself lacks the qualifications in the relevant area.

In Finland, Norway and Sweden, the occupational health service must be an independent actor.

In Denmark, Iceland and Sweden, the employer also has a general duty to obtain the external professional knowledge required to carry out health and safety activities at the enterprise, if this knowledge is not available within the enterprise's own organisation. For enterprises in Norway that are obliged to have an occupational health service, assistance is to be obtained from this service.

\subsubsection{First aid}

Apart from Norway, all the Nordic countries have regulations concerning first aid at the workplace.

Denmark, Finland, Iceland and Sweden have regulations to the effect that employers must safeguard that employees can receive physical and psychological first aid. In Finland, Iceland and Denmark, these regulations only mention "first aid", but the term covers both physical and psychological first aid.

In Denmark, the obligation to make first aid available includes appointing and training the people that will be responsible for first aid.

Sweden has a separate Executive Order on First aid and Crisis Management. In this executive order, crisis management refers to the physical and social support required in connection with accidents, acute crisis situations, serious incidents and similar which may trigger a crisis reaction.

\subsection{Separate regulations for the psychosocial working environment}

\subsubsection{Bullying}

All of the Nordic countries have separate regulations stipulating that employees must be protected against bullying in the workplace. See chapter 1 on the clarification of the concept of PWE for an outline of the various terms used about bullying by the different countries.

Denmark has an Executive Order on the Performance of Work which states that work must not entail a risk of physical or psychological health impairment resulting from bullying, including sexual harassment. 
In Finland, a separate regulation obligates employees to refrain from harassment or other inappropriate and unprofessional treatment of other employees which can entail a risk to their safety and health. If employers become aware that bullying (harassment) has taken place, they have a duty to rectify this.

Iceland has an Executive Order on Workplace Bullying. The Icelandic working environment authority is required to make an inspection visit if they receive a complaint about bullying.

Sweden has an Executive Order on Harassing Behaviour in the Workplace. This Executive Order understands harassing behaviour as repeated, reproachable or negative behaviour that is aimed at individual employees in an offensive manner, and which can lead to exclusion from the workplace community of the employees in question. Employers must plan and organise work so that bullying is prevented as far as possible, and they must react to any signs of bullying. Persons who have been exposed to bullying must be provided with help and support as soon as possible by the employer.

\subsubsection{Violence and threatening behaviour}

Apart from Denmark, all of the Nordic countries have separate regulations on violence and threatening behaviour.

In Denmark the general regulations apply, including the regulation that work must be planned and performed appropriately in a health and safety context. Furthermore, separate regulations on solitary work and escape routes may also be applied.

Finland has detailed regulations on the duty of the employer to prevent violence where there is an obvious risk of violence. Among other things, the employer must ensure that the necessary safety procedures and measures are in place, including access to raise the alarm. Furthermore, instructions for how to manage threats must be drawn up to protect employee safety.

Iceland's provisions on violence and threatening behaviour are included in its Executive Order on Bullying.

Norway has a regulation stipulating that, as far as possible, employees must be protected from violence, threatening behaviour and unacceptable strain as a result of work-related contact with other people.

In Sweden, corresponding regulations are provided for in a separate Executive Order on Violence and Threatening Behaviour in the Workplace. This executive order stipulates detailed regulations on the duty of the employer to investigate and prevent the risk of violence and threatening behaviour. 


\subsubsection{Social relations}

There are no other regulations pertaining to social relations in Denmark, Finland and Iceland apart from regulations on bullying. Only Norway and Sweden have regulations on social relations other than those pertaining to bullying.

Norway has a regulation which requires employers to plan work in a manner that safeguards the integrity and dignity of employees, as well as a regulation which states that employees must have access to communicate with other employees.

In Sweden, employers must endeavour to ensure that work allows employees opportunity for social contact and collaboration.

\subsection{Collaboration on the working environment at the enterprise}

All of the Nordic countries have detailed regulations regarding collaboration between employees and management about the working environment at the enterprise. All countries must have a health and safety representative who safeguards the interests of the employees in the collaboration with the employer. This collaboration comprises the psychosocial as well as the physical working environment. The employer/its representative and the employees are obligated to participate in this collaboration.

In Norway, the employer may appoint a representative from among its employees if a representative is not appointed by the employees themselves.

\subsection{Duties and rights of employees}

\subsubsection{Duties of employees}

All Nordic countries have rules governing the duties of employees. These duties differ.

In Denmark and Iceland, the rules are formulated in more general terms, as employees must help ensure that working conditions are adequate in terms of safety and health. In Denmark, the employee must also help check the effectiveness of the measures taken to promote health and safety. 
Finland has a special rule stipulating that employees may not subject other employees to bullying (harassment) and similar to the effect that this may cause to nuisance or a risk to the safety and health of employees.

Finland, Norway and Sweden have rules stipulating that an employee must follow the instructions provided, and use the safety devices available.

In all countries, employees who become aware of errors or deficiencies which may adversely affect safety or health and which they cannot remedy themselves, must report this to a member of the health and safety organisation, their supervisor, or their employer. According to Norwegian rules, this duty to report also applies if the employee becomes aware of bullying (harassment) or discrimination.

\subsubsection{Rights of employees}

In all countries, the employee is entitled a safe and healthy working environment.

All countries have slightly different rules governing the rights of employees in situations where work may endanger the life and health of employees. In Iceland, Norway and Sweden, the health and safety representative may stop work which causes immediate and serious danger to life and health. In Sweden, the health and safety representative may also put a stop to work if the employer is violating an order issued by Arbetsmiljöverket, the Swedish working environment authority. Note that the Swedish Arbetsmiljöverket has an obligation to make an inspection, if the health and safety representative has reported a working environment problem which the employer has failed to resolve despite having been made aware of the problem.

In Denmark, the rule is not formulated as a right to stop work but rather as a right to leave the workplace or a danger zone in the event of serious or immediate danger which cannot be avoided. Note that, so far there has been no precedence to apply this rule in connection with improvement notices concerning the psychosocial working environment.

In Finland, employees have a right to abstain from performing work if the work entails serious danger to their life and health, and the health and safety representative may also stop work.

As previously mentioned, Finland has a rule stating that employees have the right to propose working environment initiatives and to be informed of whether the employer will implement these proposals. 


\subsection{How the authorities deal with anonymity and confidentiality}

All five Nordic countries have rules on anonymity and the duty of confidentiality.

In Denmark, Iceland and Sweden the national working environment authorities must not inform the enterprises that an inspection visit is taking place because of a complaint. In Denmark, there is an absolute duty of confidentiality, which means that the anonymity of the reporting party cannot be lifted even if the reporting party gives their consent. In Sweden, the national working environment authority also has a duty of confidentiality concerning the identity of the employee, although the employee may waive this right wholly or partly. With regard to psychosocial complaints, the national working environment authority in Iceland, Vinnueftirlitid, will take up the case if the reporting party is willing to waive his or her anonymity. If the reporting party does not wish to waive his or her anonymity, Vinnueftirlitiđ will visit the enterprise and make a general assessment of the psychosocial working environment.

In Denmark, Norway and Sweden, the national working environment authorities are subject to the general rules on duty of confidentiality for authorities governing information on individuals, etc. This also applies in Finland, with the exception that the Inspection Act enables the authority to reveal the identity of the complainant if necessary, and if the reporting party has given his or her consent.

In Finland, the national working environment authority may take up a case if the complainant waives his or her anonymity. This not only applies in cases of bullying, but for all types of cases. Anonymity is lifted if necessary for the inspection and if the reporting party has given his or her written consent, for example, in cases concerning terms and conditions of employment, discrimination and psychosocial strain. In such cases, the Finnish working environment authority may take up the case with the employer and in this context reveal the identity of the complainant.

The Icelandic working environment authority, Vinnueftirlitid, only processes complaints about the psychosocial working environment if the complainant has waived anonymity. If the anonymity is not lifted, the authority will still visit the enterprise and deal with psychosocial issues in general.

In Norway, the name of the reporting party must generally be kept secret, also with regard to the person who is being reported, but the reporting party may grant power of attorney for the anonymity to be 
lifted. The Norwegian working environment authority only takes up cases on bullying if the anonymity is lifted with regard to the employer.

\subsection{Authorities' sanction options}

In all Nordic countries, the national working environment authorities may issue improvement notices on the psychosocial working environment.

If given an improvement notice, the employer is obligated to solve the working environment problem ascertained by the national working environment authorities. The inspection authorities may order the enterprise to find an immediate solution in the event of immediate danger. The inspection authorities may also choose to set a time limit for this. The latter option is applied in situations where there is no immediate danger.

If the employer fails to comply with the notice, the working environment authorities may refer the enterprises to legal prosecution or issue fines to the enterprises. The national working environment authorities are also authorised to prohibit performance of work that is of immediate danger to the life and health of employees until such working conditions are resolved. Prohibition notices are rarely issued in connection with the psychosocial working environment, however.

In Denmark, the following reaction options are used in connection with the psychosocial working environment at enterprises, i.e. these reaction options are being used, and are not merely a theoretical option:

- Written guidelines - given to enterprises if the working environment authority, Arbejdstilsynet, ascertains a minor violation of the working environment legislation, but finds no basis for an actual ruling (improvement notice). The inspector mainly gives these guidelines by referring to Arbejdstilsynet's printed guidelines.

- Decisions without improvement notice - given to enterprises if Arbejdstilsynet has ascertained violation of the working environment legislation but the enterprise is not ordered to act for one of the following reasons: (1) if Arbejdstilsynet has considered giving an enterprise an improvement notice, but the enterprise has solved the problem in the consultation phase, (2) if the enterprise solves a problem ascertained before the end of the inspection visit, or (3) if, in connection with an accident investigation, Arbejdstilsynet ascertains that the working environment legislation has been violated in connection with the accident, but that e.g. no immediate improvement notice or notice with time limit can be 
issued because the enterprise has already launched the relevant preventive measures or because the work in question is no longer being performed.

- Notices with time limit - given to enterprises if Arbejdstilsynet has identified a serious violation of the working environment legislation. The enterprise is ordered to find a permanent solution to the problem before expiry of the time limit.

- An immediate improvement notice - given to enterprises in cases where Arbejdstilsynet has ascertained a serious working environment issue which must be solved immediately. Enterprises which are issued an immediate improvement notice may be allowed to find a temporary solution until the problem can be solved permanently. Immediate improvement notices are typically issued in the event of serious danger to employees due to the risk of violence.

- Section 21 investigation improvement notices - given to enterprises in cases where Arbejdstilsynet has concrete suspicions that the working conditions are not adequate in terms of safety and health, or as part of a more general investigation, or ongoing checks of the conditions in specific sectors, for example. The improvement notice means that the enterprise must investigate its psychosocial working environment to ascertain whether working conditions are adequate. A consultancy notice will always be issued together with an investigation improvement notice, which means that the investigation must be carried out by a health and safety consultant authorised by Arbejdstilsynet.

- Consultancy notices - given to enterprises if Arbejdstilsynet ascertains a complex psychosocial working environment issue. Problems with bullying, including sexual harassment, are always relatively complex, and therefore enterprises with problems of bullying, including sexual harassment, are ordered to use an authorised consultancy firm in the working environment field to assist with solving the problem.

\section{Notices and consultations with enterprises}

When Arbejdstilsynet intends to issue a notice with time limit to an enterprise, before a final improvement notice is made the enterprise will be consulted in writing on Arbejdstilsynet's description of the actual conditions at the enterprise. This procedure follows from national public administration legislation. 


\section{Feedback on notices}

If an enterprise is issued an improvement notice with time limit, an immediate improvement notice or a prohibition notice (see below), before expiry of the time limit the enterprise is obligated to notify Arbejdstilsynet of how the working environment issues in question have been resolved.

Arbejdstilsynet may make one or several unannounced check-up visits at the enterprise to ensure measures solutions have been taken.

\section{Appeals about notices}

If the enterprise disagrees with notices issued by Arbejdstilsynet, the enterprise may appeal against the notice, and this is then processed by the Council of Appeal on Health and Safety at Work. The Council will determine whether the improvement notice should be upheld.

\section{Method improvement notices vs. function improvement notices}

Arbejdstilsynet has no legal basis for ordering a specific solution (method improvement notice) on psychosocial working environment issues. In the majority of cases, Danish rules do not stipulate a specific solution to be implemented but rather a level of due care to be ensured, typically "fully appropriate in terms of safety and health". Therefore, inspectors issue function improvement notices with regard to psychosocial working environment problems. This type of notice orders the enterprise to bring its working environment up to a prescribed level of appropriateness. The enterprise itself decides how to achieve this.

Whether or not Arbejdstilsynet issues an improvement notice with time limit, an immediate improvement notice or another reaction always relies on a specific assessment of the psychosocial working environment at the enterprises.

\section{Prohibition notices and police report}

Arbejdstilsynet may also issue a prohibition notice against continuing dangerous work. This sanction option may be used in relation to psychosocial working environment issues. The enterprise may be reported to the police in the event of gross violation of the Working Environment Act, or if it fails to comply with an improvement notice. The police may subsequently indict the enterprise. The prosecution decides whether the enterprise should be indicted and the prosecution has the burden of proof.

Violations of the Working Environment Act are typically subject to a fine, but may also lead to imprisonment in particularly serious cases. 
In Finland the inspector prepares an inspection report on the basis of each inspection, which may include the following reaction or sanction options in relation to the psychosocial working environment at enterprises:

- Written advice - given in connection with minor violations of the working environment legislation. The employer must eliminate or adjust the conditions in the psychosocial working environment which violate provisions in the working environment legislation.

- Improvement notice - given in connection with more significant violations of the working environment legislation. If the inspector ascertains risks or nuisances in the psychosocial working environment during the inspection which have a (negative) impact on the safety and health of the employees, the inspector may issue an improvement notice to the enterprise. An improvement notice is issued with a time limit.

An improvement notice may also be issued if the employer fails to follow written advice.

The inspector must check that the employer has complied with the notice within the time limit set. If the employer fails to comply with the notice within the time limit set, the inspector must without delay bring the matter before his supervisor who can then make a binding decision which is attached with an administrative fine.

In the case of justified suspicion that someone has committed an act subject to penalty pursuant to legislation under the jurisdiction of the working environment authorities, or under part 47 of the Criminal Code, the authority must report this to the police, who must then make a preliminary investigation.

Written advice or improvement notices issued to enterprises must always be justified on the basis of legislation. Written advice may be issued on all matters subject to inspection by the inspection authority. An improvement notice and a binding decision may only be issued in relation to matters covered explicitly by legislation.

The inspector must follow up on whether the employer has followed the advice or notice. Follow up can be carried out either by conducting a new inspection or by requesting the enterprise to prepare a written report.

In Iceland, the working environment authority, Vinnueftirlitid, may react differently depending on the assessment of the specific conditions and the seriousness of a working environment problem. Vinnueftirlitid may 
lay down a time limit for when a problem must be solved and may order an enterprise to use consultants to find solutions to a working environment problem if necessary. Vinnueftirlitiđ may also issue daily fines, prohibition notices against dangerous work and report an employer to the police if the enterprise fails to comply with statutory requirements.

The Norwegian working environment authority, Arbeidstilsynet, has a number of sanction options to ensure statutory compliance. In relation to the organisational and psychosocial working environment, the following reaction options are used to a greater or lesser extent:

Improvement notice - Arbeidstilsynet may issue an improvement notice to enterprises that they must carry out necessary measures if matters are identified during an inspection at the enterprise which are not in compliance with statutory requirements. An improvement notice is announced in advance as a consequence of requirements laid down by the Public Administration Act, which ensures the enterprise time to make objections to the notice.

When an enterprise is issued a notice to improve working conditions, Arbeidstilsynet will typically lay down the terms for compliance with the improvement notice and establish when the case can be closed.

For example:

"The employer must launch initiatives and/or prepare a plan for how best to safeguard employees against violence, threats and other negative strain as a consequence of contact with other people. This must be done in collaboration with the health and safety representative."

The terms of the notice may be as follows:

In order to assess whether the notice has been met, Arbeidstilsynet must receive the following before expiry of the time limit:

- A list of initiatives implemented.

- A plan of initiatives and time limits for their completion.

- A description of the extent to which the health and safety representative has participated.

The enterprise must report back in writing to Arbeidstilsynet about compliance with the notice with any documentation which the enterprise has been ordered to prepare. Pursuant to the Public Administration Act the enterprise may appeal against the notice.

Fine: If the enterprise fails to comply with a notice, Arbeidstilsynet may give notice of fines and impose fines. These may be fines in the form of lump sums, daily, weekly or monthly amounts. The aim of fines is to 
make the enterprise into complying with an improvement notice. The size of the fine is not set by the legislation, but in practice the fine set to put stress on the enterprise. Fines may vary from a few hundred kroner to more than a million kroner, depending on the size of the enterprise and the severity of the working environment problem.

Prohibition notice: Arbeidstilsynet may put a stop to all or part of the work at an enterprise. This measure may be applied if an enterprise fails to meet an improvement notice within the time limit set, or if Arbeidstilsynet becomes aware of matters which may pose an immediate danger to the life and health of the employees. After the inspection, a formal statement is submitted to the enterprise regarding the stoppage of work. Where there is doubt that violation of legislation may pose an imminent danger to the life and health of the employees, Arbeidstilsynet must assess whether to issue an improvement notice with a short time limit. In the case of psychosocial conflicts, the most correct step will be to issue an improvement notice, possibly with a short time limit. If the notice is not complied with, a prohibition notice may be issued to put pressure on the enterprise.

Violation charge: In 2014, Arbeidstilsynet was given the option of issuing administrative fines if a person acting on behalf of an enterprise violates the provisions laid down by the Working Environment Act. Contrary to improvement notices, fines, etc., the purpose of the violation charge is to impose a penalty on the enterprise even if the instrument is not considered a penalty pursuant to the Criminal Code but rather an administrative sanction. The charge is to impose a burden on the enterprise to demonstrate society's reaction to the violation of legislation. Arbeidstilsynet's other instruments aim at ensuring statutory compliance. Administrative fines are useful for relatively easily ascertainable violations, and if it is not necessary to make a specific assessment with regard to the violation. The charge should only be imposed if other instruments are clearly inappropriate or insufficient, and if the violation charge is deemed to be more effective. The violation charge is used mostly when the infringement is not sufficiently serious to be reported to the police, but where other instruments are insufficient. Arbeidstilsynet has limited experience with this instrument as it is relatively new. However, the violation charge may be relevant within the scope of the organisational working environment in the event of recurring violations of regulations, e.g. working time regulation for drivers (including requirements for a work plan, working hours, resting periods, breaks, night work and Sundays off).

Police report/penalties: According to the practices of Arbeidstilsynet, serious violations of the working environment legislation must 
be reported to the police. Arbeidstilsynet formally requests that the police investigate and possibly instigate legal proceedings on possible offences. The police and the prosecution may then order the enterprise to pay a fine, or a court of law may order the enterprise to pay a penalty, or the person/persons responsible in the enterprise may be subject to imprisonment.

In Sweden, an inspection report is sent to the enterprise following an inspection in which the deficiencies or problems observed in the working environment are described together with a time limit stipulating the time by which the employer must have resolved such deficiencies or problems. It is also possible to set specific requirements for action through an inspection communication, but this is less common. Some time after the inspection, the enterprise is asked for either a report back in writing on the actions/initiatives launched, or the enterprise is revisited to check that the employer has remedied the deficiencies or problems identified.

If the deficiencies are not remedied within the time limit set, Arbetsmiljöverket may issue a prohibition notice or a notice (with sanctions) to remedy the deficiencies/problems. A prohibition notice which is not complied with by the enterprise, and which is not subject to a penalty may, following legal proceedings instigated by Arbetsmiljöverket, carry up to one year's imprisonment for the employer responsible.

An indictment means that Arbetsmiljöverket requests the prosecutor to instigate legal proceedings at a court of law to ascertain any violation of the Working Environment Act. An indictment includes the request itself and a justification of the indictment from the Arbetsmiljöverket's investigation of the incident or the issue forming the basis for the request. If, following their own investigation of the matter, the prosecution decides against instigating legal proceedings against the enterprise, Arbetsmiljöverket may take further steps and call for the decision to be re-examined.

Swedish legislation enables direct penalties in the form of fines without prior issuance of a prohibition notice or notice. Such fines are called sanction charges and may be issued in the event of the following psychosocial working environment issues:

- Violation of age limits and rules on working hours for minors.

- If incorrect information has been provided in response to a request from arbetsmiljöverket.

Employers will only be subject to a fine for the above violations in the event of intentional or negligent actions. 


\subsection{The legal basis for the psychosocial working environment}

"Legal basis" means the regulations referred to if a national working environment authority issues a notice or other sanction.

In Denmark, notices are governed by the Working Environment Act and in relevant general Executive Orders. There are no separate Executive Orders on the psychosocial working environment.

In Finland, all notices are governed in the Occupational Safety and Health Act. Finland has no Executive Orders on the psychosocial working environment.

In Iceland, all notices are governed in the Working Environment Act. Iceland has an Executive Order on Bullying at the Workplace. Notices regarding working hours and similar are governed by the national Working Environment Act.

In Norway, notices are governed by the Working Environment Act and relevant general statutory instruments, particularly the Internal Control Regulations and the Executive Order on Organisation, Management and Participation. Norway has no Executive Orders specifically pertaining to the psychosocial working environment.

In Sweden, notices are most often governed by specific Executive Orders and not by the Working Environment Act. Reference is only made to the Working Environment Act if there are no relevant rules to refer to in the Executive Orders. For the psychosocial working environment area, Sweden has Executive Orders on violence and threatening behaviour in the working environment, harassing behaviour at work, solitary work, first aid and crisis support, adaptation of work and rehabilitation, as well as social support for employees working in private homes. 



\section{The Nordic strategies for PWE inspection}

This chapter describes the Nordic countries' goals and strategies for their national working environment efforts, including in particular efforts for the psychosocial working environment.

All the Nordic countries have defined political goals, strategies or action plans for regulatory action. Working environment action is often seen as a way of achieving some of the overall goals set for welfare, social and health policy, however is also a means of achieving goals set for labour market and employment policy; this is expressed as the goal to achieve a long and healthy working life for everyone. These political statements all have in common that they point to the importance of ensuring a healthy and stimulating working environment in which employees feel safe and secure, and that this leads to improved production for enterprises and the welfare state as a whole.

In their strategies or action plans for working environment action, all the Nordic countries have included the psychosocial working environment as a priority area for inspection authorities in the future.

However, the level of detail in the description of goals and the methods to achieve these goals vary significantly from country to country. This may in part be due to national traditions for strategies, as well as differences in where the working environment area and national inspection authorities are placed in the national administration structure of the individual country. Similarly, there are also great differences in the way in which the Nordic inspection authorities design and realise their activities for the psychosocial working environment, including current or planned initiatives to achieve the goals presented in their strategies. Finally, it should be noted that both Denmark and Finland have set quantitative goals for their future working environment action in the form of goals to reduce psychological strain. 


\subsection{National working environment strategies}

Denmark's 2020 strategy for working environment action expresses political agreement that occupational burnout and stress are serious health and safety issues, and that focus on the psychological working environment should be increased. As a result, the psychological working environment is one of the focus areas in the 2020 strategy.

This strategy identifies three priority areas for future working environment efforts. In addition to the psychological working environment, other priority areas are serious accidents at work and musculoskeletal disorders. As regards the psychological working environment, the goal is to reduce the percentage of employees suffering from psychological overload by 20 per cent in the period 2012 to 2020 .

The objective of the goal is to reduce the number of employees suffering from severe strain. There are three goals for this group:

- An overall goal that focuses on how employees experience workrelated stress themselves.

- A goal for bullying and harassment combined with signs of depression.

- A goal for violence and threatening behaviour combined with signs of depression.

In order to achieve the objectives, the Danish Working Environment Authority, Arbejdstilsynet, and all other working environment stakeholders, e.g. the Working Environment Council and the Sectoral Working Environment Councils, must contribute by means of the instruments at their disposal (e.g. inspections, campaigns and information). Similarly, Danish enterprises must also strengthen their efforts with regard to prevention of psychosocial working environment issues.

In 2011 Finland adopted a 2020 work environment and well-being at work policy. This policy specifies Finland's social and health strategy. Overall this strategy aims to increase life-long work by three years by 2020. To achieve this, over a 10-year period leading up to 2020, the number of occupational diseases and the number of occupational accidents are to be reduced. Moreover, the number of incidents of self-assessed physical strain is also to be lowered. As regards the psychosocial working environment, a goal has been set that the number of incidents of self-assessed psychological strain is to be reduced by 20 per cent. 
To achieve the overall goals, a number of specific areas have been identified, e.g.:

- Joint initiatives to improve the quality of management at enterprises/organisations.

- Strengthening of the preventive role of occupational health care services.

- Improving communication efforts.

- Updating of working environment legislation so it matches the needs of modern life at work.

- Designing inspection practices and competences to ensure uniform and efficacious inspections.

- Developing a method with which to assess the impact of inspections.

To date, Iceland has not made any special agreements with regard to PWE inspections. Iceland is currently preparing a new policy for the period 2014-2020. The minister for social affairs has decided to establish a working group with representatives from the social partners, political representatives and the Icelandic working environment authority, Vinnueftirlitid. This working group is to prepare a working environment policy for Iceland. The preliminary strategy includes recommendations to work systematically with the following areas within the psychosocial area.

- Preventive initiatives aimed at stress.

- Preventive initiatives aimed at bullying.

- Preventive initiatives aimed at threatening behaviour and violence.

- Preventive initiatives aimed at other psychological risk factors in the working environment, e.g. work overload.

The new strategy will entail collaboration with the social partners, and it will draw on the results of a large working environment conference held in Reykjavik in autumn 2013 to strengthen preventive measures aimed at psychological risk factors, as well as on experiences from Vinnueftirlitid's inspections. At the conference, representatives from the entire Icelandic labour market discussed the most important priority areas. The goal of the previous strategy for 2009-2013 was to reduce the number of incidents of permanent disability caused by psychological factors by 5 per cent.

In Norway, in addition to the political platform of the government at any given time, a resolution from the Norwegian Parliament about work- 
ing conditions, the working environment and safety at Norwegian workplaces forms the basis for the country's working environment policy. The resolution underlines that an important prerequisite for achieving the main goal of an inclusive labour market is to create working conditions and a working environment that ensure the health and ability to work of individuals throughout their working life.

The annual priorities for 2013 in the field of safety and health at work state" that it is a challenge that diseases etc. are inflicted on employees as a consequence of organisational and psychosocial working environment strains". In the resolution it is stated that, for many years, musculoskeletal and psychological disorders have constituted by far the largest groups of diagnoses with regard to long-term absenteeism and early retirement. In addition, focus has sharpened on the fact that some parts of Norwegian industry and specific sectors and enterprises do not have appropriate working environment conditions for employees.

In Sweden the national action plan for workplace safety and health forms the basis of working environment efforts for a 5-year period. The action plan for 2010-2015 states that special focus is to be on the importance of the psychosocial working environment in connection with inclusion of individuals who are outside the labour market by striving to promote enterprises' preconditions for accepting and retaining these individuals. The action plan also focuses on the interpersonal conditions within the workplace and mentions bullying, sexual harassment, acts of violence and threatening behaviour as focus areas for enterprises' working environment efforts. Moreover, the action plan also expresses a need for more knowledge about how every individual in a workplace can contribute to improving conditions for a healthy and safe workplace for everyone.

The 2013 government resolution that stipulates goals and requirements for the Swedish working environment authority, Arbetsmiljöverket, for the following year, does not include any detailed requirements and descriptions of goals for inspections of the psychosocial working environment.

From and including 2014, a new planning method will be used with a view to increasing influence and the possibility to channel resources to priority areas. A strategic plan including overall goals, as well as how these goals are to be met, has been prepared for 2014 to 2016. This plan is based on analyses from external contributors as well as analyses and experience gained from internal departments. Arbetsmiljöverket's own internal plan is based on this strategic plan. The internal plan will be made operational at unit and department level. The plan states that 
"there has been an alarming development in the number of incidents involving the psychosocial working environment".

In the period in question, Arbetsmiljöverket will give priority to the following overall goals for the psychosocial area:

- More employers are to introduce systematic working environment efforts.

- Fewer individuals on the labour market are to suffer occupational accidents.

- Fewer individuals on the labour market to be exposed to a poor psychosocial working environment.

\subsection{Policy and strategies for PWE inspection by authorities}

Overall, the way in which the inspection authorities in the Nordic countries administer their working environment legislation in practice is very similar. However, there are some differences with regard to the administration and organisation of the inspection authorities. For example the national inspection authorities in Denmark, Norway and Sweden belong to the ministries of labour or employment and have one central unit, for example an agency, and several regional inspection centres. In comparison, in Iceland the working environment field falls under the ministry of social affairs, and Finland has no central inspection authority. Instead responsibility for the area of occupational safety and health is divided between the ministry of social affairs and health, and regional divisions for occupational safety and health.

In Denmark, the working environment authority's (Arbejdstilsynet's) current strategy for inspections focusing on the psychological working environment is based on a long-term goal to reduce the number of employees exposed to psychological overload by 20 per cent from 2012 to 2020.

As a consequence of this, Arbejdstilsynet is to develop and prioritise its activities so as to help achieve this political goal. To achieve the greatest impact, inspection campaigns target the most important health and safety issues as well as those enterprises that are anticipated to have the most severe problems. Thus Arbejdstilsynet focuses its efforts in particular on sectors and job groups in which employees are especially exposed to problems with the psychological working environment. 
The overall working environment strategy has a total of 19 initiatives, of which one specifically focuses on the psychological working environment. As a result of this initiative, in 2012, in collaboration with the social partners, the Arbejdstilsynet examined how Danish enterprises can support efforts to develop and maintain a healthy psychological working environment. The committee in charge of this study agreed to examine two areas: the psychological working environment in organisations undergoing change, and the psychological working environment in connection with inclusion.

Political agreements were entered into both in 2006 and in 2010, and significant funding has been allocated to special inspection campaigns aimed at the psychological working environment and ergonomics in sectors with high attrition rates. In 2010, the agreement about the special inspection campaigns was extended to include a number of specific campaigns aimed at attrition and occupational burnout from 2011 up to and including 2014. On the basis of this, since 2011 Arbejdstilsynet has been conducting specific inspection campaigns aimed at working environment problems related to musculoskeletal strain as well as the psychological working environment, with special focus on entering into dialogue with enterprises and providing guidance. In 2012 a majority of the Danish Parliament (Folketinget) consolidated these special efforts in the agreement, Et godt og langt arbejdsliv for alle (A good and long working life for everyone), and extended the special initiatives up to and including 2015.

Moreover, the psychosocial and physical working environment is given equal importance with regard to violations of the Working Environment Act. Finally, it has been decided to carry out a number of specific inspection campaigns in 2013-2015 aimed specifically at the psychosocial working environment.

As regards Finland, its inspection strategy is included in a framework agreement between the ministry of social affairs and health, and the regional authorities responsible for the actual inspections. The ministry allocates funding and stipulates a set of goals for a four-year period that are to help realise its overall social and health policy strategy.

The psychosocial working environment is included in this framework agreement, which states that inspections are to be carried out in sectors that have a higher incidence of harmful psychosocial risk factors than average. Examples mentioned are harassment, violence and threatening behaviour by clients as well as other psychosocial risk factors. Sectors identified for inspection in the four-year period include the social and healthcare sector, the education sector, retail, public 
administration, hotels and restaurants, and the IT sector. In addition to this, inspections are also carried out on the basis of reports or "tips" from enterprises, for example in cases of harassment or other forms of psychosocial stress of individuals.

In contrast to the other Nordic countries, the social partners are represented in the board of the Icelandic working environment authority, Vinnueftirlitiđ, and are included in decisions about priority areas. So far, no political agreements about PWE inspection campaigns have been made. Vinnueftirlitiđ's strategy and initiatives build on statistics for permanent disability from the Icelandic occupational disease insurance scheme and results from Vinnueftirlitiđ's own research activities. Initiatives aimed at the psychosocial working environment include a goal to reduce the percentage of individuals inflicted with a disability due to psychosocial factors by 5 per cent. Vinnueftirlitiđ's inspection policy and its priorities have changed; over the past few years more emphasis has been on psychosocial working environment factors compared with more traditional factors such as machine safety.

Special initiatives aimed at the psychosocial working environment include:

- Revision of Executive Order on Harassment. Final approval by the ministry is still pending.

- Revision of inspection procedures for the psychosocial working environment, including procedures concerning bullying, violence and harassment in the workplace.

- National inspection campaigns within the social and healthcare sector with special emphasis on psychosocial factors and systematic working environment efforts, including contributions to national campaigns aimed at bullying at schools and other workplaces.

- Revision of the working environment directory for the psychosocial working environment. This directory is used when a more detailed overview of the psychosocial working environment is needed.

A new policy for the psychosocial working environment for the period 2014-2020 is currently being discussed. A strategy or an overall objective has not yet been defined, however several focus areas have been proposed. Moreover, regular questionnaire surveys have also been proposed to map the working environment conditions of employees, including any psychosocial risks. The objective of these proposals is to significantly reduce risks in the workplace. 
In Norway, the working environment authority's (Arbeidstilsynet's) strategic plan for 2008-2012 included seven thematic initiative areas, of which one concerned the psychosocial working environment. The authority announced that its aim was to work to "reduce and prevent psychological strain factors that can be linked to psychosocial and organisational conditions". In addition to this priority, four of the other initiative areas in various ways focused on organisational working conditions. The new strategic plan for 2013-2016 includes three main objectives for Arbeidstilsynet:

- Employees must have legal and safe working environment conditions, and the number of occupational diseases and injuries is to be reduced.

- Enterprises are to work systematically to achieve a safe working environment.

- Enterprises must ensure inclusion and must plan work in such a way that exclusion from the labour market is avoided.

The strategic plan includes five strategies:

- Conduct campaigns aimed at sectors at risk: cleaning, social and healthcare, building and construction, hotels and restaurants and the transport sector.

- Improve collaboration between the social partners.

- Prepare guidelines for new enterprises and young employees.

- Follow up on reports from enterprises/employees.

- Conduct inspection activities based on the annual priority areas.

The organisational and psychosocial working environment is deemed important areas in these five strategies. With regard to the annual priority areas and risk assessments, the strategy explicitly states that focus should be on the five working environment factors: organisational conditions, psychosocial conditions, ergonomics, chemical and biological conditions as well as technical conditions related to safety/accidents.

In Sweden the annual strategic decision document states how the working environment authority, Arbetsmiljöverket, should plan and develop its organisation and campaigns in the coming year. 
The strategic plan for Arbetsmiljöverket's efforts in 2014 concerning the psychosocial working environment states that the following areas are to be prioritised:

- In-depth analysis of threatening and violent behaviour.

- Development and use of all instructions for the psychosocial area.

- Strategy for the working environment for women and a school project.

- Continuation of strategy efforts concerning work strain and stress and threatening behaviour and violence with a view to achieving the goals set. 



\section{Prioritisation of PWE inspection activities}

\subsection{Inspection authorities' prioritisation of PWE inspections}

The Danish, Finnish, Norwegian and Swedish working environment authorities use a risk-based approach in their selection of enterprises for inspection. This means that the working environment authorities place special emphasis on the sectors, job groups and enterprises which they deem to be more exposed to risk factors e.g. in the psychosocial working environment. In general, the national working environment authorities base their prioritisation on recommendations from their national research institutions on sectors and job groups at special risk of workrelated strain and stress. The more specific method of selecting the individual enterprises for inspection differs from country to country. There are also differences from country to country in how inspectors focus on psychosocial working environment problems in the inspection activities they carry out during inspections at enterprises. This applies to the topics and risk factors that are brought up during an inspection (see chapter 1 on the definition of psychosocial working environment), and to the grounds for making inspection visits.

Denmark is the only Nordic country which makes routine PWE inspection visits to a majority of enterprises. All of the Nordic countries conduct inspection campaigns or initiatives focusing in particular on psychosocial issues within sectors deemed especially at risk. In 2012, Denmark, Finland, Iceland and Sweden participated in a pan-European inspection campaign funded by SLIC (Senior Labour Inspectors Committee) and coordinated by Sweden. This campaign focused on the psychosocial working environment at enterprises in the hotel and restaurant sector, the social and health sector and the freight transport sector. Across all Nordic countries the sectors especially at risk are the social and health sector, the educational system, and public administration. Other inspection campaigns focus more specifically on selected risk factors, such as violence and threatening behaviour, e.g. in connection with certain job functions, such as job functions that require the exercise of 
authority. External reports, e.g. in the form of complaints about the working environment, are investigated in all of the Nordic countries to some degree or other. There is general focus on investigating complaints about bullying, just as reported accidents involving exposure to violence and threatening behaviour are also investigated. Below is a brief outline of the most important points with regard to individual country's PWE inspection activities.

The Danish working environment authority, Arbejdstilsynet, has inspected the psychosocial working environment at enterprises within all sectors in connection with its "basic inspections" since 2007. This change in practice was part of a revision of Arbejdstilsynet's inspection model at the time; a change occasioned by a political desire to strengthen the Authority's inspection efforts with regard to the psychosocial working environment. From 2007 to 2011, basic inspections took place as unannounced inspections to perform a screening of the working environment. If a screening led Arbejdstilsynet to suspect serious working environment problems, the inspectors would agree a new visit for a socalled "adapted inspection". This was a visit to identify and address the problems suspected during the screening at the first visit.

On 1st January 2012, "risk-based inspections" became Arbejdstilsynet's new basic inspection practice in place of screening and adapted inspections This was in order to target inspections at enterprises with the most serious working environment problems. It has been agreed that risk-based inspections are to be Arbejdstilsynet's basic inspection practice up to and including 2019. During this period, Arbejdstilsynet will pay at least one inspection visit to half of all enterprises with between one to two full-time positions, and Arbejdstilsynet will visit all enterprises in Denmark with at least two full-time positions. The selection of enterprises for risk-based inspection is by random sampling and by use of an index system. Amongst other things, the index system focuses on visits to sectors with high attrition rates during the period 2012 to 2019, and on identification of problems within the Authority's three prioritised working environment areas: the psychosocial working environment, serious occupational accidents and musculoskeletal disorders. In principle, enterprises in sectors where these problems are prominent will be selected for visits before enterprises in other sectors, and the mentioned working environment areas will be afforded special focus during the inspection visits. Enterprises which have received an improvement notice from Arbejdstilsynet during the period will receive follow-up inspection visits by Arbejdstilsynet until serious working environment problems are no longer observed at the enterprise. 
When the enterprise is due to be selected for a new risk-based inspection visit, the psychosocial working environment will be afforded special emphasis. If an enterprise receives guidance on the psychosocial working environment during an inspection visit, it will receive a followup inspection visit at a later stage, just as in the case of an improvement notice. Guidance on other working environment problems does not entail a new inspection visit.

In addition to PWE inspection in connection with the basic inspections that take place in all sectors, Arbejdstilsynet also conducts inspection campaigns in sectors with high attrition rates due to ergonomic and psychosocial risk factors. Sectors with high attrition rates which have been afforded special attention with regard to inspection of psychosocial risk factors include institutions for children and young people, the homecare sector, adult residential institutions and the passenger transport sector. Arbejdstilsynet has been conducting inspection of sectors with high attrition rates since 2007. From 2007 to 2010, these inspections were performed as mere checks, i.e. visits to check whether the enterprises met requirements in the Working Environment Act. From 2011 to 2015, this type of inspection is being planned as two, dialogue-based inspection visits. During the first of these visits, Arbejdstilsynet enters into dialogue with the enterprise about its working environment, while during the second visit, which is conducted one to six months later, Arbejdstilsynet maps the psychosocial working environment to check whether the enterprise is in compliance with the working environment legislation. In addition to the inspection campaign aimed at sectors with high attrition rates, during 2013 to 2015 Arbejdstilsynet is also conducting campaigns aimed exclusively at psychosocial risk factors in sectors and job groups especially at risk. These campaigns are being conducted as simple checks or as targeted inspections.

In the period 2013 to 2015, Arbejdstilsynet is inspecting the following sectors: homecare services, residential institutions, daycare institutions, mental health services, as well as the police, emergency response services and prisons. The job groups targeted in inspection campaigns include teachers, nurses social workers/welfare officers/family counsellors and parking attendants. The enterprises in these campaigns are selected because they have been assessed to be particularly exposed to the risk factors violence and emotional demands. However, in practice, inspectors will target all relevant psychosocial risk factors that fall within Arbejdstilsynet's jurisdiction.

Targeted inspection is Arbejdstilsynet's term for inspection visits with the objective to perform a specific and predefined mapping and 
assessment of the working environment. As mentioned, targeted inspections focusing on the psychosocial working environment may be occasioned by sector-specific campaigns, or may also be carried out on the basis of reports about accidents (e.g. violence or robbery), occupational diseases (stress-related diseases), as check-up on compliance with previously issued improvement notices, and as working environment complaints by employees, health and safety representatives, relatives etc. Arbejdstilsynet has special focus on investigating complaints about bullying, and a separate complaints procedure has been established in order to ensure efficient processing of complaints within this area.

In Finland, enterprises and sectors are selected for inspection on the basis of a risk-based approach. The overall framework for activities by the Finnish regional working environment authorities is determined in four-year contracts, with the current contract running from 2012-2015. The current framework contract includes inspection activities aimed at the psychosocial working environment under the heading "Forlængelse af arbejdskarrieren" (extending working career). According to this contract, the working environment authorities inspect the prevention of psychosocial strain in the workplace at enterprises where this type of strain is deemed to be greater than average in the sector in question. The sectors in focus for the period 2012 to 2015 include: Social and health services, education, retail, public administration, the hotel and food industry, IT services, and security services. Furthermore, the Finnish working environment authorities shall also target psychosocial risk factors during all authority-initiated inspections where deemed relevant, and as otherwise appropriate for the inspection visit. PWE inspection also takes place as in response to "client" complaints, i.e. by examining complaints from employees who have witnessed, or who have themselves been exposed to, bullying or other individual psychological strains. The Finnish working environment authorities have had a practice of carrying out inspection of bullying, violence and threatening behaviour since 2002. Other psychosocial risk factors have not been addressed to the same extent.

The Icelandic working environment authority, Vinnueftirlitiđ, has published 38 sector-specific working environment directories identifying the most prominent working environment problems and risk factors in different sectors, and, thus also, the subjects which inspectors should place emphasis on during inspections. The psychosocial working environment is included in all of these directories, although with different emphasis because, for example, a hospital may be deemed to have more psychosocial risk factors than at factory workshop. 
All enterprises must complete a systematic risk assessment and must prepare action plans for how to solve the problems identified by the risk assessment. If, during and inspection visit, inspectors observe that an enterprise has failed to complete a risk assessment, the enterprise will be required to do so.

In addition to the inspection of the systematic working environment efforts by enterprises in relation to the psychosocial working environment, in 2012 Vinnueftirlitiđ completed nationwide inspection campaigns within the health and care sector, with special focus on psychosocial risk factors and systematic working environment efforts. In 2012, Vinnueftirlitiđ participated in nationwide campaigns against bullying at schools and in the workplace. Furthermore, Vinnueftirlitid is a recurrent participant in the EU Healthy Workplaces Campaigns.

The Norwegian working environment authority, Arbeidstilsynet, uses a risk-based approach in its prioritisation of enterprises for inspection. This approach is primarily applied to inspections that are initiated by Arbeidstilsynet itself, and the objective is to ensure that Arbeidstilsynet is aiming its efforts at those working environment factors which are deemed to be most important in relation to preventing major working environment problems.

The risk-based identification approach in Norway involves prioritising at three levels. The specific selection of enterprises to inspect is based indirectly on an overall knowledge base which involves an overall strategic identification of the greatest working environment problems at Norwegian workplaces. This overall knowledge base sets the framework for efforts by Arbeidstilsynet for periods of four years at a time. The sectors and the topics to be inspected (in the form of risk conditions and working environment challenges) are decided on the basis of the overall prioritisation for the given period. The specific enterprises for inspection are identified within this prioritised framework. This identification is based on e.g. information about the individual enterprise, previous inspection experience, as well as tips and reports e.g. from employees and health and safety representatives at the enterprise.

Arbeidstilsynet's strategic plan from 2008 to 2012 included seven areas of prioritisation, of which one focused explicitly on the psychosocial working environment in a strategy to prevent unacceptable psychological strain. For the period 2013 to 2016, Arbeidstilsynet will pay particular attention to organisational working conditions, in particular in the most exposed sectors and where psychosocial working environment issues will also be an important area for inspection. During the period, special efforts will be targeted at the social and healthcare sector, the 
cleaning sector, the building and construction sector, the transport sector, as well as hotel and restaurants. There will also be efforts targeted new labour-market entrants, both young employees and newly established enterprises. To some extent, inspection of the organisational working environment and of psychosocial risk factors will be interlinked. In 2013, three out of six national inspection activities based on annual prioritisation focused on the organisational working environment: prevention of social dumping; activities targeted at outsourcing and insourcing of labour; and increased awareness of organisational working conditions that can lead to unacceptable health impairment, including musculoskeletal disorders and psychological strain.

In addition to the inspection activities already mentioned, during the period 2013 to 2016, the Norwegian working environment authority will prioritise follow-up on external reports, i.e. employees and others who contact the working environment authority about a possible working environment problem at a given enterprise. The reports most often resulting in a PWE inspection visit are reports by individuals experiencing bullying, for example, or other reports about illegal conditions at a given enterprise. It has been decided that Arbeidstilsynet is to place particular priority on reports from employee representatives, i.e. health and safety representatives and union representatives.

In Sweden, inspection of the working environment at enterprises is primarily carried out as risk-based inspection. Prioritisation by the Swedish working environment authority, Arbetsmiljöverket, of enterprises and working environment areas to inspect is planned through an index system which divides enterprises into three levels, of which level 1 includes enterprises assessed to have the highest risk of work-related strain and stress, and which therefore should be given first priority in inspection efforts. The index system includes data on accidents at work, absenteeism due to sickness, number of employees, and the enterprise's systematic working environment efforts. The system does not include factors relating specifically to the psychosocial working environment.

The recommendations from the index system are included in the strategic planning of inspection efforts. However, Arbetsmiljöverket also prioritises inspection of the psychosocial working environment for other reasons. Amongst other things, Arbetsmiljöverket conducts nationwide and regional projects which target PWE inspection in specific sectors and which target specific risk factors in the psychosocial working environment. Arbetsmiljöverket is obliged to prioritise carrying out inspections requested by health and safety representatives at 
enterprises. Such requests and complaints could pertain to the psychosocial working environment at the enterprise.

Arbetsmiljöverket also conducts national inspection campaigns which focus on the psychosocial risk factors in specific sectors. In 2010 to 2011, the focus of these inspection campaigns included violence and threatening behaviour in the retail sector, and in 2011 to 2013, campaigns focused on violence and threatening behaviour in situations involving the exercise of power. In 2012, Arbetsmiljöverket headed a European campaign under the auspices of SLIC (Senior Labour Inspectors' Committee), which focused on psychosocial risk factors in exposed sectors. Arbetsmiljöverket also conducted inspections in the context of the campaign. In 2013, Arbetsmiljöverket spotlighted the working environment of women, including the particular conditions characterising the psychosocial working environment of women. In 2013 to 2016, Arbetsmiljöverket will spotlight the systematic working environment efforts by Swedish schools; in particular, prevention of violence and threatening behaviour.

\subsection{Training inspectors to conduct PWE inspection}

This section provides a description of how the Nordic working environment authorities develop the skills of their inspectors so that they can conduct PWE inspections. Skills development refers to training of newly employed staff as well as to continuing training of existing staff.

Generally speaking, skills development by the Nordic working environment authorities with regard to the psychosocial working environment follows the same principles in Denmark, Finland, Norway and Sweden. Iceland is the only country that does not include PWE inspection in the training of its inspectors. The Icelandic working environment authority, Vinnueftirlitiđ, does, however, seek to strengthen the authority's competences in the area by recruiting inspectors with skills pertaining to the psychosocial working environment. In Denmark, Finland, Norway and Sweden, all newly employed inspectors must complete basic training which includes a theoretical and a practical introduction to PWE inspection. On-the-job training, where less experienced inspectors learn how to conduct inspections from, and in the enterprise of, more experienced inspectors, is also an important part of the skills development of inspectors. With regard to on-the-job training, specialised inspectors in Denmark, Finland, Norway and Sweden play a special role as sparring partners for their less experienced colleagues. Denmark, 
Finland, Norway and Sweden have regular and ongoing introduction to new inspection areas for inspectors, e.g. in the form of a review of new inspection instructions and newly developed sector-specific material. Finally, Denmark, Norway and Sweden have ongoing continuing training activities focusing on PWE inspection; either as mandatory or voluntary training for inspectors.

In Denmark, all inspectors complete basic training in major working environment areas during their first year of employment. A total of three whole days are allocated to PWE inspection. The part of the training relating to the psychosocial working environment has special emphasis on providing an outline of the politically defined inspection powers of Arbejdstilsynet, and on introducing Arbejdstilsynet's riskbased approach to PWE inspection. This course concentrates on training inspectors in identifying and assessing the psychosocial working environment using the tools available to inspectors. Inspectors are trained in the use of Arbejdstilsynet's question guides, interview techniques, group interviews, as well as in carrying out a specific assessment of psychosocial risk factors.

In 2007, inspectors were trained in a newly developed inspection method, "the simple method", when Arbejdstilsynet launched a screening of the psychosocial working environment at all enterprises in Denmark. This course trained all inspectors in the use of a new screening tool to identify the possible existence of major PWE risk factors. This screening tool has since been replaced by Arbejdstilsynet's sectorspecific guidance tools. In connection with the launch of a new inspection campaign within a given sector, there will be a start-up workshop for the inspectors involved on the psychosocial working environment problems prominent in the sector. Furthermore, instruction memoranda about the sector are developed which e.g. provide an introduction to relevant risk factors in the psychosocial working environment in the sector in question.

Arbejdstilsynet hosts two annual theme days for inspectors which focus on specific themes relating to the psychosocial working environment. These days are held together with the Danish National Research Centre for the Working Environment, which presents the latest research within subjects that relate to PWE inspection.

The general rule in Denmark is that professional development and training in overall and theoretical aspects of PWE inspection are carried out by Arbejdstilsynet's centrally placed working environment knowledge centre, Arbejdsmiljøfagligt Center, while sector-specific skills development and training relating to specific inspection prob- 
lems are carried out by three local task forces as well as by other qualified inspectors at the various local inspection centres. Arbejdstilsynet's task forces are also responsible for on-the-job training, as well as supervision and sparring with colleagues with generalist skills with regard to psychosocial working environment problems. The task forces also have a key role in Arbejdstilsynet's skills training with regard to the psychological working environment, which is a formalised, nationwide continuing training programme.

In Finland, all inspectors participate in basic training which covers introduction to inspection guidelines and practical case examples on psychosocial working environment problems. In each region, there are inspectors with special training in carrying out inspection of client-initiated cases about discrimination, bullying and other psychosocial strain. Such training has a theoretical part and on a practical part in the form of onthe-the job training in teams with experienced inspectors. In the summer of 2013, guidelines on how to carry out inspection of psychosocial risks were completed. All inspectors received a single-day course on these guidelines. The more specialised inspectors receive more in-depth training on the subject. From 2014, the basic training programme for new inspectors includes a half-day course on inspection of bullying and a halfday course on inspection of other psychosocial risks.

In Iceland, all newly employed inspectors go through the same basic training programme. There is no specific PWE inspection training involved in this programme, although there is a general introduction to the subject. The regional working environment authorities endeavour to ensure that the inspection staff represents a broad cross-section of working environment competences and the authorities consider this in their recruitment of new employees. If required, inspectors receive guidance and support from centrally employed specialists in the area. Inspectors also receive training in relevant subjects in connection with implementation of campaigns about the psychosocial working environment and when new inspection tools are introduced.

In Norway, all newly employed inspectors complete theoretical and technical introduction to the psychosocial and organisational working environment as specialist subjects. Large parts of the theoretical and practical training take place in the region where the inspector is employed, and are delivered by the new employee's colleagues and manager. During the first three years of employment, all inspectors must complete a more in-depth training module. One of these in-depth training modules is a module on the psychosocial and organisational working environment, which provides knowledge e.g. about the psychological and the organisa- 
tional working environment, and which provides the inspectors with skills to conduct inspections and write decisions in the area. Inspectors who conduct inspection of the psychosocial and organisational working environment are also offered courses in communication and group processes. The Norwegian working environment authority, Arbeidstilsynet, has established several different skills networks with a view to strengthening its access to professional, up-to-date knowledge and knowledge sharing. These national skills networks on the psychosocial and organisational working environment are tasked with contributing to quality assurance of inspection-technical activities within the psychosocial and organisational working environment; and they are also tasked with ensuring that knowledge about inspection is brought up to date and that experience from inspection activities is shared from one activity to the next. Finally, the networks are also tasked with ensuring up-to-date introduction for new employees as well as skills development within the subject area of the psychosocial and organisational working environment.

In Sweden, all inspectors complete a six-month basic training programme. This basic training programme includes an introduction to psychosocial working environment factors and PWE inspection. After a few years of employment, inspectors are offered continuing training which includes further training about psychosocial working environment factors. Furthermore, inspectors can apply for supplementary courses within the area as required. Newly employed inspectors conduct inspections together with more experienced inspectors with a view to gradually taking over the inspections from the more experienced inspector. In each district there are inspectors with overall responsibility for cases involving the psychosocial working environment due to their experience and educational background, and these inspectors act as support and sparring partners for their less experienced colleagues. Inspectors responsible for cases involving the psychosocial working environment are organised in a skills network together with centrally employed specialists in the area. The network meets on a regular basis to share knowledge and develop professionally.

\subsection{Time spent on PWE inspections}

It is not possible to make a complete and comparable account of the time spent by each Nordic country on PWE inspection. Only the Norwegian working environment authority draws up an actual statement of its resource consumption on inspections based on time, in the form of time 
spent by inspectors on inspecting the area, stated in FTE (full-time equivalents). In Norway, however, inspections of the psychosocial working environment cannot be distinguished from inspections of the organisational working environment. In Sweden, it is not possible to draw up statements of the time spent by inspectors which provide an adequate picture of how much time they spend on PWE inspection. Iceland states that it does not register time spent on PWE inspection, and Denmark and Finland do not state their resource consumption in time spent, but in number of PWE inspections carried out.

In Denmark, it is not possible to account for how much time is spent on PWE inspection in isolation. However, the Danish working environment authority, Arbejdstilsynet, does have statements of the number of inspection visits at which the psychosocial working environment was inspected. The psychosocial working environment is included in all of Arbejdstilsynet's basic inspections. That is, in screenings and subsequent adapted inspections conducted up to and including 2011, as well as in the riskbased inspections that replaced the screenings as of January 2012. Furthermore, it is also relevant to include inspection campaigns that spotlight PWE inspection. During 2010 to 2011, Arbejdstilsynet made a total of 62,813 screening visits. Of these, 2,517 were selected for subsequent adapted inspection, e.g. on the basis of suspicion of psychosocial working environment issues at the enterprise. During 2010 to 2012, a total of 11,355 visits were completed in inspections involving PWE inspection. A total of 90 inspection visits were conducted which investigated complaints about bullying, as well as 177 process guidance visits; special guidance visits offered to enterprises that had received an improvement notice concerning their psychosocial working environment.

In Finland, there is no statement of how much time the regional working environment authorities spend on PWE inspection relative to inspection of other areas. However, Finland has prepared an overview which shows the number of inspection visits at which inspectors dealt with major psychosocial risk factors relative to the total number of inspection visits in 2012. This overview reveals that the Finnish working environment authorities conducted a total of 22,500 inspection visits in 2012. Of these, violence and threatening behaviour were dealt with at 5,453 visits (24 per cent of all visits), bullying at 5,135 visits (22 per cent of all visits) and other psychosocial risks at 2,649 visits (12 per cent of all visits).

For Iceland, it is not possible to provide an answer to how much time is spent on PWE inspection. However, Iceland describes that the area is 
being afforded more priority than previously and that, consequently, more time is being spent on dealing with the subject at inspection visits.

In Norway, PWE inspection is included as part of both the psychosocial working environment and the organisational working environment. The same applies to the resource consumption statements by the Norwegian working environment authority, Arbeidstilsynet. Therefore, it is not possible to make a statement which distinguishes between the resources spent on inspections of psychosocial risk factors and the resources spent inspecting "prevention of musculoskeletal disorders", for example. Furthermore, the statements of the authority's resource consumption do not exclusively include resources spent on inspections, but instead they include all of Arbeidstilsynet's outreach activities. Resources spent on inspections have therefore not been isolated from resources spent on other activities, such as processing applications for exemption from working time regulations etc.

Norway's time consumption is stated as the number of full-time equivalents spent by inspectors on inspection projects covering the organisational and psychosocial working environment. This statement shows that the time spent on inspection activities within the organisational and the psychosocial working environment accounts for around 25 per cent of the full-time equivalents spent in total by Arbeidstilsynet in the period 2010 to 2012.

Sweden registers time, e.g. in connection with inspection campaigns, however these registrations cannot be used in a statement of how much time inspectors spend on PWE inspection.

\subsection{Number of PWE-related improvement notices}

This section attempts to provide an account of the proportion of improvement notices related to the psychosocial working environment relative to other working environment problems. "Improvement notice" is used as an overall term for the various types of requirements placed on enterprises to rectify violations of the Working Environment Act.

It is not possible to provide a directly comparable account of the total number of PWE-related improvement notices by the Nordic countries. This is mainly due to the fact that the psychosocial working environment as an area includes different risk factors across the countries (see chapter 1 on the clarification of the concept of PWE, theoretical background and inspection practice) Denmark, Norway and Sweden draw up systematic statements of the number of improvement notices made within 
the respective authorities' power of reaction. So far, this is not the practice in Finland and Sweden. Furthermore, the statements of reactions by the national working environment authorities in Norway and Sweden categorise PWE-related improvement notices together with improvement notices about requirements for the systematic working environment efforts by enterprises.

In the period 2010 to 2012, the Danish working environment authority made a total of 62,982 improvement notices within all the working environment areas. Of these improvement notices, 1,552 were regarding the psychosocial working environment, which corresponds to a share of 2.5 per cent. In the same period, 15,846 improvement notices were issued to enterprises to the effect that they prepare or bring up to date their workplace assessments. A workplace assessment must always include a risk assessment of psychosocial risk factors.

As of yet, there is no systematic statement in Finland of the total number of reactions by the regional working environment authorities on working environment problems in the psychosocial working environment.

Iceland issues notices with time limits if an enterprise has failed to complete a workplace risk assessment. Risk assessments must include risk factors within the psychosocial working environment. It has been estimated that specific notices regarding psychosocial risk factors account for less than 1 per cent of the total number of notices issued in 2012.

In Norway, a great number of reactions, including PWE-related notices, are made with reference to the national working environment authority's Internal Control Regulations which describe the requirements posed on enterprises to carry out systematic working environment efforts. As this Executive Order is not applied exclusively to psychosocial working environment problems, preparing an accurate statement of the number of improvement notices within the area is not possible.

Sweden's statement of improvement notices within the area of the psychosocial working environment shows that, for 2010, 15.5 per cent of all requirements imposed by the authorities were within the area of the psychosocial working environment. In 2011, this figure was 12.1 per cent, while in 2012 it was 10.8 per cent of all requirements relating to topics within this area. It has been assessed that the actual figure is greater, because requirements relating the psychosocial working environment will often be categorised in areas that relate to requirements for systematic working environment efforts by enterprises. 



\section{Methods to carry out PWE inspections in the Nordic countries}

\subsection{Inspection methods in the Nordic countries - summary}

This chapter describes the approach used by national working environment authorities in the Nordic Countries when carrying out inspections of major working environment problems, such as work-related stress, violence and bullying in the psychosocial working environment, including the methods and tools applied to analyse and assess the psychosocial working environment and the structure of the inspection process.

As mentioned previously, for example in chapter 2 concerning the legal basis for inspections and the inspection activities of the Nordic countries, the different countries have very different approaches to their PWE inspections. As stated below, the differences are quite distinct when observing the approach in practice in these countries to inspection of the main risk factors in the psychosocial working environment. This is seen in the way that the authorities organise and structure their PWE inspection activities, as well as the specific methods applied in the inspection.

\subsubsection{Inspection of the main psychosocial working environment problems}

The working environment authority in Denmark, Arbejdstilsynet, carries out two types of PWE inspection; 1) risk-based inspection which is the basic inspection carried out by Arbejdstilsynet with a broad focus on the working environment, and 2) targeted inspection, exclusively or primarily focusing on assessing the psychosocial working environment at an enterprise.

In Denmark, Arbejdstilsynet's PWE inspection is defined in a number of recommendations prepared by the social partners and the Danish Ministry of Employment, including Arbejdstilsynet, in the so-called Methods Committee. This means that even though Arbejdstilsynet in- 
spects the psychosocial working environment during most inspection visits, in practice Arbejdstilsynet only makes improvement notices regarding the risk factors or negative impacts in the psychosocial working environment which are linked to the job functions of the individual employees. These include violence and threatening behaviour, consequences of traumatic incidents, high workloads and time pressure, emotional demands, bullying and planning of night work.

In Finland, the regional working environment authorities carry out PWE inspections both as authority-initiated inspections (at the working environment authority's own initiative), and as client-initiated inspections following an external request. Both types of inspection include the risk factors: bullying, violence and threatening behaviour, as well as psychosocial strain.

The working environment authority in Iceland, Vinnueftirlitid, carries out authority-initiated inspections of the preventive measures taken by enterprises in relation to psychosocial risk factors such as psychosocial strain, violence and threatening behaviour, and bullying, as well as clientinitiated inspections, prompted by complaints of bullying, for example.

For a number of years, the Norwegian working environment authority, Arbeidstilsynet, has carried out inspections of the specific psychosocial and organisational working environment at enterprises. Arbeidstilsynet is now increasing focus on inspecting organisational working conditions, particularly in authority-initiated inspections. The aim of the inspection is to check whether enterprises have developed organisational measures to prevent psychosocial problems, and also to check how such measures work in practice. Arbeidstilsynet's inspection of the specific psychosocial working environment, e.g. the risk factors; bullying and harassment, etc. is carried out primarily as follow-up on reports by individuals.

In Sweden, PWE inspections are carried out in connection with national inspection projects and during compulsory inspections prompted by reports by health and safety representatives and other employees. The most common way to carry out an inspection is ordinary inspections. These are announced, authority-initiated inspections that are primarily carried out as inspection campaigns aimed at a particular sector or job group. Furthermore, the Swedish working environment authority, Arbetsmiljöverket, investigates complaints of e.g. bullying, submitted by e.g. health and safety representatives and other external "clients". Arbetsmiljöverket primarily inspects the systematic working environment efforts by the enterprises. This inspection is supplemented with an assessment of the psychosocial conditions in the specific working environment at the enterprises visited. 


\subsubsection{Inspection of the working environment and systematic working environment efforts}

In Denmark PWE Inspections carried out by the working environment authority, Arbejdstilsynet, include inspection of the psychosocial problems in the psychosocial working environment at a specific enterprise. Inspectors obtain information regarding the psychosocial impacts on employees, as well as regarding the enterprises' methods for preventing such impacts. As Arbejdstilsynet always carries out specific assessments of the working environment, inspections in Denmark always involve physical visits to enterprises at which representatives from both management and employees are consulted. For use in Arbejdstilsynet's assessment of the psychosocial working environment, the inspectors collect information about the specific psychosocial working environment at an enterprise, as well as information about the psychosocial working environment from the working environment efforts at the enterprise. The Danish Working Environment Act lays down no requirements for special procedures or policies, etc. in relation to the psychosocial working environment, and inspection of the systematic working environment efforts of enterprises is only carried out in connection with the statutory workplace assessment (WPA).

The Finnish authority-initiated inspections have primarily been focusing on assessing the systematic working environment efforts of enterprises. The inspectors carry out inspection of the systematic working environment efforts of enterprises by checking the procedures laid down by enterprises for analysing and assessing the psychosocial risk factors at the workplace, and inspectors assess the competences of enterprises to work with the working environment and to cooperate with the associated occupational health care service. Authority-initiated inspections are carried out as physical visits at the enterprises, possibly combined with written correspondence between the national working environment authority and the enterprise, whereas client-initiated inspections focus on inspecting the employer's management of individual problems within the psychosocial working environment. In client-initiated inspections, such as investigations of complaints about bullying or psychosocial strain, the inspectors make their assessment on the basis of information collected about both the specific working environment at the enterprise, and by checking whether the working environment efforts of the enterprise meet the statutory requirements. Such inspections are primarily carried out as a written correspondence/consultation procedure between the authorities and the parties to the case. 
In Iceland, the purpose of the inspection is to assess whether the enterprise has a practice to prevent working environment problems, and whether such practice is working. During the inspection, which is always a visit at the enterprise, Vinnueftirlitid mainly focuses on assessing the systematic working environment efforts of the enterprise, and this includes the risk assessments made by the enterprise and its plans for prevention and management of bullying, for example. In most situations, the assessment made by Vinnueftirlitid on the psychosocial working environment is made on the basis of information about the systematic working environment efforts of the enterprises, as well as information about the specific psychosocial working environment.

In Norway, the inspection of organisational working conditions is done by inspectors checking the systematic working environment efforts of enterprises, including documentation of whether they comply with the formal requirements laid down by the Working Environment Act on organisation of the working environment and occupational health and safety work. This check most often takes place in connection with inspection visits at the enterprise. In most situations, Arbeidstilsynet's investigation of complaints concerning the working environment comprises a review of the documents relevant to the case, supplemented by interviews with management and other relevant persons at the enterprise. The inspection activity carried out determines whether Arbeidstilsynet only checks the systematic working environment efforts of the enterprises, or whether the inspection is combined with an inspection of the specific working environment.

In Sweden, inspection of the psychosocial working environment is supported by a number of different inspection methods which the inspectors may use in their PWE inspections. The most common inspection, the ordinary inspection, is conducted as a combined review of the enterprise's systematic working environment efforts and an inspection of the specific working environment at enterprise, including follow-up on preventive measures previously launched by the enterprise, as well as walk-around tours of the enterprise where the inspector interviews employees.

In the appendix to this report provides a detailed overview showing the extent to which the working environment authorities in the Nordic countries conduct inspections of the specific working environment, the systematic working environment efforts, or both, in their PWE inspection and their inspection of organisational working conditions. 


\subsubsection{Structuring PWE inspections}

In all five Nordic countries, inspection visits which focus specifically or exclusively on the psychosocial working environment are announced in advance. Announcing the visits ensures that the working environment authorities are able to meet the persons relevant, and it ensures that the enterprise has an opportunity to clarify what the authority expects from the visit. Only Denmark also conducts inspections of the psychosocial working environment at unannounced visits; i.e. socalled risk-based inspections.

In Finland, and partly in Iceland, Norway and Sweden, prior to a visit, the authorities collect information from the enterprise about the working environment and the working environment efforts of the enterprise. The information collected could be the enterprise's or the occupational health service's own mapping of the working environment, risk assessments, and the enterprise's programme for safety and health.

In all five Nordic countries, an inspection visit focusing on the psychosocial working environment will begin with a meeting with representatives from the enterprise's management and health and safety organisation. At the meeting, the inspectors review the enterprises' written documentation on its working environment and the systematic working environment efforts, and discuss matters relevant to the inspection. In countries where the inspection focuses mostly on checking the documentation of enterprises on their systematic working environment efforts, i.e. Finland, Iceland and Norway, in some situations the inspection will be concluded after a meeting between the inspection authority and the enterprise representatives.

Like in Denmark and Sweden, in some situations Finland and Norway will supplement their collection of working environment information with a tour of the enterprise, checking the plan of the workplace and talking with employees. In Iceland, in situations where anonymity cannot be breached in connection with a complaint, a general inspection visit is carried out, focusing particularly on the psychosocial working environment, and the inspector will tour the enterprise.

In Denmark, Norway and Sweden, the tour at the enterprise may be supplemented with one or more interviews with groups of employees or individuals, or it is possible to skip the tour entirely and move directly to carrying out interviews with the employees. In all three countries, group interviews generally take place with employees and managers separately.

In Denmark and Sweden working environment inspectors meet separately with representatives from management. This is partly to obtain information on the management's assessment of the psychoso- 
cial working environment and partly to verify the information obtained from the group interview. After the data collection, a final meeting is held with representatives from management and the health and safety organisation. The inspectors brief the representatives on their assessment of the working environment, discuss the assessment with management and the health and safety organisation and warn about any improvement notices.

\subsubsection{Standardised tools for PWE inspections}

All Nordic countries have developed different standardised guidelines, questionnaires and checklists which inspectors may use to structure their collection of information on the psychosocial working environment at enterprises.

In Denmark, the primary tool for PWE inspections is the 24 sectorspecific guidance tools issued by Arbejdstilsynet. The question guides are used for all types of PWE inspection.

In Finland, the regional working environment authorities use the Valmeri questionnaire which includes nine questions concerning problems with the psychosocial working environment.

Iceland has recently started using a questionnaire similar to the Finnish, but with thirteen questions about the psychosocial working environment. Moreover, one or more of Iceland's 38 working environment directories are used, covering the different sectors, as well as more elaborate directories for the psychosocial area.

In Finland and Iceland, the questionnaires are submitted to the enterprises, then completed by the employees and processed by the relevant working environment authority. In both countries, the replies may provide an index of the psychosocial working environment at the specific enterprise together with a comparison with national average replies for the relevant sector.

In Norway, Arbeidstilsynet has prepared 60 checklists which are adapted to the different organisational conditions and various working environment conditions characteristic of the different sectors, as well as the themes relevant for the different inspection activities. The checklists include questions about the organisational working conditions and the psychosocial working environment.

Like the Danish guidance tools, the checklists are generally reviewed during the visit. The checklists are used as interview tools for use by the inspectors in conversations and interviews as a basis for their assessment of the psychosocial working environment. 
In Sweden, Arbetsmiljöverket has developed a number of different tools adapted to the different inspection activities by the authority. Arbetsmiljöverket uses sector-specific checklists when completing ordinary inspections, e.g. in connection with national inspection projects.

\subsubsection{Preferred methods for PWE inspections}

Denmark, Norway and Sweden, which have experience using group interviews, agree that this is the preferred method for mapping the psychosocial working environment at enterprises. This is the most commonly used method in Denmark, but has not been used as often in Norway and Sweden. This is because group interviews are considered timeconsuming and difficult to plan. In Finland, the questionnaire submitted and completed prior to an inspection is the primary method for mapping the psychosocial working environment.

\subsection{Inspection methods in Denmark}

Assessments by Arbejdstilsynet of the psychosocial working environment at an enterprise are based on the requirements laid down by the working environment legislation. Inspections of the psychosocial working environment carried out by Arbejdstilsynet must therefore include an assessment of whether work has been planned and organised appropriately in terms of safety and health, and whether work poses a risk to the employees in terms of safety and health, either in the short or long run.

\section{Danish WEA inspection of key working environment problems}

As stated in the description of the Danish Methods Committee in the chapter on legislation, not all factors or negative impacts in the psychosocial working environment are inspected by Arbejdstilsynet. With reference to the recommendations from the Methods Committee, Arbejdstilsynet must assess whether there is a basis to inspect the psychosocial working environment at an enterprise in more detail by assessing the cause of the problems, i.e. whether a problem in the psychosocial working environment is directly or indirectly caused by the job function of the individual employee. The following paragraphs describe some fundamental principles relating to inspection of the psychosocial working environment in Denmark. 


\section{Announced and unannounced inspections}

Politicians have decided that risk-based inspection, which is the basic inspection carried out by Arbejdstilsynet, must generally be carried out as an unannounced visit. In relation to the methods used by Arbejdstilsynet to examine the psychosocial working environment, e.g. interviews with management and employees in groups or individually, Arbejdstilsynet often needs to plan data collection together with the enterprise. For risk-based inspection, this can take more than one visit, which then enables planning and implementation of data collection with regard to the psychosocial working environment.

When Arbejdstilsynet carries out inspections which are not riskbased inspections, inspection of the psychosocial working environment will typically be carried out as an announced inspection, because an announced visit gives the enterprise the opportunity to plan the inspection in advance.

\section{Inspection of the specific working environment}

Inspection of the psychosocial working environment carried out by Arbejdstilsynet includes inspection of the problems caused by risk factors in the specific psychosocial working environment at enterprises. If such problems in the psychosocial working environment are assessed to pose a risk in terms of safety and health of the employees, Arbejdstilsynet will react by issuing an improvement notice to the enterprise. Inspection of the specific psychosocial working environment is also supported by information from the working environment efforts of the enterprise, e.g. workplace assessments, statistics on absenteeism due to sickness, etc. The inspection is primarily focused on the specific psychosocial working environment.

During the inspection, Arbejdstilsynet examines the psychosocial impacts on employees and the steps taken by the enterprise to prevent these psychosocial impacts. The inspectors must assess whether there is balance between the impacts on the employees in the form of risk factors, and the preventive steps required to ensure that employees are not exposed to risks in terms of safety and health. This means that there must be a balance between the demands on employees (the risk factors) and the possibilities of the employees to meet these demands (the prevention). If a risk factor is not sufficiently mitigated, employees will typically suffer the work-related consequences, whereas the negative consequences should be absent if prevention matches the impact. It should be stressed that in practice, a specific assessment of the balance between impacts and prevention is always carried out. 


\section{Collection of data on the psychosocial working environment}

When Arbejdstilsynet carries out PWE inspections, the inspectors collect data about the risk factors in the specific enterprise. For this purpose, Arbejdstilsynet has prepared 24 guidance tools each aimed at a specific sector (e.g. home care) or a specific job type (e.g. teaching).

On the basis of data collected about the incidence of risk factors, preventive steps taken by the enterprise on such risk factors, as well as any work-related consequences, Arbejdstilsynet must assess whether the work poses a safety and/or health risk to the employees.

\subsubsection{Structuring the inspection process}

Generally, Denmark operates with two types of inspection visit aimed at the psychosocial working environment. One type is the basic inspection carried out by Arbejdstilsynet, also known as the "risk-based inspection". The other type is the targeted inspection. A detailed inspection has a wider meaning with multiple purposes, e.g. investigations of accidents and complaints, following up previously issued improvement notices and visits carried out as part of national inspection campaigns. In practice, the inspection process and planning of the visits are adapted to the purpose of the visit and to the needs of the enterprise, but there are a number of common characteristics in PWE inspections which can be highlighted. As mentioned, Arbejdstilsynet's basic inspections - the riskbased inspections - must be unannounced, but by far the majority of inspection visits focusing on the psychosocial working environment are announced in advance to ensure that Arbejdstilsynet can talk to relevant people at the enterprise and to ensure that all parties know what to expect from the visit.

Generally, most visits begin with a meeting with the enterprise's management and health and safety organisation. Here the workplace assessment is reviewed and there are discussions with enterprise representatives about the psychosocial working environment and any preventive steps which have been implemented. After the meeting, there may be a tour of the enterprise to observe the working environment and talk with the employees, or there may be group or individual interviews, or a combination of both. In some cases several interviews and observations are made, for example at large enterprises or enterprises located at several addresses. Moreover, the inspector also carries out separate interviews with management representatives. The inspection is completed with a joint meeting with management and the health and safety organisation. Here the inspectors give their assessment of the working envi- 
ronment, any preventive steps taken by the enterprise are discussed, and notification is given of any improvement notices. All improvement notices on psychosocial risk factors are submitted for written consultation in the enterprise for a minimum of 14 days.

\subsubsection{Preparation of a risk-based inspection}

Prior to a risk-based inspection, the inspectors must review the information provided on the enterprise. The following information is made available to the inspectors:

- Arbejdstilsynet's ten most recent cases concerning the enterprise, including

- Arbejdstilsynet's three most recent inspection visits at the enterprise.

- The ten most recently reported accidents at the enterprise (if any accidents have been reported at all).

The specialist preparation of the PWE inspection is by ensuring that the inspectors review the working environment directory for the relevant sector. Arbejdstilsynet has drawn up working environment directories aimed at 36 sectors. Here the working environment problems typical for the sector in question are described, including psychosocial working environment issues. The directories provide the inspectors with an overview of the risk factors for investigation at the relevant enterprise. The inspectors are also expected to supplement their knowledge about the sector by studying relevant instruction memoranda about the sector, which also identify relevant risk factors in the different sectors.

Moreover, the inspectors must study the descriptions provided in Arbejdstilsynet's internal instructions (At-intern instruks IN-4-1) on completion of the PWE inspection process.

The inspectors may also prepare for their inspections by studying the relevant guidance tools for the sector in order to gain a detailed overview of the risk factors involved in the psychosocial working environment; factors they must consider in their inspection.

In principle, an inspector must make the above preparations prior to every risk-based inspection. However, once the inspector has studied the same documents several times, the contents of the documents will eventually be familiar to the inspector.

As described elsewhere in this report, risk-based inspections are generally unannounced. This means that if, during an inspection, Ar- 
bejdstilsynet suspects that there are psychosocial working environment issues, the Authority will have to enter into agreements with the enterprise on more thorough investigations of the psychosocial working environment. The inspectors will make an agreement with the enterprise on extension of the risk-based inspection and the inspectors will then revisit the enterprise at a later date. This type of inspection considered an extension of risk-based inspection. Prior to this inspection, the inspectors will make an agreement with the enterprise on the methods for examining the psychosocial working environment in the new inspection visit. For example, this could be by making an agreement with the enterprise to make available a number of employees for a group interview or several individual interviews. It may also be agreed that Arbejdstilsynet can make observations of the specific work carried out at the workplace.

\subsubsection{Preparation of a targeted inspection}

The preparation for a targeted inspection does not differ significantly from the preparations for a risk-based inspection. The inspectors must study the same documents as for the risk-based inspection.

The most important difference between a risk-based inspection and a targeted inspection focusing on the psychosocial working environment is that generally the targeted inspection focuses on a specific working environment problem, for example the psychosocial working environment. In contrast, the risk-based inspection is an inspection which takes into account the entire working environment and in particular three areas prioritised by Arbejdstilsynet up to 2020: serious accidents, musculoskeletal strain and the psychosocial working environment. Another difference is that targeted inspection focusing on the psychosocial working environment is often carried out as an announced inspection. This is because the methods used by Arbejdstilsynet to examine the psychosocial working environment at enterprises usually mean that the employees at the enterprise must allocate time to talk with Arbejdstilsynet individually or in groups. The announcement of a targeted inspection is typically by phone. Arbejdstilsynet agrees an appointment for the inspection with the enterprise. The agreements are confirmed by post or in an email to the enterprise. 


\subsubsection{Collection of information on the psychosocial working environment}

Arbejdstilsynet has drawn up internal guidelines: Kortlægning af psykisk arbejdsmiljø (At-vejledning D.4.1). Moreover, the most important data collection methods are described in a set of internal instructions (Atintern instruks IN-4-1). The following paragraphs describe the most important points in the different methods.

\section{Data collected before the inspection}

- Reported incidents of occupational diseases related to the psychological working environment. Information on reported occupational diseases may indicate the type of psychosocial working environment issues present at an enterprise. If two cases of occupational diseases have been reported as a consequence of e.g. Bullying, the inspectors should focus particularly on clarifying whether there is a problem with bullying.

- Reported accidents (violence, traumatic events, etc.). Information on reported accidents, e.g. Violence, means that the inspectors must pay attention to this problem in their mapping of the psychosocial working environment.

- Complaints about the working environment from employees are also relevant when preparing the inspection. Arbejdstilsynet cannot use the individual complaints as data, as the authority has a duty of confidentiality with regard to complaints relating to the working environment. However, complaints can be used to draw attention to psychosocial working environment issues of relevance.

- Information about psychosocial working environment issues provided by the media, unions, general practitioners or occupational health clinics.

\section{Data collected from the inspection:}

The following paragraphs describe four methods which can be used by Arbejdstilsynet to collect data on the psychosocial working environment at an enterprise:

- Group interviews.

- Interviews with individuals (including interviews conducted when touring the enterprise).

- Observations.

- Questionnaires. 


\section{Group interviews}

The method mostly used by Arbejdstilsynet for collecting information pertaining to the psychosocial working environment is group interviews. This method is based on experience from focus group interviews at which employees can describe their specific psychosocial working environment. This method enables the inspectors to collect data about the most important psychosocial working environment issues. There are many advantages of choosing the group interview method. This method enables inspectors to use the employees' own descriptions and assessments of their specific working environment.

Both management and the health and safety organisation at the enterprise are responsible for selecting people for individual and group interviews. Persons are selected on the basis of Arbejdstilsynet's wishes for the composition of the group. The enterprise is encouraged to compose a group which provides a representative cross-section of the enterprise. If it is a large enterprise, there may be a need to make agreements about several group interviews in order for Arbejdstilsynet to gain a "representative" view of the psychosocial working environment at the enterprise. There is always the risk, however, that the group interview will not provide a representative view of the enterprise. This may be counteracted by conducting several group interviews with various group compositions.

Group interviews are particularly applicable in situations where it is necessary to gather employees across specialist groups or departments, or if it is necessary to gather more detailed information about an individual department. The method enables the collection of current information about the specific work and makes it possible to detect problems and challenges in the work.

The group can be composed in several ways, e.g. employees as well as management at the enterprise, or just employees from a specific professional group or department.

Generally, the most optimal scenario is between four and eight employees from the enterprise participating in a group interview. Group interviews normally last between 1 and 2 hours.

In group interviews, the inspectors use the risk factors described in the question guide prepared for the sector or job group as their point of departure. It is also possible to use the sector-specific working environment directories and the knowledge already provided to the inspectors about the psychosocial working environment at the enterprise.

To prepare participants for the group interview as well as possible, a letter briefing about the interviews will be delivered to the partici- 
pants. The letter will inform about the thematic agenda for the inspection visit and about the inspection process overall, among other things, what will happen to the information given to Arbejdstilsynet after the inspection visit.

\section{Interviews with individuals}

Interviews with individuals comprise a semi-structured interview between selected individuals and the inspectors. Arbejdstilsynet uses interviews with individuals when, for different reasons, group interviews cannot be used for collection of information about the psychosocial working environment.

The advantage of this method is that it is good for creating a sense of confidentiality between the inspector and the interviewee. This may e.g. be an advantage when identifying difficult and personal problems in connection with bullying, for example. The method has its limitations, however, because of its dependence on the relationship between the inspector and the interviewee.

Agreement to carry out systematic interviews with individuals may be made with the enterprise prior to and during the inspection visit. It is voluntary for the employees to participate in interviews.

As with group interviews, in individual interviews, the inspectors take as their point of departure the risk factors described in the question guide prepared for the sector or job group in the working environment directories for the sector, as well as the knowledge already provided to the inspector about the psychosocial working environment at the enterprise.

\section{Observation}

During an observation, the inspector examines the working environment at the enterprise systematically and in detail. When assessing the psychosocial working environment it can be of great significance that the inspectors themselves have been present to form an impression of work demands. This could be when assessing the extent of attentiveness and concentration required by employees when carrying out specific work. Arbejdstilsynet typically uses observation to add to the data collection in connection with group conversations.

The observations may provide specific examples of the psychosocial working environment in reality. For example, if the introductory meeting at the enterprise or the workplace assessment reveals that employees experience heavy time pressure and conflicting work demands, examples of these issues may be gathered during observations. 


\section{Observation could:}

- Provide information about form and tone of communication at the enterprise.

- Support other information about the psychosocial working environment, for example information collected at an introductory meeting with the health and safety organisation or from group interviews with the employees.

- Enable discovery of circumstances which have not surfaced in the other data collection.

Observation also has its limitations and therefore it is recommended to supplement this with other data collection methods. Arbejdstilsynet recommends that inspectors use observation in the following situations:

- When it is necessary to gain an overview of the flow of the work.

- When it is important to observe particularly stressful situations.

- When assessing different demands which the employees find difficult to describe.

- When the employees state that they experience many interruptions in their work.

- When employees state that there is heavy time pressure.

To ensure that enterprises accept the use of this method, Arbejdstilsynet makes arrangements with each enterprise in question as well as with the employees to be observed so to avoid unnecessary disturbance in the work.

It is important for Arbejdstilsynet that the employees who are subject to observation are informed about the observation to ensure that they are not uncomfortable with being observed. Therefore the enterprise is recommended to give its employees written and verbal notification.

Data from the observations is part of the overall assessment of the psychosocial working environment at the enterprise.

\section{Questionnaires}

The questionnaire method, as described in Arbejdstilsynet's guidelines on mapping the psychosocial working environment, is a quantitative method for mapping the psychosocial working environment.

One of the advantages of using a questionnaire is that it ensures that all known working environment problems are addressed.

One of the disadvantages is that an anonymous questionnaire cannot identify which employees have issues nor specify the nature of these 
issues. Questionnaires only provide the information given by those completing them. Moreover, as a minimum of 15-20 persons must complete questionnaires in order to maintain anonymity.

Questionnaires are suitable in situations such as:

- Uncertainty about data, e.g. the scope of the problem.

- In case of conflicting data, e.g. in cases concerning bullying.

Today Arbejdstilsynet does not use the questionnaire method much, as the logistics of collecting data can be relatively comprehensive and time-consuming.

\section{Other methods for collection of data on the psychosocial working environment at enterprises}

Arbejdstilsynet uses data from introductory and final meetings with management and the health and safety organisation. As early as during an introductory meeting, management and the health and safety organisation may provide information on the psychosocial working environment at the enterprise for use in overall data collection and which may constitute an element in the overall assessment of the psychosocial working environment at the enterprise.

Arbejdstilsynet may also use data from interviews with management separately, and may also discuss data acquired from their investigations at the enterprise. This data is presented to management in anonymised form. This discussion with management may include data on management's framework and terms.

Finally, Arbejdstilsynet may use data in the form of written documentation collected from management or the health and safety organisation. This could be workplace assessments, employee satisfaction surveys or similar surveys of the psychosocial working environment at the enterprise, as well as statistics about absenteeism due to sickness, statements of staff turnover, etc. The inspector may also review any written working environment policy and other written documentation demonstrating the working environment efforts by the enterprise. Furthermore, information may be collected on episodes of violence, other types of occupational accidents and near-miss accidents, as well as absenteeism due to sickness. 


\subsubsection{Assessment by Arbejdstilsynet of information on the psychosocial working environment}

When assessing the information collected during an inspection, the inspectors will assess whether the enterprise has taken the preventive steps necessary in relation to any problems the employees might encounter at the enterprise. As described above, an important part of Arbejdstilsynet's PWE inspection is the assessment made by inspectors regarding the specific working environment. When making this assessment, the inspectors should note the following three elements:

- The incidence of the risk factor.

- Preventive measures by the enterprise.

- Work-related consequences of the risk factor.

Arbejdstilsynet illustrates the inspectors' assessment in the figure below:

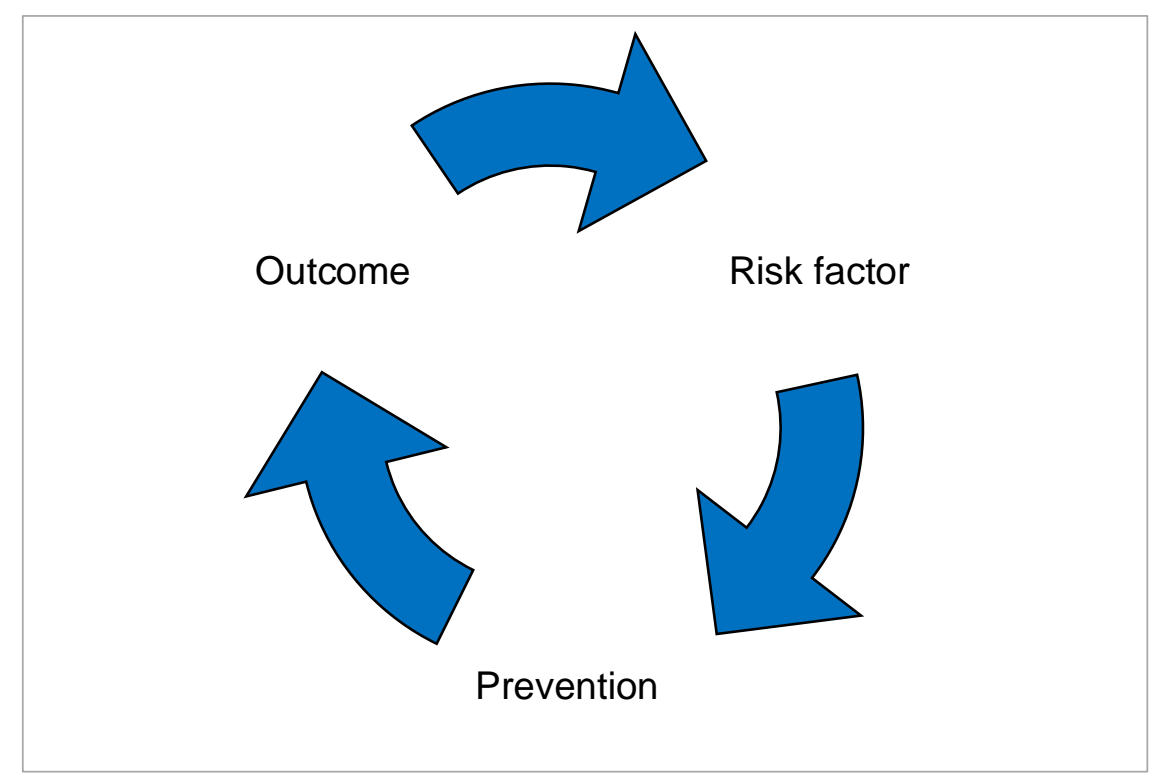

These three elements are part of the assessment of all types of psychosocial risk factors, but the assessment itself varies depending on the risk factors/problems in the psychosocial working environment which must be assessed. 
Depending on the enterprise or sector being inspected, Arbejdstilsynet focuses on the following risk factors in the psychosocial working environment in connection with the inspection:

- Heavy work load and time pressure.

- High emotional demands.

- Violence and threats of violence.

- Bullying.

- Planning of night work.

In addition to the risk factors above, Arbejdstilsynet can also set requirements for the enterprise on measures concerning psychological first aid.

In the following paragraphs, the principles for assessment of the psychosocial working environment are described in relation to the risk factors above. An example of how Arbejdstilsynet assesses the most important risk factors in the psychosocial working environment is the risk factor "Heavy work load and time pressure" which will be described first in detail. This description will then form the basis for reviewing Arbejdstilsynet's assessment of other important risk factors in the PWE inspection.

\section{Heavy work load and time pressure}

Heavy work load and time pressure is also called a quantitative demand of work. Quantitative demands are about the work load and pace of work, for example that:

- Work must be carried out at a high pace.

- Work must be carried out without breaks.

- There are many short deadlines.

- Overtime is necessary for the employees to do their job.

\section{Assessment of the safety and health risk of the risk factor:}

The work of the inspectors in cases pertaining to heavy work load and time pressure is to document that work has not been planned and executed appropriately in terms of safety and health.

When assessing whether there is a safety and health risk involved in heavy work load and time pressure, there must be data on the incidence of heavy work load and time pressure as well as on work-related consequences. 
Data on the incidence of heavy work load and time pressure is also about quantitative work demands:

- Work carried out at a high pace over a longer period.

- Work for many hours per week over a longer period.

- Work both at a high pace and for many hours per week over a longer period.

To substantiate documentation for an incidence of heavy work load and time pressure, data on the part of the work-related consequences relating to time is taken into account, e.g. whether there is a high pace of work throughout the day, whether it is impossible to take breaks/lunch is being skipped, whether there is much overtime which is impossible to counterbalance with time off, or whether holidays/days off are being cancelled.

It is necessary to examine both data on the incidence of heavy work load and time pressure and the work-related consequences relating to time. In both cases, this is the part of the data relating to time/quantity (the amount and pace of work).

The above can be supplemented by information about the nature of the demands on employees. This may e.g. be work requiring high concentration, a high degree of difficulty/complex tasks, large responsibility for other people or assets, or many interruptions in work.

To assess whether there is a safety and health risk involved in heavy work load and time pressure, there must also be data on work-related consequences.

Data on work-related consequences in this context involves the consequences which are not about time. This could be tasks required to be carried out but which the employees fail to carry out; that there are deadlines or statutory requirements not being met, etc. Focus is on documenting that the heavy work load and time pressure have serious and unacceptable work-related consequences.

Data on the quantitative work demands and the work-related consequences is decisive for documenting that heavy work load and time pressure are not being adequately prevented.

Data on prevention may not be necessary when assessing the basis for issuing an improvement notice. If there is documentation proving the incidence of heavy work load and time pressure, and if such documentation shows that this has serious and unacceptable work-related consequences, this will automatically mean that prevention is inadequate. 
Two overall elements constitute the core element in cases concerning heavy work load and time pressure; two elements which must always be documented before any improvement notice can be made:

- The inspectors must be able to document that the heavy work load and time pressure have occurred over a longer period and that consequently the employees have been unable to obtain sufficient physical and psychological restitution and rest. The specific definition of "a longer period" depends on how demanding the work is.

- The inspectors must also be able to document that the heavy work load and time pressure have an actual impact on the work of the individual and his or her possibilities of carrying out the work without becoming ill. It must be possible to link the data on heavy work load and time pressure to the work of the individual. This is done by using data from the relevant question guide on the incidence of the risk factor together with the work-related consequences. An example of the consequences of heavy work load and time pressure for the individual and his or her possibilities to carry out the work without becoming ill could be a bus driver who cannot meet his timetable and who is then unable to rest during his break.

When assessing the safety and health risks, inspectors must pay particular attention to the temporal extent of the work and the actual impact on the individual's work, and both elements must be described and substantiated in the improvement notice issued to the enterprise.

Arbejdstilsynet's assessment of whether the different risk factors pose a risk to the employees is generally made in the same way as described above. However, as described in the following, there is a difference in the emphasis on the three elements; incidence, prevention and consequences in relation to the different risk factors.

\section{High emotional demands}

High emotional demands are typically present in jobs where employees come into contact with clients and citizens (e.g. patients and students). For many job groups, contact and communication with citizens constitute a basic condition of the work which cannot be removed. If it is impossible to avoid high emotional demands, Arbejdstilsynet require enterprises to document that the risk of stress is being adequately prevented.

\section{Assessment of the safety or health risk of high emotional demands}

When assessing whether there is a safety or health risk resulting from high emotional demands in work, inspectors must consider whether the 
preventive measures by the enterprise match the emotional demands. This requires data on the incidence of high emotional demands and the prevention of high emotional demands.

Data on the incidence of high emotional demands is about the impacts on the employee from contact with citizens.

Data on prevention is about the measures which the enterprise takes to ensure that work is carried out appropriately in terms of safety and health. In relation to prevention of high emotional demands, data must be collected about: help and support from managers and colleagues, influence on planning, prioritisation and execution of work, as well as instruction, learning and education.

When assessing whether prevention of emotional demands is sufficient, a match between the emotional demands and prevention is important. A specific assessment must always be made of the preventive measures taken by the enterprise in relation to the emotional demands of the work.

Data on the work-related consequences is not necessary for the assessment of whether the emotional demands pose a safety or health risk for the employees. If there is documentation of high emotional demands in work and documentation showing that the risk is inadequately prevented, the assessment should not necessarily take into account whether there are e.g. complaints from clients/relatives or employee dissatisfaction at the workplace. The important element is that there is a safety and health risk not being adequately prevented.

\section{Violence and threats of violence}

Arbejdstilsynet divides the risk factor; violence and threatening behaviour into physical and psychological violence. Physical violence is bodily assault in the form of attacks, kicking, hitting, shoving, biting or spitting. Psychological violence is e.g. threats of violence directed towards employees, threats of vandalism against the workplace or property of the employees, or threats relating to e.g. the family of the employees. Threats may also be expressed without the use of words, e.g. with clenched fists, moving a finger to simulate cutting a throat, etc. Psychological violence may also be other offensive behaviour, e.g. humiliation, suspicion-casting, insulting or discriminatory statements. Psychological violence may also be exercised through electronic media such as texting, e-mails and websites. Finally, robbery is a particular type of violence where a person uses physical violence or threats of violence to obtain money or other valuables. 


\section{Assessment of the safety and health risk of violence and threats of violence}

When assessing whether there is a safety and health risk of violence and threats of violence, there must be data on the incidence of violence and threats of violence as well as on preventive measures taken by the enterprise.

Data on the incidence of violence and threats of violence is about the risk of violence and threatening behaviour at the workplace and the severity of the incidents that may occur. Data on the incidence is also about any actual incidents and their severity, frequency and scope.

Data on prevention by the enterprise is about the overall measures which the enterprise takes to ensure that work is carried out appropriately in terms of safety and health. This data is mainly about the steps taken by the enterprise to avoid or reduce the number and severity of episodes of violence, and about the steps taken by the enterprise to manage and follow up on actual episodes of violence to reduce the scope of the injury, i.e. management by the enterprise immediately after a specific incident.

Data on the incidence of violence and threats of violence and on the lack of enterprise prevention is thus decisive for documenting that the risk of violence and threatening behaviour is being inadequately prevented.

As the risk of violence and threatening behaviour is often a condition of work which cannot be removed entirely, prevention is in focus. As in the case of high emotional demands, it is decisive for the assessment of the safety and health risk whether there is a match between the nature and scope of violence on the one hand, and prevention by the enterprise on the other. The preventive measures matching a specific risk of violence and threats of violence will always be subject to a specific assessment.

\section{Bullying}

According to Arbejdstilsynet, the following three conditions define bullying:

- If one or more persons regularly and over a longer period, or repeatedly and seriously, expose one or more persons to offensive behaviour.

- If the person exposed regards this behaviour as offensive or degrading.

- If the person exposed is unable to defend him/herself effectively against this offensive behaviour, e.g. Due to an unequal power structure. 
Bullying may e.g. be:

- Hurtful comments.

- Slander.

- Unfair deprivation or reduction of responsibilities and tasks.

- Unfair belittlement or incapacitation e.g. On the grounds of age, gender, religion, nationality and sexuality.

- Hostility or silence in reply to questions or attempts at conversation.

If the acts of bullying have a sexual nature, the violations are sexual harassment.

\section{Assessment of the safety and health risk of bullying:}

When assessing whether bullying has occurred, there must be data on the incidence of bullying.

Data on the incidence of bullying is about describing the specific situations involving bullying, the nature of these situations, the occurrence and duration of these situations, the persons involved in the bullying, and whether the victims of bullying see these actions as hurtful or degrading and whether they are unable to defend themselves effectively.

Data on prevention and the work-related consequences is not decisive for this assessment, as the incidence of bullying in itself is a violation of the working environment legislation.

\section{Planning of night work}

EU defines night work as work carried out from 10 p.m. to 5 a.m. When assessing whether night shifts are planned adequately in terms of safety and health, the decisive element in the assessment is whether there are many consecutive night shifts. Following an assessment of existing research, Arbejdstilsynet has decided to define many consecutive night shifts as five night shifts or more.

\section{Assessment of the safety or health risk of night-work planning}

When assessing whether employees are exposed to a health risk as a consequence of many consecutive night shifts, the inspectors focus on the incidence and prevention of the risk factor. In addition to the incidence of five or more consecutive night shifts, focus is on the nature of the work itself, i.e. whether there is at least one other problematic aspect. Problematic work demands include: 
- Dangerous work/risk of accidents.

- Responsibility for assets or the life and mobility of other people.

- Large demands on concentration and attentiveness.

Data on prevention of health risks involved in many consecutive night shifts is about the enterprise's organisation of work. This could be:

- That no night shifts are longer than nine hours.

- That after night work, employees have a period off which is sufficient to catch up on sleep deprivation.

- That work is planned clockwise (i.e. Shifts move from day to evening to night).

- That there are no violations of the 11-hour rule (11 hours off between shifts).

- That employees know their work shift in good time (e.g. One month in advance).

- That the duration of shifts is adapted to work requirements.

Data on the work-related consequences is not necessary for the assessment of whether many night shifts are being sufficiently prevented.

\section{Psychological first aid}

Arbejdstilsynet's assessment of whether an enterprise is meeting the requirements laid down by the Working Environment Act in relation to the above risk factors is based on the principles in working environment legislation on prevention of employees' risk of exposure to safety and/or health problems. However, this is in contrast to when Arbejdstilsynet examines the measures taken by enterprises concerning psychological first aid in connection with traumatic events.

When employees are exposed to a particular risk of traumatic events, Arbejdstilsynet may set requirements for the enterprise on measures concerning psychological first aid.

Traumatic events are events where a person experiences or witnesses an event involving e.g.:

- Early death.

- Serious injury.

- Imminent risk of death.

- Serious threats to the physical or psychological safety and health of an individual or others. 
There are two situations in which Arbejdstilsynet may set requirements for the enterprise in the event of serious risk of traumatic events, i.e.:

- If there is a serious risk of traumatic events, and the enterprise has not taken the precautions necessary concerning psychological first aid.

- If there has been a specific traumatic event of such intensity that strong reactions may be expected, and the inspection takes place within 24 hours of the incident, or if employees at the time of the visit are severely affected by the incident (regardless of whether the inspection takes place later than 24 hours after the incident), and if the enterprise has failed to offer psychological first aid.

When assessing whether an enterprise has launched the precautions necessary concerning psychological first aid, Arbejdstilsynet may prioritise whether the enterprise has defined the psychological first aid, whether persons have been assigned to take charge of the first aid, whether such persons have received proper training, whether they have the competencies necessary, the equipment available, and whether the employees have been informed about the contents of the measures concerning psychological first aid.

The enterprise may make arrangements with external helpers who can take charge of the psychological first aid, if the enterprise is unable to ensure a sufficient number of internal staff to take charge of psychological first aid. The enterprise must, however, appoint persons to provide psychological first aid over the phone until the external helpers can take over. The external helpers must be qualified to give psychological first aid and they must reach the injured person quickly.

\section{Complex issues}

Psychological working environment problems cannot always be categorised under one single risk factor as in the examples above. Sometimes the psychosocial working environment is subject to even more complex issues involving several risk factors. These may be situations with high emotional demands as well as heavy work load and time pressure.

During inspections examining complex psychosocial working environment issues, the incidence of different risk factors is identified, as well as measures to mitigate these risks and any work-related consequences. Against this backdrop, the inspectors make an overall specific assessment of the psychosocial working environment. 


\section{Standardised tools for PWE inspections: guidance tools}

Arbejdstilsynet has developed a "tool" to support inspectors on their inspections of the psychosocial working environment. The tool is called a guidance tool and is directed towards specific sectors or job groups. Arbejdstilsynet has prepared a total of 24 guidance tools which in principle cover all types of enterprise in Denmark. The guidance tools are publicly available at the Arbejdstilsynet website.

A guidance tool is structured such as to enable coverage of the most important risk factors within a specific sector or job group. The guidance tools include a number of questions relating to each risk factor; questions which the inspectors can use in their identification of the various risk factors. The guide is not a checklist but rather an interview tool.

The questions relating to each risk factor follow the systematics described in the section on how to assess data from the inspection, i.e. there are questions about the incidence of the risk factor, prevention of the risk factor and work-related consequences.

There are no fixed procedures for how inspectors are to use the guidance tools. Inspectors are able to use the guide in connection with interviews with the health and safety organisation and in connection with individual or group interviews with the employees.

\subsection{Inspection methods in Finland}

Historically, there have been differences in the way different regions and inspectors have carried out inspections of the working environment in Finland. In order to make the inspections more uniform, national coordination groups have been established, of which one coordinates inspection of the psychosocial working environment and has prepared guidelines for this inspection.

PWE inspections are carried out according to the guidelines, i.e. written procedures which provide general instructions as well as more specific guidelines for inspections of specific working environment risks. Three of these guidelines relate to the psychosocial working environment; inspection of bullying, violence and threatening behaviour, as well as psychosocial strain.

In Finland, inspection is broken down into two groups: Authorityinitiated inspections planned by the authority itself and client-initiated inspections carried out at the request of a client. The authority applies the main part of its resources on authority-initiated inspections. Accord- 
ing to estimates by the national working environment authority, only 20 per cent of the resources are spent on client-initiated inspections.

The objective of authority-initiated inspections of the psychosocial working environment is to assess whether the workplace has a practice for preventing health and safety impacts at the workplace and whether this practice actually works. In its authority-initiated inspection of the psychosocial working environment, inspection is carried out of the enterprises' prevention of the three types of psychosocial working environment problems mentioned above.

In the authority-initiated inspection of psychosocial risks, the inspector assesses whether the workplace has working practices to eliminate or prevent the psychosocial risk factors which occur in the work. The inspector assesses whether the preventive steps taken by the workplace are adequate in relation to the risk factors. The inspector investigates whether the employer has identified and assessed the risk factors, and whether the employer has taken the steps necessary to eliminate or mitigate the harmful effects of the risk factors. The authority also assesses whether the occupational health care service at the enterprise, or other external experts have identified relevant psychosocial risk factors, whether the employer has acted on any problems identified, and whether the enterprise has followed the recommendations from the external working environment experts.

Authority-initiated inspections of violence and threatening behaviour are mainly carried out as inspections in specific sectors assessing the enterprise's safety conditions, risk assessments, instructions and training of employees, etc. The inspectors investigate specific incidents of violence which have led to serious injury, in the same way as other types of accidents would be investigated. At inspection visits to an enterprise at risk of violence and threatening behaviour, assessment will be made of the preventive measures taken by the enterprise, whether the employer is following up on episodes of violence, and whether the employer is carrying out inspections of the effects of the relevant measures. Finally, the inspector assesses whether prevention of violence is adequate in relation to the risk at the workplace.

During authority-initiated inspections of bullying the inspectors review and assess the enterprise's procedures for preventing and managing bullying. The inspection authority mainly considers the enterprise's own mapping and assessment of the risk of bullying. Among other things, the inspectors assess whether the enterprise's management is competent to identify and act on bullying. 
During the client-initiated inspections, the inspectors' point of departure is clients' specific reports regarding the working environment at an enterprise. Such reports could be about violations of working environment legislation, complaints about the working environment, or other reports regarding inspections, e.g. from an employee at an enterprise or from the health and safety organisation. Reports relating to the psychosocial working environment are received via telephone, e-mail or letter. The inspection authority is obligated to respond to all requests for inspection from clients and to inform the persons in question about further processing.

When the regional inspection authority in Finland receives a report about bullying, the inspector first assesses whether the working environment problem described constitutes bullying as defined in working environment legislation, and thus whether it qualifies as a working environment problem within the scope of the inspection authority. If so, an inspector will investigate the specific aspects of the report; the behaviour experienced as bullying, the persons involved in the bullying and the time of the alleged bullying. If a case of bullying is ascertained at the enterprise, the employer's management of the matter is investigated. If the employer does not have the required knowledge, the inspector will advise the employer on how to handle the matter.

During all client-initiated inspections, an important principle is the maintenance of the anonymity of the reporting party. The identity of the reporting party may be revealed if it is necessary for the inspection, however, only after consent from the person in question. If the inspection authority is to take up a case of bullying, the reporting party must always give consent to a lapse in the right to anonymity.

During inspection of a case of bullying, case processing comprises written correspondence/consultation with the person exposed to bullying, and with the employer. During this consultation, the inspection authority presents the information obtained in the case and requests that the employer explains his reactions after being informed that bullying has taken place at the enterprise. The purpose of this process is to determine whether the employer has met his or her statutory obligations, and particularly, whether the employer has initiated action to deal with the bullying. If not, the inspection authority may order the employer to meet his or her obligations in accordance with the requirements set by working environment legislation.

The regional working environment authorities also carry out inspections of reports from clients (e.g. employees) dealing with other matters than bullying. These cases concern the individual's own experience of 
psychosocial strain at work. Such reports are treated in the same way as cases about bullying in that the people in question sign a request for enforcement actions, etc. Such matters are often processed through a written procedure carried out by the working environment authority. The inspectors may, however, choose to carry out inspections by visiting the enterprise in question.

\subsubsection{Structuring the inspection process}

When the regional working environment authority inspects the psychosocial working environment, the inspectors will often follow an approach based on standardised inspection procedures.

Before the inspection at the enterprise itself, the inspector may review the documentation of the working environment. A review may be made of the occupational health care service's analysis of the working environment, the enterprise's risk assessment and safety and health programme. Before the inspection, a questionnaire known as the Valmeri questionnaire will be forwarded to the enterprise, and the health and safety representatives at the enterprises ensure that the employees complete the questionnaire.

During the inspection, the regional working environment authority will examine the enterprise's routines for safety management and risk assessment, its health and safety collaboration, and its use of the occupational health care service. Furthermore, the regional working environment authority will review the enterprise's programme for health and safety. Similarly there will be a review of the enterprise's procedures to prevent and manage violence and threatening behaviour, bullying and other forms of harmful psychosocial impacts. Employees' responses in the Valmeri questionnaire will be checked, and the inspectors may take a tour at the workplace to investigate the physical conditions and talk with the employees.

Following each inspection of an enterprise (either in the form of inspection visits or in the form of a written correspondence and consultation procedure), the inspector in charge will draw up an inspection report. This report is submitted to the employer, the health and safety representatives and other parties in the case, e.g. the person exposed to bullying. In the inspection report, the inspection authority may stipulate requirements for the employer in the form of improvement notices with time limit, etc., and summarise the results of the Valmeri questionnaire. The data collected by inspectors from the visit is entered into the working environment authority's inspection database. 
After having imposed an improvement notice on an employer, the regional working environment authority will check that the employer meets the requirements within the stipulated time limit. The regional working environment authority may decide to visit the enterprise, or request a written report about compliance with the requirement. If written advice is issued, the authority can choose to await compliance with the requirement until its next visit to the enterprise.

\subsubsection{Standardised tools for PWE inspections}

As an aid to help the inspector describe and assess prevention and management by the enterprise of the risk factors in the working environment, the working environment authorities have developed a number of different standardised description tools. The results of the tools may not be used directly for setting requirements for the enterprises. For PWE inspection activities, the Valmeri questionnaire is used, in which nine questions relate directly to the psychosocial working environment at enterprises. The Valmeri form is the only standardised tool used by the inspectors to analyse the psychosocial working environment. The questionnaire is usually completed by the employees prior to inspection visits. The replies may be calculated electronically and provide an index of the psychosocial working environment at the specific enterprise together with a comparison with national average replies in the relevant sector.

\subsection{Inspection methods in Iceland}

In recent years the psychosocial working environment has increasingly entered the agenda in Iceland and Vinnueftirlitid, the working environment authority in Iceland, is constantly seeking to develop procedures and methods to inspect the area. In Iceland, the same general principles apply for PWE inspection as for all other inspection in the working environment field.

The objective of authority-initiated inspection by Vinnueftirlitid of the psychosocial working environment is to assess whether the workplace has a practice for preventing health and safety impacts at the workplace and whether this practice actually works. In its authority-initiated inspection of the psychosocial working environment, Vinnueftirlitid inspects prevention by the enterprise of psychosocial risk factors, including stress, violence and threatening behaviour, as well as bullying. It is important that the assessment is based on facts, including information 
from management, employees, the health and safety organisation at the enterprise, and possibly from the occupational health service. Inspection places primary importance on the enterprise's systematic working environment efforts, including its risk assessment.

If Vinnueftirlitid is to take up a case of bullying, the reporting party must always waiver the right to anonymity. When Vinnueftirlitiđ investigates complaints of bullying, it focuses on the systematic working environment efforts at the enterprise. If the inspector deems that the enterprise does not have the competences required to manage working environment problems itself, there will be a requirement that the enterprise uses an external authorised health and safety consultant to have a risk assessment of the psychosocial working environment drawn up. Vinnueftirlitiđ requires that enterprises prepare a plan for preventing bullying and a plan for how to manage bullying, if this does occur. There may also be requirements that an existing plan be revised. The enterprise must inform its employees about these action plans. Vinnueftirlitiđ will follow up any improvement notices regarding bullying within three months.

\subsubsection{Structuring the inspection process}

When Vinnueftirlitiđ inspects the psychosocial working environment, the inspector will often follow an approach based on standardised inspection procedures.

Before the inspection at the enterprise itself, the inspector will review the documentation of the working environment. The inspector will look at descriptions of the working environment by the workplace, its risk assessment and its programme for occupational safety and health. Trials are being conducted in 2014 of using a short questionnaire which is sent or handed to the enterprise during or after the inspection visit.

Two-three hours are allocated for the inspection visit itself. In the inspection, the inspector will examine the enterprise's routines for safety management and risk assessment, and its health and safety collaboration. Furthermore, the inspector will review the enterprise's programme for health and safety. Similarly there will be a review of the enterprise's procedures to prevent and manage violence and threatening behaviour, bullying and other forms of harmful psychosocial impacts.

After having imposed requirements on an employer, Vinnueftirlitiđ must check that the employer meets these requirements within the stipulated time limit. If the enterprise does not report back, a reminder will be sent. With regard to bullying, Vinnueftirlitiđ will visit the enterprise after three months to follow up on the matter. 


\subsubsection{Standardised tools for inspection of the psychosocial working environment}

As an aid to help the inspector describe and assess prevention and management by the enterprise of the risk factors in the working environment, Vinnueftirlitiđ has developed a number of different standardised description tools. At the inspection visit, the inspector must use relevant sector-specific working environment directories. All the directories include a section on the psychosocial working environment describing the psychosocial risk factors relevant for the sector. Inspectors are expected to be able to discuss these factors with the enterprise during the visit. If, during this conversation, it transpires that the enterprise lacks a risk assessment of the psychosocial risk factors, Vinnueftirlitid will issue an improvement notice that these risk factors be incorporated in the enterprise's risk assessment.

The Icelandic working environment authority has drawn up a special working environment directory which deals with just the psychosocial working environment. This directory is designed to describe the psychosocial working environment in depth. The directory is used by the inspectors from Vinnueftirlitid and by the enterprises themselves. Vinnueftirlitid has recently developed a questionnaire for inspections of the psychosocial working environment, with thirteen questions directly aimed at the psychosocial working environment at enterprises. The questionnaire is usually completed by the employees prior to inspection visits. The replies provide inspectors with an index of the psychosocial working environment at the specific enterprise together with a comparison with average replies for the relevant sector as well as replies for the business community in general.

\subsection{Inspection methods in Norway}

In Norway, inspection of the psychosocial working environment covers two areas: inspection of organisational working conditions and inspection of the psychosocial working environment.

Arbeidstilsynet, the Norwegian working environment authority, checks for psychosocial risk factors such as violence and threatening behaviour, bullying and harassment. If the inspector has suspicions that the working environment at the enterprise does not meet statutory requirements, in the past an improvement notice has usually been issued that the enterprise itself is to describe and risk-assess the situation and, if necessary, implement initiatives to solve the working environment 
problem. However, in recent years Arbeidstilsynet has worked on developing inspection to include focus on the organisational working conditions. This has been done because the statutory requirements for the psychosocial working environment build on a precondition that work is organised, planned and managed with a view to preventing physical and psychological impacts. The aim is therefore to check whether the enterprises have developed organisational initiatives to prevent psychosocial problems as well as to check how, through their health, environmental and safety activities and routines, enterprises work together on this practice. In inspections initiated by Arbeidstilsynet, checks of psychosocial risk factors are limited to primarily establishing whether violence and threatening behaviour are a current risk factor in the working environment. There may also be inspection of whether the enterprise has systems and procedures to prevent and manage violence, threatening behaviour, bullying and harassment.

Inspection by Arbeidstilsynet of organisational working conditions is by inspectors checking enterprises' documentation of whether they comply with the formal requirements laid down by the Working Environment Act on organisation of the working environment and their working environment efforts. This may include whether an enterprise has a legal work contract and whether members of the health and safety organisation have completed the required skills development programme. Arbeidstilsynet also checks the health, environmental and safety activities and routines at enterprises. This includes whether an enterprise has appointed a health and safety representative, whether the enterprise is linked to an occupational health service, whether identification and risk assessment of all relevant aspects of the working environment has been carried out, and whether there are routines to prevent psychological strain, e.g. as a result of violence, threatening behaviour, emotional demands, conflicts and bullying.

Specifically, inspection regarding bullying and harassment etc. is primarily conducted as follow-up to reports by individuals. This means when one or more employees have contacted Arbeidstilsynet asking for help in a situation in which they feel they have been exposed to bullying. Arbeidstilsynet has drawn up a central procedure for following up reports by individuals, which describes how inspection should be planned, notified, conducted and followed up.

All reports by individuals are assessed on the basis of the information available on the specific case. On this basis Arbeidstilsynet decides how to proceed. Arbeidstilsynet may decide that the matter is to be concluded without intervention by Arbeidstilsynet. The employee will then receive 
guidance on how he or she can deal with the matter personally. Arbeidstilsynet can also decide to conduct an inspection at the workplace on the basis of the specific case. Finally, Arbeidstilsynet can conduct inspection at the workplace in order to check whether there is a general problem at the workplace which may involve more of the employees.

The objective of investigating reports by individuals is to determine whether statutory requirements are being complied with. It is not the job of Arbeidstilsynet to negotiate solutions and compromises between the parties involved. Any improvement notices are designed to have the employer initiate an improvement process. The improvement notice is not designed to push the enterprise towards a specific result in the process. For example, Arbeidstilsynet can order the parties involved to complete a conflict-management process. Arbeidstilsynet cannot order the parties to reach an agreement.

When inspection follows up reports by individuals, it may be relevant to order an enterprise to conduct an internal investigation in order to reveal whether there is an employee health risk related to specific aspects of the working environment. For example, an enterprise can be ordered to determine whether employees are exposed to unacceptable psychological strain as a result of a conflict at the workplace. This gives the enterprise a better basis to determine whether there has been a breach of the psychosocial working environment requirements in the Working Environment Act. Inspectors assess whether the enterprise is able to complete such an investigation, or whether it needs external assistance. The criteria in this assessment include the level of conflict at the enterprise, management's willingness to conduct an investigation, whether there are the required skills and resources at the enterprise, and whether the enterprise has access to external players who meet the objectivity and neutrality requirements.

The inspections conducted as part of a follow-up to a report by an individual will usually involve a review of relevant case documents as well as interviews with the relevant people at the enterprise who can help shed light on the case. Arbeidstilsynet will always interview the management and usually the health and safety representative. The interviews are based on a checklist which is adapted to the specific circumstances.

During inspection of the psychosocial working environment, inspectors from Arbeidstilsynet have access to a number of inspection methods. The framework for how to perform an inspection is primarily defined by the national guidelines for inspection linked to the various activities and focus areas, including inspection of the psychosocial working environment. However, as a rule, inspectors themselves decide which 
method is the most appropriate for the specific inspection. The methods available for inspectors when inspecting the psychosocial working environment are as follows:

\section{Planned and announced inspections}

By far the majority of inspections of the organisational and the psychosocial working environment are announced in advance. The inspectors themselves decide whether they will phone an enterprise to agree an appointment, or whether they will send written notification to the enterprise of an appointment decided in advance. The enterprise is usually notified of the inspection about two to four weeks before the visit itself.

The written notification of the visit describes when Arbeidstilsynet will visit, how long the visit is expected to last, the theme of the visit, how the visit will be conducted, who will be visiting from Arbeidstilsynet, who Arbeidstilsynet would like to meet, and how the enterprise is to prepare for the visit. The notification can describe the documentation the enterprise is to prepare and possibly submit to Arbeidstilsynet prior to the visit.

\section{Unannounced inspection}

Arbeidstilsynet rarely makes unannounced inspections when it is to inspect the psychosocial working environment. Unannounced inspections are often used to inspect organisational working conditions and health, environmental and safety activities and routines at enterprises in which employees do not have a permanent work site. This includes the building and construction sector and the transport sector, for which there are checks on enterprises' work contracts and whether the health and safety organisation meets statutory requirements.

The following methods can be applied within each of these approaches:

\section{Observation}

Arbeidstilsynet utilises observation when it conducts a general tour of an enterprise and when inspecting specific and predefined conditions during an inspection visit. As a method, observation is utilised relatively little when inspecting the organisational working environment and the psychosocial working environment. However, a tour of the enterprise is often carried out as part of the inspection in combination with various types of interviews.

Observation can give an impression of the organisation of the workplace, how the enterprise manages restructuring, as well as of the organisation of work with regard to varied work, management, pace of work, 
as well as employees' opportunities for social contact and influence on their own work. The method also makes it possible to see who is working at the workplace with regard to age groups, as well as ethnic and gender representation.

Observation is a useful method to supplement and verify information on the working environment which has been obtained through other means such as interviews and reviews of written documentation. Separate tools have not been developed for inspectors to use in structuring and quality-assurance of their observations of the working environment.

\section{Interviews}

When inspectors in Norway inspect the organisational and psychosocial working environment, they most often utilise some type of interview. For example, inspectors utilise interviews to obtain information about the organisation of the enterprise, the number of employees and their functions, the health, environmental and safety activities and routines at the enterprise, and possibly the consequences of problems in the working environment. Inspectors also use interviews to obtain information about what employees themselves think about the working environment, including their impressions about how working environment efforts work in practice.

When inspecting the organisational and psychosocial working environment, Arbeidstilsynet most often utilises a partly structured interview in which the themes the inspector is to ask about are set in advance, while the actual sequence of the themes is set during the course of the inspection. This means that the interviewer can follow the interviewee's "narrative" at the same time as obtaining information about the themes which it has been decided in advance must be covered. This method enables the interviewee to take up themes along the way which the inspector had not otherwise thought about in advance. Checklists have been drawn up for all national inspection activities. These lists have been especially adapted to the inspection method and the themes covered by the inspection activities. Arbeidstilsynet also utilises less structured, briefing interviews, e.g. in preliminary dialogue about an inspection visit, and it also uses more structured interviews when reviewing a checklist with questions and checkpoints in a structured sequence.

Interviews can be with individuals or with groups. Depending on the type of interviews, the inspector usually chooses between two types of inspection: "inspeksjon I" or "inspeksjon II". In inspeksjon I, which lasts for up to two hours and can be announced or unannounced, interviews are usually with the employer and the health and safety organisation 
simultaneously. If it is an unannounced inspection, the inspection is completed with the daily manager or the employees available if the daily manager is not available. In inspeksjon II, which can last for up to an full working day and which is usually an announced inspection, several different types of interview can be used, including group interviews or interviews with individuals at the enterprise. For example, a joint interview with the employer and the health and safety representative may be made, followed by a separate group interview with selected employees.

\section{Interviews with individuals}

Arbeidstilsynet can decide to conduct interviews with individuals if:

- Arbeidstilsynet wants to form an initial overview of the working environment at the enterprise and its working environment efforts.

- A small enterprise is not able to release more than one person at a time.

- Arbeidstilsynet deems it necessary to interview people individually in order to access important information, e.g. if there is a high level of conflict at the enterprise.

- Arbeidstilsynet wants to clarify the degree of consensus at the enterprise on a given matter, e.g., by interviewing the parties in a case separately.

\section{Group interviews}

Interviews with individuals can show that there are different perceptions of the same matter at the same enterprise. This is particularly relevant with regard to the psychosocial working environment. Individual interviews are demanding on time and resources if there are a lot of people at an enterprise. In order to ensure that enterprises are able to allocate more interviewees for the inspection by Arbeidstilsynet, and to create a space in which interviewees can share and discuss different perceptions of the working environment, the use of group interviews is becoming increasingly more common when performing inspections of the psychosocial working environment.

The group interview is a method in which one or more inspectors gather several representatives from the enterprise. These include managers, health and safety representatives, shop stewards or a crosssection of employees. The interview is facilitated by an inspector who encourages the interviewees to account for or discuss one or several themes related to the working environment or working environment efforts at the enterprise. Arbeidstilsynet uses group interviews to: 
- Make the working environment and working environment efforts a common issue rather than something for individuals; to raise the perspective of the working environment from the individual to group level or to system level.

- Collect information from several people at the enterprise than is possible with individual interviews.

- Demonstrate the breadth of descriptions and assessments and to form an impression of whether there is overall agreement or disagreement and, if so, what any disagreement is about.

Furthermore, the group interview can establish a common platform for further work on working environment improvements at the enterprise; it can demonstrate that data collection by Arbeidstilsynet builds on openness and it can ensure that different groups of employees are heard in relation to the themes being taken up.

For both individual interviews and group interviews, it is important to clarify the criteria to be applied in selecting interviewees and whether the enterprise or Arbeidstilsynet is to make the selection. An interview group will often be composed such that management and employees are interviewed separately. Arbeidstilsynet considers language, cultural differences and type of employment when deciding on the composition of a group. The number of interviewees taking part depends on the themes and objectives of the interview. Usually five to six people take part. One and a half hours is usually allocated for the interview, but the duration depends on the number of participants as well as the purpose and structure of the interview. The number of different topics to be taken up is assessed in relation to the timeframe, structure and purpose of the interview.

Group interviews are time-demanding for both Arbeidstilsynet and the enterprise and they require a lot of preparation and planning. Therefore it is important to give good notice of inspection visits. As group interviews place great demands on inspectors, it is normal to have two inspectors present at these interviews. 


\section{Document review as a method of inspection}

A review of an enterprise's written documentation is often completed prior to an inspection visit at which interviews are held. The method is known as the two-stage method and it follows a Swedish model. Document review is used to obtain information about:

- Organisational and psychosocial working conditions.

- Health, environmental and safety activities and routines and the health and safety organisation.

- Composition of the personnel group.

- Employees' descriptions and assessments of workplace safety and health in connection with mapping the working environment.

- Health records and welfare records (e.g. Absenteeism due to sickness records) if this information is available in writing.

Written documentation at an enterprise can include organisation diagrams and other descriptions of working terms and conditions at the enterprise, e.g. agreements on working hours, pay schemes and work processes. There will also be descriptions of working environment efforts by the enterprise, both as descriptions of specific working environment efforts and descriptions of the enterprise's working environment management systems. The document review is an important tool with regard to checking whether an enterprise has met requirements related to specific conditions which the enterprise has a duty to document.

The document review can provide an impression of an enterprise's routines and systems, but it does not necessarily say anything about how they function in practice. Therefore, Arbeidstilsynet focuses on verifying the information to ascertain what activities actually are being carried out in practice. An enterprise's working environment documentation is included in all phases of the inspection, from planning to performance of the inspection, to writing the inspection report.

\subsubsection{Structuring the inspection process}

A typical inspection of the organisational and psychosocial working environment in Norway will usually have the following structure:

1. Before the inspection the inspector selects the inspection method on the basis of central guidelines. The choice of inspection method by the inspector determines the amount of time to be earmarked for the 
inspection visit, whether documentation is to be obtained from the enterprise in advance, and whether two inspectors are required.

2. The inspection is announced to the enterprise prior to the visit. The announcement states the time and date of the visit as well as the expected duration. If Arbeidstilsynet requires written documentation in advance of the visit, this request will also be in the announcement.

3. When the inspector arrives at the enterprise, the visit usually starts with a meeting with the daily management of the enterprise and the health and safety representative. The enterprise's occupational health service may also take part in the meeting.

4. The relevant checklist and check points are reviewed at the meeting. The inspector reviews the written documentation of the enterprise and has a dialogue with the enterprise about matters arising.

5. The inspection can be concluded after this meeting, possibly with a tour of the enterprise.

6. If the inspection also includes a separate meeting with employees, it is usual to do this as a group interview in extension of the interview with management and the health and safety representative. There will usually be two inspectors at the group interview, of whom one usually facilitates the interview while the other takes notes. An interview guide is used in the group interview which is usually different from the guide used in the interview with the management/health and safety representative.

7. After the group interview, a concluding meeting is held with the management/health and safety representative. A brief summary of the inspection is usually presented at this meeting as well as the inspector's general impressions of the enterprise.

8. The inspection report is sent to the enterprise by no later than four weeks after the inspection. The inspection report summarises the inspection and describes any breaches or infringements. If breaches are ascertained, notice of an improvement notice will be sent.

9. The enterprise will usually receive the improvement notices for consultation for three weeks. If Arbeidstilsynet has not received a consultation reply from the enterprise within this period, the improvement notice will enter into force and the enterprise will receive a final improvement notice.

10.Arbeidstilsynet will stipulate time limits in the final improvement notice for when the improvement notices are to be complied with. Compliance is checked by Arbeidstilsynet and Arbeidstilsynet is entitled to impose fines if it is deemed that the improvement notices have not complied with within the time limit. 


\subsubsection{Standardised tools for PWE inspections}

Arbeidstilsynet has drawn up a total of 60 checklists which in different ways have been adapted to inspection activities. All the checklists have two parts: The first part is the same for all the checklists and comprises questions about the enterprise's organisation, composition of the employee group and terms of employment, the enterprise's health and safety organisation and its links to the occupational health service. The second part of the checklists aims at the different organisational conditions and varying working environment conditions characteristic of the different sectors, as well as the themes relevant for the specific inspection activity. The themes are included in the checklists in different ways and include the enterprise's health, environmental and safety activities and routines, prevention and follow-up of absenteeism due to sickness, prevention and management of conflicts, bullying, violence and threatening behaviour, as well as discrimination and how the enterprise adapts work in relation to the abilities of the individual employee.

\section{Preferred methods for PWE inspections}

Most inspectors in Norway who inspect the psychosocial working environment will probably say that they prefer the group interview method as the best foundation for assessing the psychosocial working environment at an enterprise. However, the group interview is a relatively demanding method in terms of time and resources and it is used much less than interviews with just management and the health and safety representative.

\subsection{Inspection methods in Sweden}

In Sweden, Arbetsmiljöverket follows the overall inspection principles described in the rule book "Rutiner för inspektion". This describes the formalities to be followed by inspectors during their inspections. The most widespread method of inspection is the "ordinary inspection", in which the inspector uses checklists as a tool to map (and assess) the psychosocial working environment. This is because the majority of the inspections are conducted as inspection campaigns aimed at specific sectors or job groups for which an important precondition is that all the enterprises selected for inspection are treated the same. In addition to managing the methods and approach linked to the concepts for inspection campaigns, in consultation with their immediate manager inspectors decide which inspection methods are to be used in the inspection. 
In general more time-demanding inspection methods are not selected and instead an approach is used in which the inspectors utilise individual elements or tools picked out from the methods which experience tells them have been especially effective in inspection of the psychosocial working environment.

After an inspection has been concluded, the inspector prepares an inspection protocol (IP) which describes inadequacies in the working environment and with which employers can decide for themselves on the initiatives to be implemented to rectify the inadequacies. These protocols are written on site or forwarded after the inspection. If it is deemed necessary, the inspector can also write an inspection notification (IM) which states specific requirements for the initiatives to be implemented by the enterprise in order to meet the working environment legislation.

\section{Ordinary inspections}

Ordinary inspections are announced inspection visits. In ordinary inspections Arbetsmiljöverket's inspectors usually begin a visit by talking to the management and the health and safety organisation. The basis for the meeting is the enterprise's systematic working environment efforts and the enterprise's documentation of risk assessments, action plans and follow-up of prevention initiatives previously implemented. After the preliminary meeting there is a tour of the enterprise and conversations with the employees. The visit ends with an additional conversation with the management and health and safety organisation in which the inspectors ask more detailed questions and present their assessment of safety and health at the enterprise.

\section{The focus method}

The focus method is based on an briefing inspection visit with a meeting with representatives from the senior management and health and safety organisation at the enterprise selected for inspection. With this basis, the subsequent inspection visit is planned and a questionnaire is prepared with about 15 questions adapted to the specific conditions at the enterprise. The questionnaire is distributed to a representative cross section of the employees at the enterprise, who, in groups of sixeight take part in focus group interviews held by the inspector from Arbetsmiljöverket. During a break in the interviews the preliminary results are compiled and presented for the group. After this the interviews continue in order to clarify uncertainties and any working environment problems suspected by the inspector. Each interview is concluded with the inspector summarising what the employees said and extracting the issues to be addressed with management. Participants 
have to approve what is taken further to management. At a subsequent visit the results of the group interview are presented for the employer and the health and safety organisation. The inspector asks questions and explains what he intends to write in the inspection report sent to the enterprise after the visit.

\section{The psychosocial pulse of the workplace}

The psychosocial pulse of the workplace is a screening instrument with a checklist to provide an overview of what is working well and what is working less well in the working environment at an enterprise. The checklist is distributed as a questionnaire to six to ten employees. The results of the checklist are collated in a bar chart and presented for the group who completed the form as the basis for more detailed questions and talks. Next the inspectors meet with representatives from the employer and the health and safety organisation and they use the material collected as the basis for further inspection and dialogue about the working environment with the employer.

\section{Two-step method (Tvåstegsmetoden)}

The inspection process is introduced with a preliminary meeting or telephone conversation in which the employer is informed about the inspection. After this an inspection notification is sent which states when the Arbetsmiljöverket is to visit and provides summary information about psychosocial risk factors, systematic working environment efforts, as well as questions the employer is to answer before the inspection visit. The employer is obliged to involve the health and safety organisation and the employees affected in responding to the questions set by Arbetsmiljöverket. By no later than one week before the inspection visit, the enterprise must send the replies to Arbetsmiljöverket, who will then draw up an agenda for the inspection. The agenda is adapted to the local conditions at the enterprise reported by the employer.

Representatives of the employer, the health and safety organisation and preferable many employee representatives take part in the inspection. The two-step method involves the employer and the employee in joint mapping and management of the working environment at the workplace, and it often turns out when Arbetsmiljöverket visits that the enterprise is already well into the process of working environment efforts for the areas identified as problematic by the mapping. If necessary, the inspector can carry out a follow-up visit at a later date. 


\section{Observation}

Inspectors from Arbetsmiljöverket can decide to apply the observation method when interviews and talks are not in themselves adequate to assess the psychosocial working environment. The method involves two inspectors observing typical work situations over a predetermined period. During the observations, focus will be on the parts of the employees' work situation which can best be assessed by observation. These include cognitive, emotional and perceptual requirements at work, employees' influence on organisation of their own work, level of information, employees' contact with customers and clients, design of the workplace, etc.

During the observation, the inspectors record detailed descriptions of what they observe. After the observation this information is recorded on a standard observation form.

After an observation, the inspector interviews selected groups of personnel in order to elaborate themes that have become apparent under the observation and they conclude the inspection visit with a meeting with the management of the enterprise at which they present the full results of the entire inspection.

The observation method focuses attention on the work being performed rather than the people actually doing the work. The inspectors also note factors which seem to compensate for the negative working environment factors ascertained. On the basis of the material collected, the inspectors balance the psychological strains they have noted against these compensating factors. After this the working environment problems Arbetsmiljöverket has ascertained are documented and requirements are placed on the enterprise to implement initiatives to manage these problems.

\section{Screening}

This method involves Arbetsmiljöverket inspecting all the enterprises in a given sector. When information announces a visit, the enterprise is referred to an information page on Arbetsmiljöverket's website in order to enable the employer and the health and safety organisation to prepare for the screening visit. The inspectors make screening visits alone. The psychosocial matters they can inspect at a screening include the systematic working environment efforts by the enterprise as well as organisational, social and psychosocial issues.

At a screening, inspectors examine how the enterprise works with the working environment and what the working environment is actually like at the enterprise. During the screening visit, the enterprise's practical work on the working environment is a pivotal element in the dialogue between the inspector and the enterprise. Screening of the work- 
ing environment by the inspector can either result in no requirements being placed on the enterprise or in one or more requirements that the employer must either map-out the working environment or implement initiatives to manage specific working environment issues. If requirements are placed on the employer during a screening visit, this is because the inspector deems that a working environment problem has been adequately identified so that more detailed inspection of the area is not necessary.

If requirements are placed on the employer during the screening visit, Arbetsmiljöverket will make a follow-up visit about three months after the screening visit. The inspectors can then assess whether a more thorough inspection of the enterprise is required. In a more thorough inspection, on a new visit Arbetsmiljöverket will examine the working environment areas it was not possible to examine adequately initially. A more thorough inspection can be completed by inspectors with special competences, e.g. within the psychosocial area, if this is deemed necessary. The screening method was most recently used in 2013 and it is unclear whether this type of inspection will be carried out again.

\subsubsection{Structuring the inspection process}

\section{Planning and organisation of inspection visits}

When Arbetsmiljöverket is to visit an enterprise to inspect the psychosocial working environment, the visit is always announced in advance. Notification can either be by Arbetsmiljöverket writing to the enterprise in advance stating the Arbetsmiljöverket will be visiting on a specific date, or by Arbetsmiljöverket telephoning the enterprise and agreeing an appointment and venue for a future visit. Announcing the visit in advance, enables the employer, health and safety representatives and other employees to earmark time for the visit. Experience shows that this ensures that the inspectors meet the relevant people and that inspectors show respect for their time and enable them to plan.

\section{Collection of information and data}

Information about the psychosocial working environment is collected through a review of documents at the workplace and through conversations with health and safety representatives and employees. Group interviews are used in some inspection methods.

All written material taken from an enterprise by the working environment authority is referenced, so that material is only taken which is 
absolutely necessary. Most of the information is provided verbally and written down by the inspectors.

When Arbetsmiljöverket receives a report from a health and safety representative of an infringement of the Working Environment Act, a meeting is agreed with the relevant employer at which the situation is examined. When employees themselves submit complaints about the working environment, they are referred to their health and safety representative and advised to allow the matter to be processed through this channel. If the report describes a serious working environment problem and there is no health and safety organisation at the enterprise, Arbetsmiljöverket will become involved in the matter directly and conduct an inspection visit at the enterprise without divulging the reason for the visit. Such an inspection visit will often include the psychosocial working environment at the enterprise taking its systematic working environment efforts as the point of departure.

\section{Assessment of information on the psychosocial working environment}

If Arbetsmiljöverket deems that the working environment at an enterprise fails to meet the statutory requirements, Arbetsmiljöverket will require the employer to rectify the problem. However, Arbetsmiljöverket focuses on underpinning the requirement from several data sources, as it can be difficult to identify the cause and scope of the problem. As Arbetsmiljöverket does not get involved in cases which only affect individuals, Arbetsmiljöverket also focuses on ascertaining the number of people at the enterprise who are affected by a given working environment problem. If, during the inspection, a suspicion arises the Arbetsmiljöverket has not received full and correct information about the working environment, Arbetsmiljöverket will conduct a more thorough inspection in order to identify where the problem originates. Arbetsmiljöverket's assessment is based on an overall perspective which includes several different elements in the working environment. For example, this can be illustrated by the inspection campaign in 2013 known as HAK (Hållbar Arbetsmiljö med Kvinnor i fokus - sustainable working environment with women in focus) in which the working environment was assessed using a checklist aimed at 1) identifying the conditions that must be present for the working environment to be assessed as inadequate, 2) identifying the consequences of the inadequacies ascertained for employees' working environment, and 3) assessing the severity of the inadequacies and proposing whether or not initiatives should be implemented to rectify the inadequacies. 


\subsubsection{Standardised tools for PWE inspections}

Arbetsmiljöverket has developed a number of different tools for use in inspections of the psychosocial working environment.

Arbetsmiljöverket uses sector-specific checklists in all national inspection projects in which it is important that all enterprises taking part in the project are asked the same questions. Checklists are also used by inspectors as memory aids in standard inspections.

In connection with the "psychosocial pulse of the workplace" inspection method, Arbetsmiljöverket uses a questionnaire with 45 questions which is distributed to groups of six to ten people. The questionnaire is divided into five themes under the headings: organisation, personnel policy, working environment efforts, risk factors and safeguarding against stress. The responses are summarised in a bar chart which is presented to the participants.

When Arbetsmiljöverket conducts inspections based on the focus method, a questionnaire with 15 questions is handed out to employee groups of six to eight people. The responses are used to establish the agenda for a subsequent group interview.

When Arbetsmiljöverket conducts inspections of enterprises' systematic working environment efforts with regard to the psychosocial working environment, the instructions form the point of departure.

When Arbetsmiljöverket is on a screening visit, inspectors use a standard checklist, which are reviewed during the visit. On the basis of the replies, the inspectors make an overall assessment of whether Arbetsmiljöverket is to require the enterprise to complete further mapping of the working environment, or whether other requirements are necessary. In inspections of the psychosocial working environment, inspectors mostly use checklists from the socalled SAM instructions and from instructions on inspections for violence and threatening behaviour, solitary work, crisis and crisis help, home care at private homes and harassing behaviour.

Arbetsmiljöverket has developed guidelines on the psychosocial working environment. These provide information about risk factors in the psychosocial working environment, consequences of a poor psychosocial working environment for individuals and the organisation, as well as information on the initiatives that can be implemented to prevent and manage a poor psychosocial working environment. 


\subsubsection{Preferred tools for PWE inspections}

In connection with the 2012 SLIC campaign, Arbetsmiljöverket completed around 300 inspection visits to workplaces in the social and health services. The evaluation of the campaign points to group interviews as participants' preferred method of identifying problems when inspecting the psychosocial working environment. As this method demands a lot of time, it is prioritised for large workplaces and for workplaces where there is already a suspicion that there are psychosocial working environment issues. The group interview is deemed to be especially suitable as it facilitates the best description of the psychosocial working environment and therefore it is the best foundation for placing clear demands on the employer. The inspectors believe that the best results come from using the instructions on the enterprise's systematic working environment efforts for all requirements placed on enterprises. Arbetsmiljöverket also has good experience from adapting sector-specific checklists so that they can ask the same questions to all enterprises under inspection, for example within a given sector. 


\section{Impact of PWE inspections}

In this project we have been curious about the impact of PWE inspections in the different countries. What impact does the working environment authorities want, what impact do PWE inspections have, and how do we measure this impact?

To begin with, the working group had two working questions regarding the impact of PWE inspections:

1. What is the impact of the different types of reaction?

2. How do we evaluate the impact of PWE inspections?

With the first question, we wanted to elucidate what happens at enterprises and with the psychosocial working environment in relation to the type of reaction from the working environment authority in each country. This issue will be elucidated as far as possible. With the second question, we wanted to elucidate whether and how to measure the impact of PWE inspections.

But why is it even necessary to ask these questions? When an authority makes an improvement notice about an individual person or an enterprise, the person or the enterprise is expected to comply with this improvement notice. Legislation must be complied with, and if this is not the case, there will be penalties. Obviously, this is also how things work in relation to the working environment legislation in the Nordic countries. So, when the national working environment authorities in Denmark, Finland, Iceland, Norway and Sweden issue an improvement notice, they expect the enterprises to comply with this notice, and experience shows that this is most often the case.

When a national working environment authority issues a notice to an enterprise that dangerous machinery is not allowed to be used before appropriate shielding has been fitted, the solution for the enterprise is both simple and lasting. All the enterprise needs to do is to make sure that the shielding is fitted. The problem is then solved and the notice has been complied with. This is not always the case with problems relating to the psychosocial working environment. These problems often entail complex issues which are not easily resolved. If prisons are experiencing psychosocial working environment issues, e.g. a risk of violence against 
employees, it will be possible to reduce the rate of violence, however it will be difficult to eliminate the risk entirely. A problem with machinery can be resolved once and for all, however the psychosocial working environment is a dynamic factor and will change in the shorter or longer term. Continuous focus on the psychosocial working environment is therefore important for enterprises, and the working environment authorities also have to relate to this reality.

Therefore, it is relevant to analyse the impact of PWE inspections on the psychosocial working environment at enterprises, and how the working environment authorities in the individual countries check this impact.

\subsection{How to measure the impact of PWE inspections}

In order to specify what we mean by impact of PWE inspections, we below refer to a memo prepared in Denmark in 2002 in connection with implementation of an impact evaluation project. A working group was set up composed of national and international experts with experience in various aspects of impact evaluations. Collaboratively with managers and employees at the Danish working environment authority, Arbejdstilsynet, the working group was tasked to design the future evaluation policy of Arbejdstilsynet with regard to working environment inspection in general.

Among other things, the working group deliberated on what can actually be measured, and came up with recommendations on how to evaluate the impact of working environment inspections in the future. The working group developed an "impact ladder", which is a sort of ranking system for what can be measured/impact-evaluated.

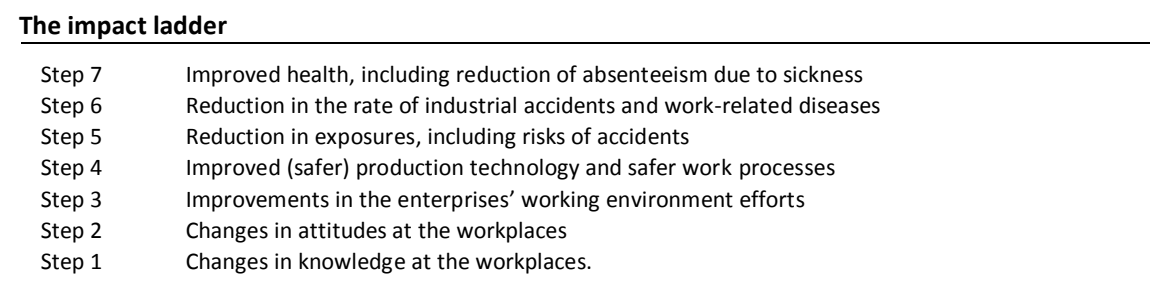

The working group recommended Arbejdstilsynet to concentrate its impact measurements on steps 1-5. Measuring the impact on steps 6 and 7 is not impossible, but will be associated with great uncertainty, as the cause-and-effect relationships at these steps are very complex. The impact of Arbejdstilsynet's inspections cannot be isolated on steps 6 and 7. There- 
fore, the working group indicated that "it is necessary to use methods which have the specific activities and measures of Arbejdstilsynet as their point of origin".

In addition, the working group recommended that future impact targets be set on the basis of expected cause-and-effect relationships in individual activities (a programme theory or change theory), so that these activities can be made the subject of evaluation.

Looking across the various initiatives for measuring impact taken by the Nordic working environment authorities, we can see that these are targeted at different steps of the impact ladder. In the review of the individual countries' initiatives for measuring impact, the initiatives will be placed on the impact ladder in order to provide a picture of the impact each country is aiming at.

\subsection{Primary trends}

Common for Denmark and Finland is that, politically, these two countries have set up national reduction targets for the psychosocial working environment up to 2020.

Denmark is focusing on national reduction targets for the psychosocial working environment, to which all working environment stakeholders and enterprises are to contribute. Denmark wants PWE inspections to contribute to the overall target (a 20 per cent reduction in the number of employees suffering psychological overload in Denmark) stated in the country's political strategy for the working environment up to 2020 . However, the strategy does not include specific targets for the extent to which the Danish working environment authority, Arbejdstilsynet, must contribute to the overall reduction target of 20 per cent. In its strategy, Arbejdstilsynet has stipulated reduction targets for stress and violence in selected sectors and job groups.

The underlying assumption is that, by complying with the improvement notices from Arbejdstilsynet, enterprises are helping improve their psychosocial working environment. Over time, Arbejdstilsynet's PWE inspections will contribute to achieving the reduction targets. However, the impact should not only come from PWE inspections. It is also assumed that regulation (legislation) and communication with/to enterprises play an important role and contribute to the overall achievement of the impact. 
Like Denmark, Finland has drawn up an overall political, strategic reduction target for the psychosocial working environment aimed at all labour market stakeholders.

The overall target in the policy is that life-long working career will be increased by three years by 2020. In order to achieve this, Finland has set a reduction target for self-assessed psychosocial impacts of 20 per cent for the psychosocial working environment up to 2020. This reduction target has been described at different levels of the impact ladder.

The target to increase life-long working career can be placed at step 7 of the impact ladder, as increasing life-long working hours entails a general improvement in employee health. On the other hand, the reduction target for self-assessed psychosocial impacts is on step 5 of the impact ladder, as the target is worded as a reduction of the impact.

Although there are no initiatives to measure impact in Iceland, this is implicitly implied in the inspection. The assumption is that increased focus on bullying in the inspection will encourage more enterprises to address this issue.

Norway is focusing on measuring the impact of inspections on enterprises' health, environmental and safety activities and routines. These measurements are carried out regularly, and in 2011 there was special focus on the psychosocial working environment, and the result of the measurements showed a positive impact. It is assumed that, if enterprises have effective health, environmental and safety activities, they will deal with any psychosocial working environment issues so that problems with the psychosocial working environment either do not arise or they are dealt with appropriately.

Sweden is focusing on creating a positive change by re-visiting the enterprises which have working environment issues. Moreover, the country is focusing on the inspection methods used by the inspectors. The assumption is that repeated inspections at the same enterprise will encourage the enterprise to work on improving the psychosocial working environment.

Looking across the Nordic countries at how they want to create, measure or observe the impacts of PWE inspections, methods have been developed to measure or observe such impacts in relation to the following areas:

- Impact on the specific working environment through repeated visits (all countries).

- Impact on enterprises' working environment efforts with regard to the psychosocial working environment (Norway). 
- Impact on the specific working environment and safety management, and impact of inspection methods (Finland, methods not available because impact evaluation in Finland is carried out by an external enterprise).

- Impact on the specific working environment as expressed in the national working environment measurements (Denmark and Finland). (However, the method of measurement used in Denmark cannot isolate the impact of Arbejdstilsynet's inspection, instead it measures the development in the working environment at national level. The same applies for Finland).

\subsection{Description of initiatives by the Nordic countries to measure impact}

The following section describes in detail each country's initiatives to measure impact, and describes both small and large activities in connection with making or measuring impact.

\subsubsection{Description of initiatives in Denmark}

In Denmark the Danish working environment authority, Arbejdstilsynet, is aiming at contributing to the overall political 2020 target to reduce the number of employees most exposed to psychological impacts (suffering from psychological overload) from the psychosocial working environment. Moreover, Arbejdstilsynet is participating in a pilot project on "impact-based management". This means that the organisation must steer towards the impact goal formulated in Arbejdstilsynet's own strategy.

\section{Performance target in the political strategy up to 2020}

As a result of the political agreement on a strategy for working environment action up to 2020, Arbejdstilsynet is to contribute to reducing the number of people mostly exposed to psychological impacts (psychological overload) from the psychosocial working environment by 20 per cent up to 2020.

The concept "psychological overload" is defined on the basis of a national questionnaire survey about the working environment and health conducted by the Danish National Research Centre for the Working Environment. A reference survey was conducted in 2012, and the survey will be followed up every other year up to 2020 . The concept of "psychological overload" is defined as psychological strain resulting in acute or 
long-term negative reactions such as stress or signs of depression. Employees mostly exposed (psychological overload) are defined on the basis of one or more of the three sub-components:

- A broad measure for psychological strain.

- A measure for bullying and harassment combined with signs of depression.

- A measure for violence and threatening behaviour combined with signs of depression.

The concept has been divided into three components because violence/threatening behaviour and bullying are present at relatively few enterprises, so if these components were to be included in an overall concept, they would be underestimated greatly in the model. As violence/threatening behaviour and bullying on their own are important risk factors to be reduced, separate targets have been set for these.

The broad measure for psychological strain is composed of 11 questions about the psychosocial working environment, which together are aligned with an outcome measurement on stress (a variation of the Perceived Stress Scale). The 11 questions cover a wide range of factors in the psychosocial working environment, e.g. quantitative requirements, qualitative requirements, influence on own work, cooperation, and support from the management.

At the baseline measurement in 2012, the survey showed that a total of 14.7 per cent were psychologically overloaded. With a reduction of 20 per cent up to 2020 , this figure must be reduced to 11.76 per cent. The extent to which Arbejdstilsynet is to contribute to this reduction of 20 per cent has not been specified. The reduction measure for the psychosocial working environment relates to step 7 of the impact ladder. The reduction target is not only a target for Arbejdstilsynet, but a target for all working environment stakeholders on the Danish labour market.

\section{Arbejdstilsynet's strategy with performance measures for 2013-2016}

The Danish working environment authority, Arbejdstilsynet, has formulated a strategy with performance targets for, among other things, PWE inspections. In its strategy, Arbejdstilsynet wants to reduce the number of people experiencing stress or who are exposed to violence in connection with their job. This is to be done by focusing on inspections in sectors traditionally challenged in the psychosocial working environment. These include the following sectors and job groups: residential institutions and home care, daycare centres, hospitals, courts, prisons and lower secondary schools. 
The performance target for stress is measured through questions in the regular national survey of working environment and health, whereas the performance target for violence is measured using a calculation of the number of reported incidents of physical abuse. Both measurements are associated with relatively large statistical uncertainty.

The fact that the reduction is to take place through inspections conducted by Arbejdstilsynet is a result of the change theory that forms the basis for the strategy: "There is documentation that, when Arbejdstilsynet reacts with an improvement notice during an inspection, the enterprise then resolves the issue identified, and the risk factor in question is eliminated/reduced..."

The performance targets regarding the psychosocial working environment in Arbejdstilsynet's strategy are stated in table 7 below:

Table 7. Performance targets

\begin{tabular}{|c|c|c|c|c|c|}
\hline $\begin{array}{l}\text { Performance requirements - Psychological working envi- } \\
\text { ronment }\end{array}$ & 2012 & 2013 & 2014 & 2015 & 2016 \\
\hline $\begin{array}{l}\text { There must be a reduction in the number of people experi- } \\
\text { encing stress compared to } 2012 \text { within the sectors: residen- } \\
\text { tial institutions and home care, daycare centres, hospitals, } \\
\text { courts, prisons and lower secondary schools. }\end{array}$ & $\begin{array}{l}\text { Base- } \\
\text { line }\end{array}$ & - & $2 \%$ & - & $6 \%$ \\
\hline $\begin{array}{l}\text { There must be a reduction in the number of reported acci- } \\
\text { dents at work in relation to the number of people employed } \\
\text { compared to } 2012 \text { within the sectors: residential institutions } \\
\text { and home care, daycare centres, hospitals, courts, prisons } \\
\text { and lower secondary schools. Measured in relation to } \\
\text { accidents in previous years. }\end{array}$ & - & $1 \%$ & $2 \%$ & $4 \%$ & - \\
\hline
\end{tabular}

Step 5 of the impact ladder describes the reduction targets as a reduction in problems experienced as stress due to work as well as a reduction in the number of reported incidents of physical abuse.

\section{Communication and dialogue with enterprises}

Impact is not only through inspections and improvement notices. Therefore, a change theory has been established for regulation and communication, respectively.

As part of the political priority of working environment actions up to 2020, Arbejdstilsynet wants to increase dialogue with enterprises: "Dialogue must take place during an inspection visit as well as whenever this is relevant. During an inspection visit, the Arbejdstilsynet will focus on entering into a dialogue based on the enterprises' own experience with health and safety issues with a view to supporting preventive work relating to the working environment and to resolving specific working environment issues". 
Dialogue is to strengthen enterprises' motivation to prevent and resolve working environment issues themselves. Dialogue is not only to take place during inspections, but all communication and dialogue with enterprises is to be strengthened through digital self-service solutions, written electronic material on Arbejdstilsynet's website, and guidance from Arbejdstilsynet's Call Centre on, for example, the psychosocial working environment.

Arbejdstilsynet's dialogue with enterprises must, depending on the situation, have an impact on steps 1-5 on the impact ladder. Therefore, Arbejdstilsynet wants to:

- Step 1)

Increase enterprises' knowledge about the psychosocial working environment.

- Step 2)

Influence the attitudes of enterprises with regard to preventing psychosocial working environment issues.

- Step 3)

Influence enterprises' management of working environment efforts.

- Steps 4 and 5)

Encourage the enterprises to better planning and organisation of work in order to reduce psychosocial problems.

\section{Working environment actions by enterprises}

In addition to the surveys of the working environment and health at individual employee level, the National Research Centre for the Working Environment is conducting a questionnaire survey on working environment actions by enterprises (VAI-questionnaire) every second year in the period 2012-2020. In 2012, about 4,900 employer or employee representatives from around 3,600 enterprises answered the questionnaire. The questionnaire, which is generally answered by a person at management level in the enterprise, includes questions about attitudes and preventive activities in connection with working environment efforts regarding the psychosocial working environment.

The impact, which can be measured through the VAI-measurements, concentrates on steps 2-4 on the impact ladder. This means that this survey focuses on enterprises' prevention attitudes, working environment efforts and production processes.

\section{Does Arbejdstilsynet see the real working environment issue?}

In 2010, the Confederation of Danish Trade Unions (LO) published a report on Arbejdstilsynet "Har Arbejdstilsynet et godt øje til arbejds- 
miljøet?". The report was published in cooperation with the Centre for Working Environment and Working Life at Roskilde University. The report includes an analysis and assessment of PWE inspections and possible effects of these. The results from the study are relatively uncertain due to the limited data in the study.

The results show that Arbejdstilsynet is quite good at identifying the "real" issues at enterprises. This means that enterprises can recognise the issues pointed out by Arbejdstilsynet, however there is room for improvement in this area. Moreover, there is a clear impact on enterprises' specific psychosocial working environment after Arbejdstilsynet has made a reaction compared to enterprises which have not had a reaction. It is assessed that the greatest improvement potential is at the enterprises which have had an improvement notice or other reaction from the authority.

Even though the study was not carried out at the initiative of Arbejdstilsynet, and as such does not constitute part of activities by Arbejdstilsynet in connection with measuring impacts, reference is still made to this study here because it can explain something about how to evaluate the impact of PWE inspections, and because, despite uncertainties, it can describe the impact of these inspections.

The Confederation of Danish Trade Unions' report focuses on step 3 of the impact ladder, i.e. whether the inspection has an impact on enterprises' working environment efforts, and step 5, i.e. whether inspections have an (positive) impact on psychosocial problems.

\section{Expected impact through repeated visits to the same enterprise}

If, in connection with an inspection, Arbejdstilsynet ascertains a serious or less serious violation of the working environment legislation in relation to the psychosocial working environment, the enterprise will either be given an improvement notice or written guidelines regarding the violation. This means that the enterprise will be re-visited and undergo a new inspection within two years. Thus the enterprise will have an incentive to work on ensuring a safe and healthy psychosocial working environment for its employees. The aim is that this will create a positive impact with regard to the psychosocial working environment at the enterprise.

The purpose of repeated visits to the same enterprise at which Arbejdstilsynet has identified psychosocial working environment issues is to make an impact on steps 1-5 of the impact ladder. No specific measurements are made of this, but it is possible for Arbejdstilsynet/inspectors to observe the impact or the change from one visit to another. 


\section{Impact of the combination of inspection and support in separate inspection campaigns}

Arbejdstilsynet knows from experience that inspections of the working environment as well as supporting enterprises by means of oral and written guidance/dialogue has an impact from PWE inspections. Therefore, Arbejdstilsynet mainly focuses on a combination of inspection and support for enterprises when carrying out inspection activity in connection with enterprises' psychosocial working environment.

Inspections and support represent a combination of Arbejdstilsynet's focus areas in its strategy, i.e. inspection, regulation and communication. The purpose of this combination is to make an impact on steps 1-5 of the impact ladder, but also on steps 6 and 7, as the activities of Arbejdstilsynet are linked to the overall political reduction targets.

\subsubsection{Description of initiatives in Finland}

As described above, Finland has prepared a policy that focuses on and describes reduction targets for the psychosocial working environment up to 2020. The section below describes Finland's other activities to create and measure impacts.

\section{Impact of PWE inspections}

Finland wants to make an impact by using the right methods to find different working environment issues. Furthermore, the country wants to make an impact by selecting the most relevant enterprises for inspection. In order to select the most relevant enterprises, a national and regional analysis of trends in working life and the working environment has been conducted. The analysis is based on various data and includes information about the following:

- In what sectors the number of workplaces is increasing.

- What sectors/job groups are exposed to risks in the physical and psychosocial working environment.

- What job groups have absenteeism due to sickness because of working environment issues.

- Early retirement due to industrial injuries, poor health etc.

Each inspection region conducts a similar local analysis, as there are regional differences. On the basis of these analyses, inspections are aimed at the selected exposed sectors and job groups for the next four years. The inspection plan is updated annually. 
Moreover, the purpose is to create a greater impact by conducting more inspections without reducing quality. In 2012, Finland therefore increased the number of inspections, whereas the time spent on inspections was similar to 2011.

Another way of creating an impact from inspections is to improve the quality of inspections. This is done through peer assessments. A group of representatives from different regions in the working environment authorities spends a week examining each regional working environment authority to assess inspections by taking part in inspections and by assessing the inspection documents.

A third way of working with impacts is by standardising PWE inspections. Therefore, three inspection guidelines have been developed on violence and threatening behaviour, bullying and harassment as well as psychosocial problems.

By improving the quality of PWE inspections, Finland is aiming to make an impact on steps 1-5 of the impact ladder, i.e. positive changes in enterprises' knowledge about and attitudes towards prevention in the psychosocial working environment, improving enterprises' working environment efforts, and work processes to reduce psychosocial strain in the working environment.

\section{Information for enterprises}

In order to support inspections, focus is on creating an impact through information for enterprises. Within the period of the framework agreement (2012-2015), Finland is therefore exploiting opportunities with stakeholders to disseminate working environment information and to better utilise such information.

The purpose of more efficient dissemination of working environment information is primarily to make an impact on step 1 of the impact ladder, i.e. increase the knowledge of enterprises.

\section{Targeted impact study}

An extensive impact study has been initiated. The study is from 20122015. An external consultancy firm is to analyse the impact of inspections in the municipal sector, including PWE inspections. A final report is expected at the end of 2015.

The impact study focuses on the inspection's impact on:

- Enterprises' safety management.

- Changes in working environment at workplace level. 
In addition to information about changes in working environment at workplace level, the purpose of the study is to provide information on how inspection methods work as well as information about good practice at workplaces.

The assumption behind the evaluation project is that inspection of, for example, the psychosocial working environment is to:

- Motivate the management of the enterprise.

- Create a positive change in the working environment of the enterprise.

- Provide information for the inspection authority about good practice when dealing with the psychosocial working environment at enterprises.

\subsubsection{Description of initiatives in Iceland}

Iceland does not conduct impact measurements of PWE inspections. At the initiative of both employer organisations and employee organisations, the public sector in Iceland has carried out questionnaire surveys focusing on the psychosocial working environment and bullying. These surveys may have contributed to the increased number of reports about bullying to the Icelandic working environment authority, Vinnueftirlitiđ. In the long term, this increased focus on bullying is likely to help improve the psychosocial working environment.

\subsubsection{Description of initiatives in Norway}

Norway regularly prepares impact evaluations. These impact evaluations concentrate on the strategic area of initiative for the Norwegian working environment authority, Arbeidstilsynet; i.e. the health, environmental and safety activities of enterprises.

\section{Impact on the health, environmental and safety activities at enterprises}

This method compares enterprises which have undergone inspection with enterprises which have not. The method includes four steps:

- An index with eight check points that constitute a reasonable interpretation of Arbeidstilsynet's objective for a strategic area of initiative. The check points make up the checklist in a new impact inspection in two groups of enterprises. 
- A sample of enterprises which has recently undergone an inspection by Arbeidstilsynet are randomly selected.

- A sample of enterprises which has never undergone inspection by Arbeidstilsynet and which are comparable with the enterprises under bullit No. 2 .

- Both groups then undergo inspection by Arbeidstilsynet, and through statistical analyses, significant differences will show the probability of an impact from Arbeidstilsynet's inspection.

The analyses prepared according to the concept above show that enterprises which have undergone inspection are more likely to have documented, preventive, systematic health, environmental and safety activities than enterprises which have not undergone inspection.

As these are randomly selected enterprises, a statistical test can show how representative these enterprises are in relation to the total population of enterprises. This is done to test/examine whether the differences found can be generalised to the entire enterprise population and thereby provide a general picture of the impact of inspections.

In 2011, the strategic impact of inspections was assessed in relation to "prevention of (inappropriate) psychological strain". With 95 per cent certainty, the assessment showed that, on average, enterprises which have undergone inspection are more likely to be able to document their systematic health, environmental and safety activities than enterprises which have not. The study also showed that enterprises which had undergone inspection differed with regard to more general variables (e.g. identification and assessment of psychosocial risk factors). On the more specific parameters (such as routines for dealing with negative deviations in the psychosocial working environment), enterprises which had undergone inspection scored higher than enterprises which had not. However, the difference was not statistically significant.

Focusing on enterprises' health, environmental and safety activities/working environment efforts, Norway wants to create and measure impact on step 3 of the impact ladder, i.e. improve enterprises' management of working environment efforts.

\section{Expected impact through repeated visits to the same enterprise}

Another approach to assess the impact of inspections is when Arbeidstilsynet carries out follow-up inspections at enterprises which have undergone inspection 1-2 years earlier, and which, in this connection, were issued with an improvement notice on their health, environmental and safety activities. In Norway, it is not common practice to carry out 
follow-up inspection; it is done now and again and in some inspection campaigns. Experience from the follow-up inspections shows that enterprises subjected to such inspection actually are improving their working environment efforts.

The focus for the impact is enterprises' health, environmental and safety activities, i.e. the purpose is to make an impact on step 3 of the impact ladder.

\section{Annual user survey}

Each year a user survey is carried out to map Arbeidstilsynet's communication with enterprises. In 2012, a total of 3,000 enterprises received a questionnaire. Twenty-five per cent of the employers answered the questionnaire, whereas only 15 per cent of the health and safety representatives took part in the annual survey. Due to the low response rate, the results of the survey should be interpreted with great caution. The study shows that enterprises find that Arbeidstilsynet's inspections have had a positive impact on their working environment.

The purpose of the user survey is to measure the impact of Arbeidstilsynet's inspections on step 5 of the impact ladder, i.e. in this context "a positive impact on their working environment" should be interpreted as fewer problems in the psychosocial working environment.

\subsubsection{Description of initiatives in Sweden}

Sweden regularly carries out impact studies of inspections of the working environment at enterprises. However, these studies are not carried out systematically.

\section{Impact study of inspections}

An external consultancy firm contacts randomly selected employers' representatives and employees' representatives at enterprises which have undergone inspection. The respondents are asked about the impact of inspections of their working environment.

This type of impact study is aimed at steps 4 and 5 of the impact ladder, in which "the impact of inspections of enterprises' working environment" is interpreted as an impact on work and production processes as well as work-related stress.

\section{Expected impact through repeated visits to the same enterprise}

The Swedish working environment authority, Arbetsmiljöverket, wants to observe the impact of inspections by re-visiting enterprises at which the authority has identified a problem in the psychosocial working envi- 
ronment. Re-visits can be repeated several times. On the basis of the requirements imposed by Arbetsmiljöverket on enterprises, Arbetsmiljöverket can assess whether the psychosocial working environment has improved from inspection to inspection. Furthermore, the inspection methods can be adjusted along the way, depending on how large an impact they are assessed to have in each specific case.

Focus of the impact is on the psychosocial working environment of enterprises, i.e. the purpose is to create an impact on step 5 of the impact ladder; a reduction in psychosocial problems.

\section{The impact of inspection methods}

The Swedish working environment authority regularly assesses the impact of different methods to describe the psychosocial working environment through inspections. Inspectors know from experience that methods such as group interviews with employees as well as individual questionnaires for employees provide the best picture of the psychosocial working environment of enterprises.

Quarterly follow-ups are carried out on all national projects, in which the inspectors answer a questionnaire about the functionality in the inspection methods chosen.

Focus of the impact of inspection methods is on steps 4 and 5 of the impact ladder. This means that the purpose of inspection/describing the psychosocial working environment of enterprises is to influence the enterprises' work/production processes in order to reduce problems in the psychosocial working environment.

\subsection{Summary}

The analysis shows that measurements of the impact of PWE inspections are not conducted systematically in any of the Nordic countries. However, as stated, each country has launched different initiatives to address the impact of inspections in general on the working environment, including the psychosocial working environment.

The analysis also shows different trends with regard to the focus of individual countries when they study the impact of PWE inspections.

Common for all these countries is their use of repeated visits to enterprises which either have specific psychosocial working environment issues or which have not included the psychosocial working environment in their working environment efforts. These enterprises are monitored over time in order to motivate them to prioritise their working environment efforts in relation to the psychosocial working environ- 
ment. This is to create a positive impact on the psychosocial working environment at enterprises. It is important to stress that it is action by enterprises that is to make the impact on the psychosocial working environment.

A pervading characteristic of all five Nordic countries is that it is not only through their inspection work that working environment authorities are striving to ensure an impact. Carrying out inspections is obviously one of the primary tasks of the working environment authorities, however dialogue with enterprises and guidance on the psychosocial working environment are also important for ensuring the desired impact. Dialogue, communication and information with and to enterprises are important elements in working environment authorities' endeavors to create an impact from inspections in general, including in relation to the psychosocial working environment. This is done in connection with inspections, but also through other media such as websites and written guidelines for enterprises. The assumption is that all elements, checks, dialogue etc. have a value in overall endeavors to motivate enterprises to create a safe and healthy psychosocial working environment. 


\section{Conclusion}

Based on the project application, we have conducted an analysis of PWE inspection carried out by the Nordic countries. The analysis is based on three general topics in inspection by the Nordic countries:

- Reaction options (improvement notices, guidelines, etc.) Provided for by working environment legislation in the individual nordic countries.

- Methods for mapping the psychosocial working environment and how these relate to working environment legislation.

- As far as possible, how reaction options (improvement notices, guidelines, etc.) Have a positive effect on the psychosocial working environment at enterprises.

The analysis of these topics can be found in the three chapters in this report about PWE regulations, methods for inspection of the psychosocial working environment and impact of PWE inspections. In order to put the analysis of these topics into a meaningful context, the analysis is supplemented by a description of other aspects in the inspection: clarification of concepts, national strategies for inspections and inspection activity. The analysis is a descriptive analysis, i.e. a statement of the conditions that exist in the individual countries, and a comparison of the differences and similarities that appear.

In connection with conducting the analysis, the project group became aware of conditions that are not included in the descriptive analysis. Based on the three topics above, the following highlights the aspects of the analysis in which we can see an interesting perspective, an interesting point, or a development potential for the Nordic working environment authorities.

\section{Regulatory foundation - legislation on psychosocial working environment}

As stated in the review in chapter 2 Comparison of PWE regulations in the Nordic countries, the level of detail in the regulations of the five countries differs. The scope of specific regulations on the topic ranges from Denmark, which has fewest specific regulations on the psychosocial working environment, to Finland, Norway and Sweden, which each have 
specific regulations in relation to different factors in the psychosocial working environment (risk of violence and bullying).

The most striking element of the review and comparison of the individual countries' legal basis is that most countries lack regulations that specifically require management of key risk factors such as heavy work load, time pressure and high emotional demands, despite the fact that these risk factors are essential for the working environment and in the authorities' inspection practice.

So why has the psychosocial area not been regulated in more detail? The working group believes that the reason for this is that the psychosocial working environment as an inspection object is still a relatively new area. Therefore, the working group sees a challenge for the Nordic working environment authorities in regulating further the psychosocial working environment area, as there seems to be a development potential in this area. Since the psychosocial working environment is a complex area, it is particularly challenging to examine whether this area can be further regulated in a meaningful manner through specific regulations. Effective regulation could provide a better basis for enterprises to know what is expected of them (what is legal, and what is illegal) within the psychosocial area.

\section{Methods for PWE inspections}

A key element in the review has been to describe differences and similarities in the methods used by the Nordic countries for identification and assessment in their PWE inspections. It is important to note that the study of the best suited method, and of strengths and weaknesses in different inspection activities as well as of methods to identify problems in the psychosocial working environment was originally based on the premise that all the five Nordic countries have the same understanding of the psychosocial working environment.

During the analysis, this premise has proven incorrect. As appears in chapter 1 Clarification of the concept of PWE, theoretical background and inspection practice, the perception of the psychosocial working environment concept varies from country to country with regard to 1) the different risk factors included in the concept, 2) the risk factors covered by PWE inspections, and 3) in relation to whether PWE inspections cover inspection of enterprises' systematic working environment efforts, the specific psychosocial working environment or both. Thus the purpose of inspections varies in terms of which aspects of the psychosocial working environment and the organisational working conditions are to undergo inspection. Denmark, Norway and Sweden, which carry out inspection in order to assess whether employees are exposed to a risk of 
falling ill from specific conditions in the psychosocial working environment, all state that structured interviews with the employees, such as individual interviews or group interviews, are the preferred method to identify the working environment issues at enterprises.

The strength of the interview method is that it enables inspectors to collect the most thorough and accurate descriptions of the work carried out by employees, of their resources to comply with the requirements in their work and thereby of the psychosocial working environment. This is perceived as a valid method, as it enables inspectors to collect relevant information which they can use in their assessment of the working environment. As the interviews are carried out on the basis of standardised guidance tools or checklists, the inspectors can, in principle, collect the same information and carry out the same assessment across enterprises and sectors.

The weakness of the interview method is primarily that it requires a great deal of resources to conduct, both with regard to content and time. The interview method is difficult, because it requires the inspectors to master the method if it is to be used effectively. If interviews are to be conducted in large enterprises, it will often be necessary to carry out relatively many interviews in order to collect information from a representative cross section of the employees, and this will be timeconsuming for inspectors as well as enterprises.

Common for all the countries carrying out inspections of enterprises' specific psychosocial working environment is that this includes relatively complex issues, and that PWE inspections in general are time-consuming compared to inspections of other areas of the working environment. The time spent on an inspection basically depends on the type of task. If complex issues regarding, for example, emotional demands at work, or work load or time pressure are to be identified in order to assess whether these demands pose a risk to employee health, the identification must be such that it is possible to make an assessment of the health risk. This requires extensive information about how work is planned, and how work is carried out at the enterprise in question. Furthermore, it requires information about what preventive steps the enterprise has taken in relation to these risk factors in order to make such an assessment.

Time is generally an important factor for all the Nordic working environment authorities. It is important to be as efficient as possible. Therefore, there is a development potential with regard to developing inspection methods in the psychosocial working environment; methods which can show the same results as the more time-consuming methods, how- 
ever in a shorter time. Yet the time factor can also be viewed from another angle. A good dialogue with enterprises is important to motivate them to work effectively on the psychosocial working environment. If a good and constructive dialogue with enterprises can help prevent future working environment issues, the time invested in this dialogue will be time saved at a later stage. PWE inspections (and working environment inspection in general) are therefore not only a question of the amount of time used on the inspection, but are just as much a question of how this time is used.

\section{Impact of PWE inspections}

The last point in the project description is about the impact that PWE inspections have on the working environment at enterprises. How is the impact of PWE inspections compared across the five Nordic countries, and is it possible to say which country has the most effective inspection?

As shown in the analysis, there are relatively large differences in how much priority PWE inspections are given in each country, how inspection is carried out, what is targeted in the inspection and what requirements the working environment authorities impose on the enterprises. In addition to these differences between the countries, there is another important aspect of PWE inspections when comparing the impact of these inspections: How do enterprises in each country comply with the requirements imposed by the local working environment authorities? We do not know whether there are differences in the "compliance culture" in the Nordic countries (i.e. whether there is a difference in how strong requirements have to be before the enterprises comply with them). This may differ from country to country. Moreover, there may be internal sectorial or regional differences in each country as well as in how individual enterprises react.

It is relevant to consider whether it is enough to set requirements for the specific working environment, or whether requirements for enterprises' systematic working environment efforts are an important precondition for getting enterprises to improve their psychosocial working environment. On the other hand, it is relevant to ask whether it is enough to impose requirements for enterprises' systematic working environment efforts regarding the psychosocial working environment in order to improve or legalise the working environment, or whether requirements should be imposed for improving the specific psychosocial working environment.

Finally, there is the question of whether it is necessary for an inspection authority to react towards an enterprise in order for the enterprise to comply with requirements regarding the psychosocial working envi- 
ronment. Previous impact studies from Denmark and Norway show that it is possible to make a positive impact on the psychosocial working environment at enterprises in the two countries, even though the national working environment authorities use different inspection methods. On this basis, the working group behind this analysis does not believe that it is possible to assess which type of reaction is the most effective, or which Nordic country is making the most impact on enterprises through PWE inspections. 



\section{References}

\section{Chapter 1}

Arbejdstilsynet (Danish Working Environment Authority, 2006). Stress. Copenhagen: Arbejdstilsynet.

Cullberg, J. (1975). Kris och utveckling. Natur och Kultur, Stockholm.

Demerouti, E., Bakker, A.R., Nachreiner, F. \& Schaufeli, W.B. (2001). The Jobs Demands-Resources Model of Burnout. J Applied.Psych. Vol. 86, pp 499-512.

Karasek, R.A. (1979). Job demands, job decision latitude, and mental strain: Implications for job redesign. Admin Sci Quart. Vol. 24, pp 285-308.

Karasek, R.A. \& Theorell, T. (1990). Healthy work. New York. Basic Books.

Karasek, R.A. \& Theorell, T. (1990). Healthy work: stress, productivity, and the reconstruction of working life. New York, NY: Basic Books, pp 89-103.

Siegrist, J., Peter, R., Junge, A., Cremer, P. \& Seidel, D. (1990). Low status control, high effort at work and ischemic heart disease: Prospective evidence from blue-collar men. Soc Sci Med. Vol. 31, pp 1127-34.

Thorsrud, E. \& Emery, F. (1969). Mot en ny bedriftsorganisasjon. Oslo: Johan Grundt Tanum forlag.

\section{Chapter 2}

\section{Denmark}

The Danish Working Environment Act - Act no. 1072 of 7th September 2010 with later amendments, as of June 2014 from http://arbejdstilsynet.dk/da/ regler/love/sam-1072-arbejdsmiljoloven.aspx

Executive Order on the Use of Technical Equipment. Arbejdstilsynet's (Danish Working Environment Authority's) Executive Order no. 1109 of 15th December 1992 with later amendments, as of June 2014 from http://arbejdstilsynet.dk/da/ regler/bekendtgorelser/a/sam-anv-af-tekniske-hjaelpemidler-1109.aspx

Executive Order on the Performance of Work. Arbejdstilsynet's Executive Order no. 559 of 17 th June 2004 with later amendments, as of June 2014 from http://arbejdstilsynet.dk/da/regler/bekendtgorelser/a/sam-arbejdets-udforelse559.aspx

Executive Order on limiting inspection by Arbejdstilsynet of enterprises' compliance with certain working environment regulations. Arbejdstilsynet's Executive Order no. 1156 of 25th November 2004 with later amendments, as of June 2014 from http://arbejdstilsynet.dk/da/regler/bekendtgorelser/b/sam-begraensning-af-atstilsyn-1156.aspx 
Executive Order on the use of authorised health and safety consultants (consultancy notice). Arbejdstilsynet's Executive Order no. 259 of 20th Marts 2007 with later amendments, as of June 2014 from http://arbejdstilsynet.dk/da/regler/ bekendtgorelser/b/sam-brug-af-aut-arbejdsmiljoradgivere-25.aspx

Executive Order on the Conditions at Permanent Place of Work. Arbejdsministeriet's (Danish Ministry of Labour's) Executive Order no. 96 of 13th February 2001 with later amendments, as of June 2014 from http://arbejdstilsynet.dk/da/regler/ bekendtgorelser/f/sam-faste-arbejdssteders-indretning-96-.aspx

Executive Order on Cooperation on Safety and Health. Arbejdstilsynet's Executive Order no. 1181 of 15th October 2010 with later amendments, as of June 2014 from http://arbejdstilsynet.dk/da/regler/bekendtgorelser/s/samarbejde-omsikkerhed-og-sundhed-1181.aspx

Metodeudvalg - Psykosociale risikofaktorer i arbejdslivet (Methods Committee - psychosocial risk factors in working life). April 1995. Published by Arbejdsministeriet (Danish Ministry of Labour), May 1995. Printed by: Schultz Grafisk, Copenhagen.

\section{Finland}

Arbetarskyddslagen (738/2002), as of June 2014 from http://www.finlex.fi/sv/laki/ajantasa/2002/20020738

Arbetsavtalslagen (55/2001), as of June 2014 from http://www.finlex.fi/sv/laki/ajantasa/2001/20010055

Arbetstidslagen (605/1996), as of June 2014 from http://www.finlex.fi/sv/laki/ajantasa/1996/19960605

Lagen om företagshälsovård (1383/2001), as of June 2014 from http://www.finlex.fi/sv/laki/ajantasa/2001/20011383

Lagen om likabehandling (21/2004), as of June 2014 from http://www.finlex.fi/sv/laki/ajantasa/2004/20040021

Lagen om tillsynen över arbetarskyddet och om arbetarskyddssamarbete på arbetsplatsen (44/2006), as of June 2014 from http://www.finlex.fi/sv/laki/ajantasa/ 2006/20060044

Semesterlagen (162/2005), as of June 2014 from

http://www.finlex.fi/sv/laki/ajantasa/2005/20050162

\section{Iceland}

Arbetsmiljölagen nr. 46/1980, as of June 2014 from http://www.vinnueftirlit.is/ media/almenn-skjol/act_no_46-1980_work_enwironment_health_and_safety.pdf

Föreskrift om åtgärder mot mobbning på arbetspladsen nr. 1000/2004, as of June 2014 from http://www.vinnueftirlit.is/media/sem-heyra-undir-vinnuvernd/ 1000_2004_reglugerd_um_adgerdir_gegn_einelti_a_vinnustad.pdf

Planering och genomförande av arbetsmiljöarbete på arbetsplatser (RG-920/2006), as of June 2014 from http://www.vinnueftirlit.is/media/sem-heyra-undirvinnuvernd/920_2006.pdf

\section{Norway}

Forskrift om organisering, ledelse og medvirkning, Dato FOR-2011-12-06-1355 Departement Arbeids- og sosialdepartementet, as of June 2014 from http://lovdata.no/dokument/SF/forskrift/2011-12-06-1355 
Lov av 17.juni $2005 \mathrm{nr} .62$ om arbeidsmiljø, arbeidstid og stillingsvern mv. (arbeidsmiljøloven), as of June 2014 from http://lovdata.no/dokument/NL/lov/ 2005-06-17-62?q=arbeidsmilj\%C3\%B8

NOU 1992: 20. Det gode arbeidsmiljø er lønnsomt for alle. Innstilling fra Arbeidsmiljøutvalget. Oslo: Statens forvaltningstjeneste, seksjon statens trykking.

\section{Sweden}

Arbetsanpassning och rehabilitering (AFS 1994:1), as of June 2014 from http://www.av.se/dokument/afs/AFS1994_01.pdf

Arbetsmiljölagen 1977:1160 (AML), as of June 2014 from http://www.av.se/publikationer/bocker/h008.aspx

Arbetstidslagen 1982:673, as of June 2014 from http://www.riksdagen.se/sv/Dokument-Lagar/Lagar/Svenskforfattningssamling/ Arbetstidslag-1982673_sfs-1982-673/

Ensamarbete AFS 1982:3, as of June 2014 from http://www.av.se/dokument/afs/AFS1982_03.pdf

Första hjälpen och krisstöd (AFS 1999:7), as of June 2014 from http://www.av.se/dokument/afs/AFS1999_07.pdf

Kränkande särbehandling i arbetslivet (AFS 1993:17), as of June 2014 from http://www.av.se/dokument/afs/AFS1993_17.pdf

Offentlighets- och sekretesslagen 2009:400 (28:14 §), as of June 2014 from http://www.riksdagen.se/sv/Dokument-Lagar/Lagar/Svenskforfattningssamling/ Offentlighets--och-sekretessla_sfs-2009-400/

Omvårdnadsarbete i enskilt hem (AFS 1990:18), as of June 2014 from http://www.av.se/dokument/afs/AFS1990_18.pdf

Systematiskt arbetsmiljöarbete (AFS 2001:1), as of June 2014 from http://www.av.se/dokument/afs/AFS2001_01.pdf

Våld och hot i arbetsmiljön (AFS 1993:2), as of June 2014 from http://www.av.se/dokument/afs/AFS1993_02.pdf

\section{Chapter 3}

\section{Denmark}

En strategi for arbejdsmiljøindsatsen frem til 2020, as of June 2014 from http://bm.dk/da/Beskaeftigelsesomraadet/Et\%20godt\%20arbejdsliv/Arbejdsmilj oe/Ny\%20strategi\%20frem\%20til\%202020.aspx

Strategi for Arbejdstilsynet 2013, as of June 2014 from http://arbejdstilsynet.dk/da/om\%20arbejdstilsynet/formaal-og-opgaver.aspx

\section{Finland}

Den social- och hälsopolitiska strategin "Ett socialt hållbart Finland 2020", as of June 2014 from http://www.stm.fi/sv/publikationer/publikation/-/_julkaisu/1550874

Policy för arbetsmiljön och välbefinnande i arbetet till år 2020, as of June 2014 from http://www.stm.fi/c/document_library/get_file?folderId=2765155\&name=DLFE16255.pdf

Ramavtalet 2012-2015 mellan social- och hälsovårdsministeriet och regionförvaltningsverkens ansvarsområden för arbetarskyddet, as of June 2014 from http://www.tyosuojelu.fi/upload/Runkosuunnitelma_2012-15.pdf 


\section{Iceland}

Mål for reduktion af forekomsten af invalidetilfælde; as of June 2014 from http://www.vinnueftirlit.is/um-vinnueftirlitid/stefna/

\section{Norway}

Meld. St. 29 (2010-2011). Felles ansvar for eit godt og anstendig arbeidsliv. Arbeidsforhold, arbeidsmiljø og sikkerheit, as of June 2014 from http://www.regjeringen.no/nb/dep/asd/dok/regpubl/stmeld/2010-2011/meldst-29-20102011.html?id=653071

Statsbudsjettet for 2013 - Prop. 1 S (2012-2013), as of June 2014 from http://www.statsbudsjettet.no/upload/Statsbudsjett_2013/dokumenter/pdf/gulb ok.pdf

Strategisk plan for Arbeidstilsynet (2008-2011), as of June 2014 from http://www.arbeidstilsynet.no/binfil/download2.php?tid=99321

Strategisk plan for Arbeidstilsynet (2013-2016), as of June 2014 from http://www.arbeidstilsynet.no/binfil/download2.php?tid=235333

\section{Sweden}

En förnyad arbetsmiljöpolitik med en nationell handlingsplan 2010-2015, as of June 2014 from http://www.riksdagen.se/sv/Dokument-Lagar/Forslag/Propositioneroch-skrivelser/En-fornyad-arbetsmiljopolitik-_GX03248/?text=true

\section{Chapter 4}

\section{Denmark}

Antal afgørelser/påbud mv. as of June 2014 from http://arbejdstilsynet.dk/ da/statistik/tilsyn\%20i\%20tal/tabel-2012-2014.aspx

Indsatser i 2013-2015 med fokus på psykisk arbejdsmiljø, as of June 2014 from http://arbejdstilsynet.dk/da/tilsyn/saerlige-indsatser-psyk.aspx

\section{Iceland}

38 brancherettede arbejdsmiljøvejvisere, as of June 2014 from http://www.vinnueftirlit.is/vinnuvernd/ahaettumat/vinnuumhverfisvisar/

Antal afgørelser, as of June 2014 from http://www.vinnueftirlit.is/media/ arsskyrslur/vinnueftirlit_arsskyrsla_2012.pdf

\section{Sweden}

Udvælge virksomheder - indekssystem, as of June 2014 from http://www.av.se/inspektion/urvalet/

\section{Chapter 5}

\section{Denmark}

Arbejdstilsynet. Kortlægning af psykisk arbejdsmiljø D.4.1 as of November 2009 from http://arbejdstilsynet.dk/da/landingssider/landingsside-psykisk/ at-vejledninger-om-psykisk-arbejdsmiljo.aspx 
Arbejdstilsynets kvalitetsprocedure for detailtilsyn (n.d.), as of June 2014 from http://arbejdstilsynet.dk/da/om\%20arbejdstilsynet/interne-instrukser-ogkvalitetsprocedurer-mv/kvalitetsprocedurer/detailtilsyn.aspx

Arbejdstilsynets kvalitetsprocedure for risikobaseret (n.d.), as of June 2014 from http://arbejdstilsynet.dk/da/om\%20arbejdstilsynet/interne-instrukser-ogkvalitetsprocedurer-mv/kvalitetsprocedurer/risikobaseret-tilsyn.aspx

Arbejdstilsynets spørgeguides til psykisk arbejdsmiljø (n.d.), as of June 2014 from http://arbejdstilsynet.dk/da/om\%20arbejdstilsynet/interne-instrukser-ogkvalitetsprocedurer-mv/kvalitetsprocedurer/generelt-for-tilsyn/g-401sporgeguides-psykisk/oversigt-over-sporgeguides.aspx

Arbejdstilsynets tilsyn med psykisk arbejdsmiljø, At-intern instruks IN-4-1(n.d.), as of June 2014 from http://arbejdstilsynet.dk/da/om\%20arbejdstilsynet/interneinstrukser-og-kvalitetsprocedurer-mv/at-interne-instrukser-mv/psykiskarbejdsmiljoe/2003-ats-tilsyn-med-psykisk-arbejdsmiljoe.aspx

\section{Finland}

Tillsynen av psykosocial belastning. Arbetarskyddstillsynens anvisningar 2/2013 (2013), as of June 2014 from http://www.tyosuojelu.fi/upload/STM_2_2013_SE.pdf

Tillsynen av trakasserier och annat osakligt bemötande. Arbetarskyddstillsynens anvisningar 1/2011 (2011), as of June 2014 from http://www.tyosuojelu.fi/ upload/Valvontaohje_1_2011_svenska.pdf

Tillsynen över våld och hot. Arbetarskyddstillsynens anvisningar 2/2010 (2010), as of June 2014 from http://www.tyosuojelu.fi/upload/Valvontaohje_2_2010_ruotsi_PDFversio.pdf

Tillsynsanvisning. Arbetarskyddstillsynens anvisningar 1/2010 (2010), as of June 2014 from http://www.tyosuojelu.fi/upload/Valvontaohje_1_2010_ruotsi_PDFversio.pdf

Valmeri-förfrågan, as of June 2014 from http://www.tyosuojelu.fi/se/instrument

\section{Iceland}

Speciell arbetsmiljövägvisare om psykosocial arbetsmiljö, as of June 2014 from http://www.vinnueftirlit.is/media/sertaekir-vinnuumhverfisvisar/ vsafe01_felaglegur_og_andlegur_adbunadur_a_vinnustad_2_utgafa.pdf

\section{Norway:}

Arbeidstilsynet (n.d.) Ulike typer tilsyn, as of June 2014 from http://www.arbeidstilsynet.no/om/index.html?tid=207111

Gaupset, S., Hagen, I. W. E., Moløkken, H. K. \& Skahjem, L.-C. (2010). Inngangsdører til arbeidsmiljøet. Rapport fra metodeprosjeket 2007-2010. Organisatorisk og psykososialt arbeidsmiljø. Trondheim: Arbeidstilsynet.

\section{Chapter 6}

\section{Denmark}

Effektevaluering af Arbejdstilsynets kerneopgave. Arbejdstilsynets notat af 19. december 2002. 


\section{Iceland}

Beskrivelse af initiativer i Island, AT’s årsrapporter, as of June 2014 from http://www.vinnueftirlit.is/fraedsla/utgefid-efni/skyrslur/

\section{Norway}

Arbeidstilsynet (2014). Tilsyn gir positiv effekt i virksomhetene. Arbeidstilsynets effektvurderinger av tilsyn i perioden 2008-2012, as of June 2014 from http://www.arbeidstilsynet.no/binfil/download2.php?tid=245954 


\section{Sammenfatning}

Denne udredningsrapport indeholder udelukkende en deskriptiv redegørelse for ovenstående temaer. Der bliver redegjort for, hvordan temaerne behandles i de fem lande, og for forskelle og ligheder på tværs af landene. I hvert kapitel beskrives de nationale forhold i alfabetisk rækkefølge efter landenes navne.

Kapitel 1: Begrebsafklaring, teoretisk baggrund og praksis for tilsyn indledes med en definition og afgrænsning af begrebet psykosocialt arbejdsmiljø. Der er ingen "autoriseret" fælles definition i Norden af, hvad begrebet psykosocialt arbejdsmiljø indeholder, så denne forståelse er den, som arbejdsgruppen har valgt som et fælles udgangspunkt. Derefter redegøres kort for de forskellige teoretiske baggrunde for tilsynene med det psykosociale arbejdsmiljø i de forskellige lande, dvs. hvilke arbejdspsykologiske teorirammer, hvert land lægger til grund for tilsynet. Endelig redegøres for, hvilke psykosociale og organisatoriske risikofaktorer, de fem lande hver især har praksis for at føre tilsyn med.

Kapitel 2: Sammenligning af reglerne for psykosocialt arbejdsmiljø i de nordiske lande er en sammenligning af de aktuelle regler, som hvert enkelt nordisk land lægger til grund for tilsynet med det psykosociale arbejdsmiljø. Kapitlet indledes med en kort historisk beskrivelse af, hvornår reglerne om psykosocialt arbejdsmiljø blev skrevet ind i de pågældende landes arbejdsmiljølovgivning.

Kapitel 3: De nordiske arbejdstilsyns strategier for tilsyn indeholder en beskrivelse af de nordiske landes mål og strategier for nationale arbejdsmiljøindsatser med fokus på indsatsen overfor det psykosociale arbejdsmiljø. Kapitlet indledes med en sammenligning af de nordiske landes overordnede arbejdsmiljøstrategier. Derefter gennemgås de forskellige landes nationale strategier mere detaljeret. Den sidste del af kapitlet indeholder en mere detaljeret redegørelse for de nordiske arbejdstilsyns strategier, mål og indsatsområder. 
Kapitel 4: Tilsynsaktiviteter med psykosocialt arbejdsmiljø indledes med en kort sammenfatning af, hvordan de nordiske lande hver især prioriterer tilsynet med det psykosociale og organisatoriske arbejdsmiljø i tilsynet med virksomhedernes arbejdsmiljø. Herefter redegøres for, hvordan de nationale arbejdstilsyn udvælger virksomheder, brancher og jobgrupper til tilsyn. Der redegøres desuden for, hvordan de tilsynsførende uddannes til at føre tilsyn med psykosocialt arbejdsmiljø i de fem lande. Sidst i kapitlet beskrives landenes tidsforbrug til tilsyn med psykosocialt arbejdsmiljø, og hvor mange afgørelser i form af påbud mv. der gives vedrørende psykosocialt og organisatorisk arbejdsmiljø.

Kapitel 5: Metoder til tilsyn med psykosocialt arbejdsmiljø handler om, hvordan de nationale arbejdstilsyn griber tilsynet an. Kapitlet indledes med en sammenfatning af, hvordan de nordiske lande i praksis fører tilsyn med centrale psykosociale risikofaktorer og organisatoriske arbejdsbetingelser. Der redegøres desuden for, i hvilket omfang myndighederne kontrollerer virksomhedernes konkrete psykosociale arbejdsmiljø henholdsvis deres systematiske arbejdsmiljøarbejde. Derefter gennemgås, hvordan man i de fem lande strukturerer selve tilsynene før, under og efter tilsynsbesøgene, og der redegøres for, hvilke standardiserede værktøjer man bruger til at afdække problemer i det psykosociale arbejdsmiljø. Endelig beskrives de nationale arbejdstilsyns bud på, hvilke metoder der foretrækkes ved tilsynet med området. Da dette kapitel er rapportens mest omfangsrige og detaljerede, følger der efter den indledende sammenfatning en detaljeret redegørelse for de enkelte landes tilsynspraksis.

Kapitel 6: Effekt af tilsyn med det psykosociale arbejdsmiljø handler om, hvilken effekt der skabes ved de nationale arbejdstilsyns tilsyn med det psykosociale arbejdsmiljø, og hvordan denne effekt måles. Kapitlet indeholder ikke enkle og entydige svar. I stedet præsenteres overvejelser og tendenser, som viser, hvordan de forskellige lande griber problematikken an. Derefter gennemgås de nordiske landes initiativer til at skabe og måle effekt, og afsnittet afsluttes med en perspektivering.

Det er vigtigt at bemærke, at rapporten er en sammenfatning af de nationale redegørelser, som er udarbejdet af arbejdsgruppens medlemmer og andre medarbejdere fra de nordiske arbejdstilsyn. De nationale redegørelser ønsker arbejdsgruppen at publicere i en bilagsrapport sammen med bl.a. nationale kvalitetsprocedurer for tilsyn, eksempler på afgørelser mv. 


\begin{abstract}
Abstrakt
Denne rapport beskriver, hvordan myndighederne i de fem nordiske lande, Danmark, Finland, Island, Norge og Sverige fører tilsyn med det psykosociale arbejdsmiljø på virksomhederne. Rapporten beskriver forskelle og ligheder i regler, samt nationale mål og strategier. Desuden beskrives landenes prioritering af tilsynet med det psykosociale arbejdsmiljø og hvordan man udvælger virksomheder, brancher og jobgrupper til tilsyn. Rapporten afrundes med en beskrivelse af aktuelle nationale tilsynsaktiviteter og tilsynsmetoder, samt hvordan effekten af tilsynene kan måles.
\end{abstract}





\section{Appendix}

The table below shows what the working environment authorities in the five Nordic countries target when they carry out inspections of the various risk factors within the psychosocial and organisational working environment. The following codes have been used to describe the basis:

0 The risk factor is not targeted in inspections.

1. Enterprises' systematic working environment efforts are targeted in the inspection, i.e. information is collected on enterprises' workplace assessment (APV), health, environmental and safety activities or similar. Registrations by enterprises of violence/threatening behaviour, absenteeism due to sickness or employee satisfaction surveys are also included.

2. Only the specific working environment at enterprises is targeted in the inspection, i.e. collection of information about the working environment as it appears during the inspection. This includes information collected by the national working environment authorities through observations or structured interviews with management and employees, etc.

3. PWE inspections are carried out on the basis of information about working environment efforts as well as the specific working environment, i.e. information from both points 1 and 2 . 
Appendix table I. List of the basis for PWE inspection (violence, threatening behaviour, bullying, harassing behaviour etc.) in the Nordic countries separate for each risk factor and country. The division in the table follows the division in chapter 1 on the clarification of the concept of PWE, etc.

\begin{tabular}{llrrrr}
\hline Risk factor & DK & FI & IS & NO & SE \\
\hline Violence and threatening behaviour & 3 & 3 & 3 & $1 / 3$ & 1 \\
Bullying** & 3 & 3 & 3 & $1 / 3$ & 1 \\
Sexual harassment & 3 & 3 & 3 & $1 / 3$ & 1 \\
Harassing behaviour & 3 & 3 & 3 & $1 / 3$ & 1 \\
Lack of instruction and training & 3 & 1 & 3 & 3 & 1 \\
Teasing & 3 & 3 & 3 & 3 & 1 \\
Integrity and dignity & 0 & 0 & 0 & $1 / 3$ & 1 \\
Discrimination & 3 & 1 & 3 & 0 & 1 \\
\hline
\end{tabular}

*) For the risk factors which under Norway have two codes, e.g. 1/3, Norway has stated that there is a difference in how it carries out inspection of the risk factors in question, depending on the inspection activity. In some inspection activities, only the enterprises' systematic working environment efforts will be targeted in the inspections. In others, inspections also target enterprises' specific working environment.

${ }^{* *}$ ) Bullying, including sexual harassment. Norway uses the concept of harassment or other inappropriate behaviour. Sexual harassment is included in this concept and, therefore, does not appear separately on Norwegian checklists in connection with inspections. Sweden uses the concept of harassing behaviour, which covers bullying. Risk factors related to bullying are also described in this context. These include teasing, discrimination as well as integrity and dignity.

Appendix table II. List of the basis for PWE inspection (organisation of work) in the Nordic countries, separate for each risk factor and country. The division in the table follows the division in chapter 1 on the clarification of the concept of PWE, etc.

\begin{tabular}{|c|c|c|c|c|c|}
\hline Organisation of work & DK & FI & IS & NO & SE \\
\hline Work load & 3 & 1 & 2 & $2 / 3$ & 3 \\
\hline Time pressure & 3 & 1 & 2 & $2 / 3$ & 3 \\
\hline Lack of influence on own work & 3 & 1 & 2 & $2 / 3$ & 3 \\
\hline Conflicting or unclear demands & 3 & 1 & 2 & $2 / 3$ & 3 \\
\hline High attentional demands & 3 & 1 & 3 & $2 / 3$ & 3 \\
\hline High emotional demands & 3 & 1 & 0 & $2 / 3$ & 3 \\
\hline Many interruptions (not breaks) & 3 & 1 & 3 & $2 / 3$ & 0 \\
\hline Highly controlled or fixed work, monotony, lack of variety & 3 & 1 & 3 & 3 & 2 \\
\hline Large responsibility & 3 & 1 & 3 & 3 & 2 \\
\hline Large information load & 3 & 1 & 3 & $2 / 3$ & 2 \\
\hline Lack of information channels in the organisation & 3 & 1 & 2 & 3 & 1 \\
\hline Organisational change & 3 & 0 & 3 & 3 & 1 \\
\hline Lack of breaks & 3 & 1 & 3 & $2 / 3$ & 3 \\
\hline Technology & 3 & 1 & 3 & 3 & 2 \\
\hline Unclear division of labour & 3 & 1 & 3 & $1 / 3$ & 1 \\
\hline
\end{tabular}

Appendix table III. List of the basis for PWE inspection (relational factors) in the Nordic countries, separate for each risk factor and country. The division in the table follows the division in chapter 1 on the clarification of the concept of PWE, etc.

\begin{tabular}{lcrrrr}
\hline Relational risk factors & DK & FI & IS & NO & SE \\
\hline Solitary work & 3 & 1 & 3 & $1 / 3$ & 2 \\
Lack of social support & 3 & 1 & 3 & $1 / 3$ & 2 \\
First aid & 3 & 0 & 3 & 0 & 1 \\
Crisis support & 0 & 1 & 0 & 0 & 1 \\
Poor collaboration & 0 & 1 & 0 & $1 / 3$ & 2 \\
Lack of employee rehabilitation & 0 & 0 & 0 & $1 / 3$ & 2 \\
\hline
\end{tabular}


Appendix table IV. List of the basis for PWE inspection (working hours and similar) in the Nordic countries, separate for each risk factor and country. The division in the table follows the division in chapter 1 on the clarification of the concept of PWE, etc.

\begin{tabular}{llrrrr}
\hline Working hours etc. & DK & FI & IS & NO & SE \\
\hline Working hours & 0 & 1 & 3 & 3 & $0^{*}$ \\
Staggered working hours & 0 & 1 & 3 & 2 & 0 \\
Shift work & 0 & 1 & 2 & $2 / 3$ & 0 \\
Night work & 3 & 1 & 3 & $2 / 3$ & $* 0$ \\
Lack of resting periods & 0 & 1 & 2 & $2 / 3$ & $* 0$ \\
Excessive overtime & 3 & 1 & 3 & $2 / 3$ & 0 \\
Lack of overtime compensation & 0 & 0 & 0 & 2 & 0 \\
\hline
\end{tabular}

*Working hours, night work, lack of resting periods - the Swedish working environment authority Arbetsmiljöverket, is formally responsible for these working environment factors if the enterprise is not covered by a collective agreement.

Appendix table V. List of the basis for PWE inspection (other factors) in the Nordic countries, separate for each risk factor and country. The division in the table follows the division in chapter 1 on the clarification of the concept of PWE, etc.

\begin{tabular}{lllrrr}
\hline Other factors & DK & FI & IS & NO & SE \\
\hline Lack of permanent workplace & 0 & 1 & 0 & 0 & 0 \\
Frequent work-related travels outside working hours & 0 & 1 & 0 & 0 & 0 \\
Pay system & 0 & 0 & 0 & $2 / 3$ & 0 \\
Inadequate management & 0 & 0 & 0 & $1 / 3$ & 2 \\
Lack of personal development for employees & 0 & 0 & 0 & $1 / 3$ & 0 \\
Lack of work contracts and employment contracts & 0 & 0 & 0 & 2 & 0 \\
Control measures & 0 & 0 & 0 & 3 & 0 \\
Unclear job description & 0 & 1 & 3 & $1 / 3$ & 1 \\
\hline
\end{tabular}


Nordic Council of Ministers

Ved Stranden 18

DK-1061 Copenhagen $\mathrm{K}$

www.norden.org

\section{Psychosocial working environment}

This report outlines how the authorities in the five Nordic countries, Denmark, Finland, Iceland, Norway and Sweden, carry out their inspections of the psychosocial working environment at the enterprises. Starting out with a description of the psychosocial risks, the report proceeds with a comparison of the differences between the different national regulations as well as an outline of the similarities. The report offers a comparison of the Nordic working environment strategies and a detailed presentation of the different targets and areas of initiative. It also presents how different methods are used in the selection of enterprises, sectors and job groups for inspection and how the inspectors are trained to carry out the inspections. The report rounds off with a description of the different national inspection methods and how to measure their effects. 